\title{
Fiber Optical Micro-detectors for Oxygen Sensing in Power Plants
}

Final Technical Report

October 1, 2002 to September 30, 2006

Gregory L. Baker*, Ruby N. Ghosh ${ }^{+}$, D.J. Osborn III*, Po Zhang ${ }^{+}$

December 2006

DOE Award Number: DE-FC26-02NT41582

*536 Chemistry Building, Department of Chemistry

${ }^{+} 2167$ BPS, Dept. of Physics

Michigan State University 


\section{DISCLAIMER}

"This report was prepared as an account of work sponsored by an agency of the United States Government. Neither the United States Government nor any agency thereof, nor any of their employees, makes warranty, express or implied, or assumes any legal liability or responsibility for the accuracy, completeness, or usefulness of any information, apparatus, product, or process disclosed, or represents that its use would not infringe privately owned rights. Reference herein to any specific commercial product, process, or service by trade name, trademark, manufacturer, or otherwise does not necessarily constitute or imply its endorsement, recommendation, or favoring by the United States Government or any agency thereof. The views and opinions of the authors expressed herein do not necessarily state or reflect those of the United States Government or any agency thereof."

\section{$\underline{\text { ABSTRACT }}$}

A reflection mode fiber optic oxygen sensor that can operate at high temperatures for power plant applications has been developed. The sensor is based on the ${ }^{3} \mathrm{O}_{2}$ quenching of the red emission from hexanuclear molybdenum chloride clusters. We report on a fiber optic technique for detection of gas phase oxygen up to $100{ }^{\circ} \mathrm{C}$ based on the ${ }^{3} \mathrm{O}_{2}$ quenching of the luminescence from molybdenum chloride clusters, $\mathrm{K}_{2} \mathrm{Mo}_{6} \mathrm{Cl}_{14}$. The inorganic sensing film is a composite of sol-gel particles embedded in a thin, oxygen permeable sol-gel binder. The particles are comprised of thermally stable, luminescent $\mathrm{K}_{2} \mathrm{Mo}_{6} \mathrm{Cl}_{14}$ clusters dispersed in a fully equilibrated sol-gel matrix. From 40 to $100{ }^{\circ} \mathrm{C}$, the fiber sensor switches $\sim 6 \times$ in intensity in response to alternating pulses of $<0.001 \% \mathrm{O}_{2}$ and $21 \% \mathrm{O}_{2}$ between two well defined levels with a response time of $10 \mathrm{~s}$. The sensor signal is a few $\mathrm{nW}$ for an input pump power of $250 \mu \mathrm{W}$. The normalized sensor signal is linear with molar oxygen concentration and fits the theoretical Stern-Volmer relationship. Although the sensitivity decreases with temperature, sensitivity at $100{ }^{\circ} \mathrm{C}$ is $160\left[\mathrm{O}_{2}\right]^{-1}$. These parameters are well suited for in-situ, real-time monitoring of oxygen for industrial process control applications. 


\section{TABLE OF CONTENTS}

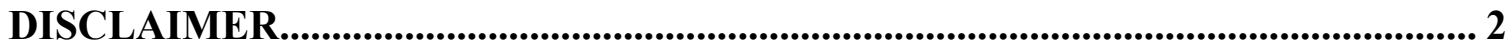

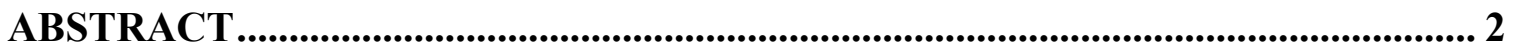

TABLE OF CONTENTS …………............................................................................ 3

LIST(S) OF GRAPHICAL MATERIALS .......................................................................... 5

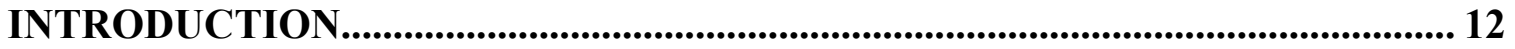

EXECUTIVE SUMMARY ...................................................................................... 17

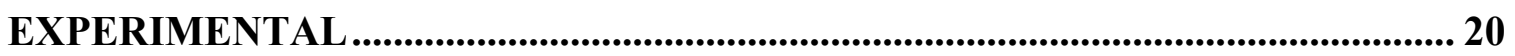

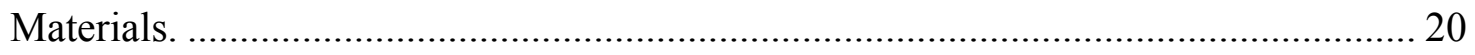

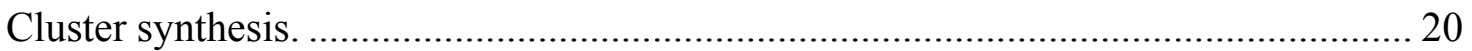

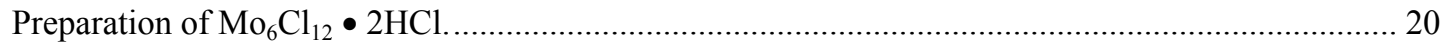

Preparation of the acetonitrile complex of $\mathrm{Mo}_{6} \mathrm{Cl}_{12} \cdot\left(\mathrm{Mo}_{6} \mathrm{Cl}_{12} \cdot 2 \mathrm{CH}_{3} \mathrm{CN}\right)$......................................... 20

Synthesis of $\mathrm{K}_{2} \mathrm{Mo}_{6} \mathrm{Cl}_{14} \cdot 2 \mathrm{H}_{2} \mathrm{O}$. (FJ-17, MM-5, MM-7, MM-8, MM-9) ...................................... 21

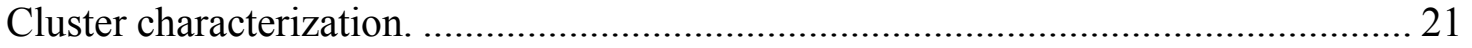

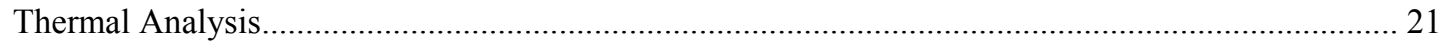

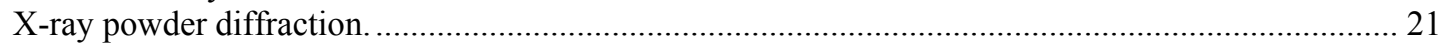

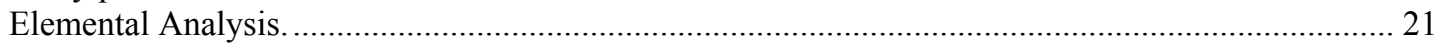

Absorption spectroscopy........................................................................................ 22

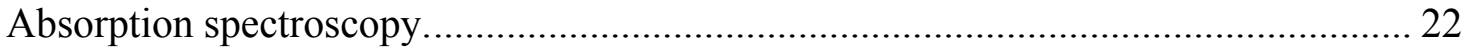

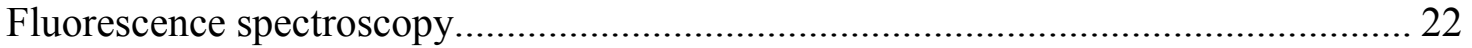

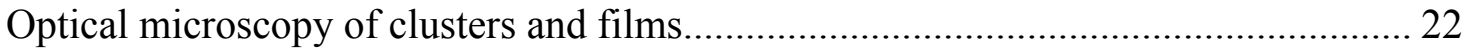

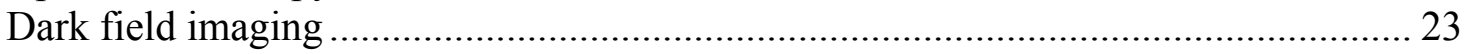

Deposition of cluster-containing sol-gel films on flat substrates and fibers................. 23

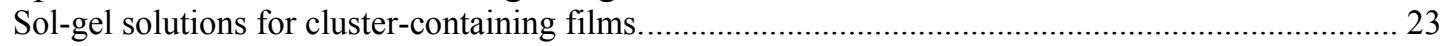

Sol gel films deposited on glass or quartz slides. ……………………………………………... 23

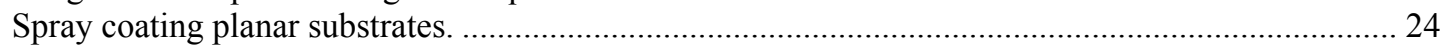

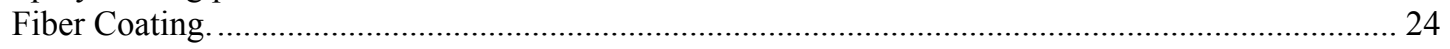

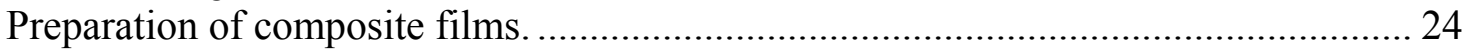

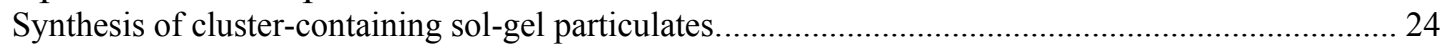

Binders for Sol-Gel Stock Solutions...……………………………………………………………. 25

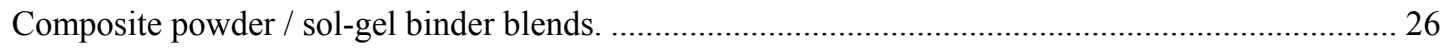

Fluorescence measurements of sol-gel films at high temperatures. .............................. 27

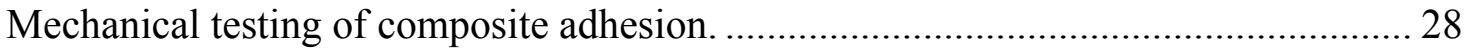

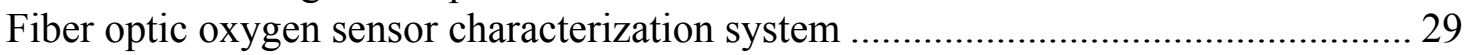

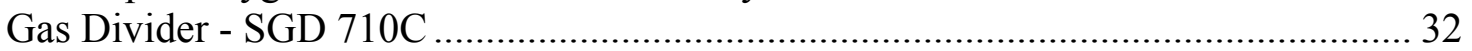

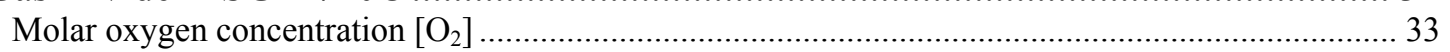

Sensor data acquisition and measurement ………………...................................... 36

RESULTS AND DISCUSSION ........................................................................................ 38

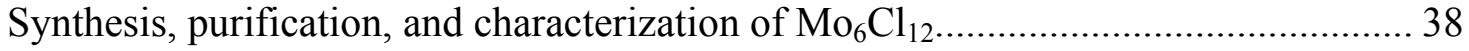

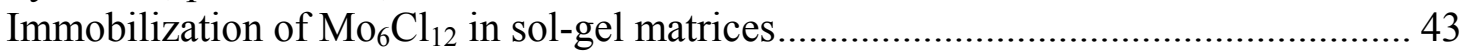

Film Deposition Techniques ..................................................................................... 46

Controlling the morphology of sol gel films on surfaces and fibers............................ 48

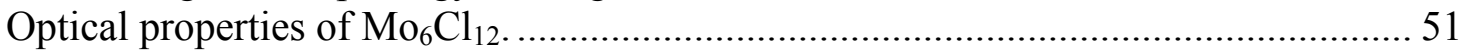

Measurement of $\mathrm{Mo}_{6} \mathrm{Cl}_{12}$ luminescence as a function of temperature. ........................ 52

Evaluation of alkali metal salts of $\mathrm{Mo}_{6} \mathrm{Cl}_{12}$ for improved thermal stability................ 54

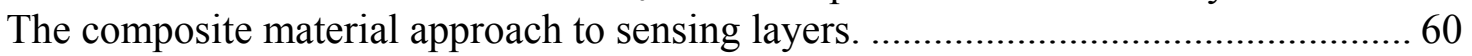

Multifiber Dip-coating of Fiber Sensors ...................................................................... 67 
High temperature survivability of $\mathrm{K}_{2} \mathrm{Mo}_{6} \mathrm{Cl}_{14} /$ sol-gel films. ................................... 70

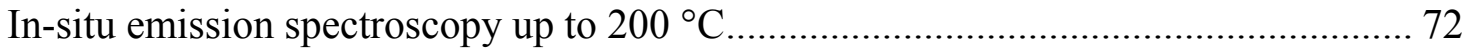

High temperature fiber sensor measurements.................................................... 75

Oxygen Sensitivity of $\mathrm{K}_{2} \mathrm{Mo}_{6} \mathrm{Cl}_{14}$ Fiber Sensors at Elevated Temperatures ............... 80

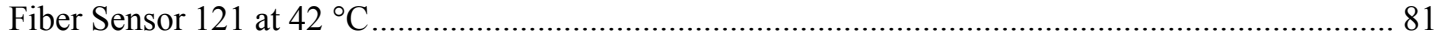

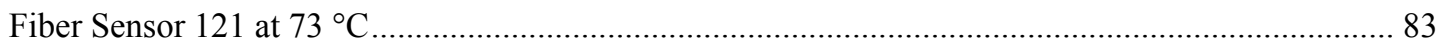

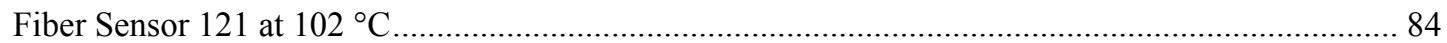

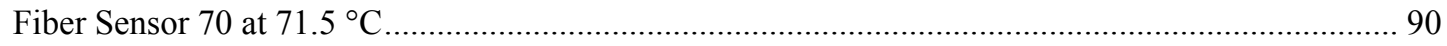

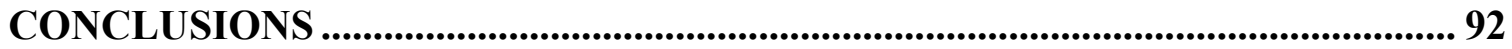

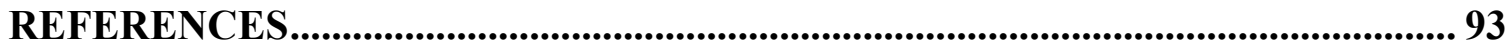

BIBLIOGRAPHY .................................................................................................................. 94

LIST OF ACRONYMS AND ABBREVIATIONS .................................................. 94

APPENDIX A - ACKNOWLEDGEMENTS....................................................... 94 


\section{LIST(S) OF GRAPHICAL MATERIALS}

\begin{tabular}{|c|c|}
\hline Figure 1. Schematic of the reflection mode fib & 12 \\
\hline Figure 2. The $\mathrm{Mo}_{6} \mathrm{Cl}_{12}$ cluster, the basis for a versatile oxygen sensor for oxygen. & 13 \\
\hline $\begin{array}{l}\text { Figure 3. Absorption and emission spectra of the } \mathrm{Mo}_{6} \mathrm{Cl}_{12} \text { acetonitrile complex. } \\
\text { The absorption band extends from } 300-400 \mathrm{~nm} \text { and the emission band extends from } \\
600-850 \mathrm{~nm} \text {. The large Stokes shift allows for simple LED excitation and } \\
\text { photodiode detection, which are essential for volume fabrication of the senor. }\end{array}$ & 14 \\
\hline $\begin{array}{l}\text { Figure 4. Luminescence spectra from the Mo-clusters demonstrating quenching by } \\
\text { oxygen: (a) argon environment and (b) laboratory air ( } \sim 20 \% \text { oxygen). }\end{array}$ & 14 \\
\hline Figure 5. Optical setup for fiber sensor measurements. & 15 \\
\hline $\begin{array}{l}\text { Figure 6. Output signal from the room temperature fiber oxygen probe. }{ }^{[1]} \text { The } \\
\text { sensor signal as a function of time for low oxygen concentrations is shown in the } \\
\text { inset. }\end{array}$ & 16 \\
\hline $\begin{array}{l}\text { Figure 7. Diagram of the sandwich-like structure used for in-situ high temperature } \\
\text { measurements of slides. }\end{array}$ & 27 \\
\hline $\begin{array}{l}\text { Figure 8. Ballistic pendulum apparatus fabricated for fiber coating adhesion } \\
\text { analysis. }\end{array}$ & 29 \\
\hline $\begin{array}{l}\text { Figure } 9 \text { LED diode spectrum from Nichia company data sheet. There is } 2 \mu \mathrm{W} \text { of } \\
\text { unwanted visible signal from the LED itself in the emission bandwidth of the Mo- } \\
\text { clusters. }\end{array}$ & 31 \\
\hline $\begin{array}{l}\text { Figure } 10 \text { (a) Semorock (FF01-377/50-25) band-pass filter spectrum, with a UV } \\
\text { bandwidth } 352-403 \mathrm{~nm} \text { and } 93 \% \text { transmission, (b) enlarged spectrum in the range } \\
500-900 \mathrm{~nm} \text {, transmission } 10^{-6}-4 \times 10^{-3} \text {. The filter is used to remove the visible } \\
\text { component of the LED output. }\end{array}$ & 31 \\
\hline Figure 11. Schematic of gas divider SGD-710 principle. & 33 \\
\hline $\begin{array}{l}\text { Figure 12. Apparatus for semi-automated high temperature fiber optical oxygen } \\
\text { sensor characterization system, for details see text. }\end{array}$ & 34 \\
\hline $\begin{array}{l}\text { Figure 13. Signal from an uncoated optical fiber as a function of fiber length. The } \\
\text { data show low auto-fluorescence }\left(2.1 \times 10^{-4} \mathrm{nW} / \mathrm{cm}\right) \text {. However, there is a } 0.07 \mathrm{nW} \\
\text { signal (bandwidth: } 590 \mathrm{~nm}-900 \mathrm{~nm}) \text { due to reflections off the front and back faces } \\
\text { of the fiber }\end{array}$ & 35 \\
\hline
\end{tabular}



Figure 14: Block diagram of the sensor and temperature data acquisition system.
Figure 15: User interface of the automated optical sensor data acquisition software
OMS_02.exe. 36

Figure 16. $\mathrm{XRD}$ patterns for $\mathrm{Mo}_{6} \mathrm{Cl}_{12} \bullet 2 \mathrm{HCl}$ (blue lines), and $\mathrm{Mo}_{6} \mathrm{Cl}_{12}$ (red line, obtained by heating the hydrochloride salt to $210^{\circ} \mathrm{C}$ under vacuum. The structure of the cluster $\left(\mathrm{M}=\mathrm{H}^{+}\right)$is shown in the inset.

Figure 17. Thermogravimetric analysis of $\mathrm{Mo}_{6} \mathrm{Cl}_{12}$. The sample was heated at $10 \%$ min in air.

Figure 18. Changes in the luminosity of $\mathrm{Mo}_{6} \mathrm{Cl}_{12}$ caused by heating in air. Weight loss data measured under the same heating protocol are shown for comparison.

Figure 19. UV/vis spectra of $\mathrm{Mo}_{6} \mathrm{Cl}_{12}$ clusters after isothermal aging at the indicated temperatures. The spectra were run in $6 \mathrm{M} \mathrm{HCl}$.

Figure 20. "Uncorrected" luminescence spectra of $\mathrm{Mo}_{6} \mathrm{Cl}_{12}$ solutions in $6 \mathrm{M} \mathrm{HCl}$ after heating to the indicated temperature.

Figure 21. Emission spectra from our current Mo cluster compound after thermal cycling to $200 \mathrm{C}$ and previous results from [Ghosh 1999 ${ }^{[1]}$. Both spectra were taken in a $0.001 \%$ oxygen environment.

Figure 22. Luminescent molybdenum clusters.

Figure 23. Absorbance and emission spectra of the acetonitrile complex of $(\sim 5 \mathrm{x}$ $\left.10^{-4} \mathrm{~mol} / \mathrm{L}\right)$. The emission is the "uncorrected" raw data, taken with an excitation wavelength of $313 \mathrm{~nm}$. Quenching of $\sim 12 \times$ is observed between nitrogen $(<0.001 \%$ oxygen) and air ( $20 \%$ oxygen).

Figure 24. Synthetic route to sol-gel immobilized clusters.

Figure 25. Emission spectra of $\mathrm{Mo}_{6} \mathrm{Cl}_{12} \cdot 2 \mathrm{CH}_{3} \mathrm{CN}$ demonstrating no change in the cluster lineshape between the $\mathrm{CH}_{3} \mathrm{CN}$ solution and the sol-gel matrix..

Figure 26. Apparatus used for controlled coating of planar substrates. The overall height is of the apparatus is approximately one meter.

Figure 27. Apparatus used for spray coating of high temperature optical fibers

Figure 28. Typical results for multilayer deposition of sol-gel solution by spray coating showing obvious cracking. The fiber diameter is $1000 \mu \mathrm{m}$.

Figure 29. Optical micrographs of the surfaces of slides coated with sol gel films. 
Figure 30. Optical micrographs of optical fibers coated with a sol-gel matrix containing $\mathrm{Mo}_{6} \mathrm{Cl}_{12}$ clusters. Note the cracking for the thick film on the right.

Figure 31. Emission spectra of Mo-cluster / sol-gel composite film 15F (inset), after heating to $200{ }^{\circ} \mathrm{C}$ for one hour. Quenching of $1.7 \times$ is observed between nitrogen $(<0.001 \%$ oxygen $)$ and air $(\sim 20 \%$ oxygen $)$. Excitation wavelength is 313 $\mathrm{nm}$.

Figure 32. Integrated luminescence intensity $(580-850 \mathrm{~nm})$ of Mo-cluster/sol gel composite film $15 \mathrm{~F}$ as a function of temperature. The measurements were taken in flowing nitrogen $(99.999 \%)$. The data were collected non-sequentially with respect to temperature.

Figure 33. Data of Figure 32, expanded to show the high temperature signal intensity. The dark counts from the photomultiplier, shown in green, leads to a signal to noise ratio $>5$.

Figure 34. Powder $\mathrm{x}$-ray diffraction patterns for (top) $\mathrm{Mo}_{6} \mathrm{Cl}_{12}$, (middle) $\mathrm{K}_{2} \mathrm{Mo}_{6} \mathrm{Cl}_{14} \cdot 2 \mathrm{H}_{2} \mathrm{O}$, and (bottom) $\mathrm{KCl}$.

Figure 35. Thermal Gravimetric Analysis in air of (-) $\mathrm{Mo}_{6} \mathrm{Cl}_{12}$ and (-) $\mathrm{K}_{2} \mathrm{Mo}_{6} \mathrm{Cl}_{12}$. The samples were (1) heated to $120^{\circ} \mathrm{C}$ at $30 \% \mathrm{~min}$, (2) held at $120^{\circ}$ for $1 \mathrm{~h}$, (3) heated to $280{ }^{\circ} \mathrm{C}$ at $10^{\circ} / \mathrm{min}$, (4) held at $280{ }^{\circ} \mathrm{C}$ for 1 hour, and (5) cooled to $40{ }^{\circ} \mathrm{C}$ at $10 \% \mathrm{~min}$.

Figure 36. Absorption spectra for cluster samples heated at $280{ }^{\circ} \mathrm{C}$ for 60 minutes and then dissolved in $6 \mathrm{M} \mathrm{HCl}$. Samples shown are $(-) \mathrm{K}_{2} \mathrm{Mo}_{6} \mathrm{Cl}_{14}$, heated in air in the TGA apparatus and (-)in a microscope hot stage, $(-) \mathrm{Mo}_{6} \mathrm{Cl}_{12}$ heated in a hot stage, and (-) unheated $\mathrm{Mo}_{6} \mathrm{Cl}_{12}$. The concentrations of each solutions were $0.17 \mathrm{~g} / \mathrm{L}$, except for the heated $\mathrm{Mo}_{6} \mathrm{Cl}_{12}$ sample, which was 23 times higher $(4 \mathrm{~g} / \mathrm{L})$.

Figure 37. Isothermal aging tests of four preparations of $\mathrm{K}_{2} \mathrm{Mo}_{6} \mathrm{Cl}_{14}$ (FJ-17, MM-5, MM-7, and MM-8 at $280{ }^{\circ} \mathrm{C}$ in air, showing the consistent thermal profiles of recently prepared batches of $\mathrm{K}_{2} \mathrm{Mo}_{6} \mathrm{Cl}_{14}$ The corresponding data for $\mathrm{Mo}_{6} \mathrm{Cl}_{14} \bullet 2 \mathrm{HCl}$.

Figure 38. A comparison of the emission spectra from three different preparations of $\mathrm{K}_{2} \mathrm{Mo}_{6} \mathrm{Cl}_{14}, \mathrm{FJ}-17, \mathrm{MM}-7$, and MM-8. Data are shown for as-prepared samples, as well as samples that have been heated to $200^{\circ}$ for 4 hours, illustrating that both lineshape and intensity are conserved. Solution concentrations: MM-8: $0.118 \mathrm{mM}$ $\pm 1.4 \%$ and $0.115 \mathrm{mM} \pm 1.4 \%$ after heating; MM-7: $0.0959 \mathrm{mM}_{-} \pm 1.4 \%$, and FJ-17: $0.087 \mathrm{mM} \pm 1.4 \%$. Within the error bars of the measurement the emission intensity scales with concentration.

Figure 39: UV/vis spectra from three different preparations of $\mathrm{K}_{2} \mathrm{Mo}_{6} \mathrm{Cl}_{14}, \mathrm{FJ}-17$, 58 MM-7, and MM-8. Data are shown for as-prepared samples, as well as samples that have been heated to $200{ }^{\circ} \mathrm{C}$ for 4 hours. The intensity of the "excess" absorption centered at $300 \mathrm{~nm}$ correlates with the age of the solutions. Solution 
concentrations: MM-8: $0.118 \mathrm{mM} \pm 1.4 \%$ and $0.115 \mathrm{mM} \pm 1.4 \%$ after heating; MM7: $0.0959 \mathrm{mM} \pm 1.4 \%$, and FJ-17 $0.087 \mathrm{mM} \pm 1.4 \%$.

Figure 40: Emission spectra in $99.999 \%$ nitrogen of (i) $\mathrm{K}_{2} \mathrm{Mo}_{6} \mathrm{Cl}_{14}$ and (ii) $\mathrm{Mo}_{6} \mathrm{Cl}_{12}$ $2 \mathrm{CH}_{3} \mathrm{CN}$ in $\mathrm{CH}_{3} \mathrm{CN}$, demonstrating that the cluster photophysics is not affected by ligand substitution. Note that the potassium salt has been heat cycled to $280{ }^{\circ} \mathrm{C}$ for one hour.

Figure 41. Schematic showing the expected morphology resulting from dip or spray coating a slurry of particles in a sol-gel binder solution. The particles correspond to pre-cured sol-gel particles containing $\mathrm{K}_{2} \mathrm{Mo}_{6} \mathrm{Cl}_{14}$ clusters.

Figure 42. Optical micrographs of sol-gel particles (a) bright field image $(10 \times)$ showing a sol-gel monolith containing MM-5 pulverized using a mortar and pestle, $25-250 \mu \mathrm{m}$ particle size, (b) a sol-gel monolith (no clusters), $1-2 \mu \mathrm{m}$ particle size, and (c) dark field image $(100 \times)$ showing a sol-gel monolith containing MM-5 pulverized via ball milling, $2-8 \mu \mathrm{m}$ particle size.

Figure 43. Typical dip coating results for deposition of composite / sol-gel binder blends $1000 \mu \mathrm{m}$ diameter fibers.

Figure 44. Dark field optical micrographs of $1-8 \mu \mathrm{m}$ sol-gel particles (cluster 59 source FJ17) prepared by ball milling (a) previously prepared wlb29 (50×), (b) wlb34g-o, (50×) and (c) wlb34g-o, dark field (100×).

Figure 45. Images showing the range of results using super glue as a binder. Large 63 particles are 25-250 $\mu \mathrm{m}$ and small particles are 1-8 $\mu \mathrm{m}$.

Figure 46. Images showing the range of results obtained from coating with different binders and particle sizes. Large particles are 25-250 $\mu \mathrm{m}$ and small particles are 1-8 $\mu \mathrm{m}$.

Figure 47. Images showing the range of film properties and adhesion obtained by varying the sol-gel aging time and co-solvent. The binder composition is $55 \%$ OtMOS / TEOS and the diameter of the particles are 1-8 $\mu \mathrm{m}$ for all samples shown.

Figure 48. Typical results for fibers coated with $53 \mathrm{w} / \mathrm{w} \%$ particles in a) $55 \mathrm{~mol} \%$ OtMOS/TEOS, b) $50 \mathrm{~mol} \%$ OtEOS/TEOS, and c) $67 \mathrm{~mol} \%$ TFP-tMOS/PtMOS.

Figure 49. Typical results for simultaneous dip-coating $51000 \mu \mathrm{m}$ diameter fibers with particle / sol-gel binder blends. Image A shows an uncoated fiber for reference. Images B - D are fibers were coated with a mixture of $53 \mathrm{w} / \mathrm{w} \% \mathrm{wlb} 29$ powder in $55 \mathrm{~mol} \%$ OtMOS/TEOS binder.

Figure 50. Images of fibers coated with $53 \mathrm{w} / \mathrm{w} \%$ wlb29 powder in $55 \mathrm{~mol} \%$ OtMOS/TEOS binder before and after mechanical testing. A and $\mathrm{B}$ are the before and after images of a fiber tested at $30^{\circ} ; \mathrm{C}$ and $\mathrm{D}$ are the before and after images 
from a second fiber tested at $90^{\circ}$. Images $\mathrm{E}-\mathrm{H}$ are from a single fiber. Image $\mathrm{E}$ shows the fiber before testing, and $\mathrm{F}, \mathrm{G}$, and $\mathrm{H}$ show results after impacting from $30^{\circ}, 60^{\circ}$ and $90^{\circ}$, respectively.

Figure 51. Room temperature emission spectra sol-gel film 29L $(\diamond) 1$ day curing at

$70^{\circ} \mathrm{C}$, ( $\bullet 54$ hours of thermal cycling between $200^{\circ} \mathrm{C}$, and the spectrum of its originating potassium salt FJ-17 ( $\square$ ) in $\mathrm{CH}_{3} \mathrm{CN}$. All spectra were measured and in $99.999 \%$ nitrogen. The film concentration is $3.6 \pm 1.6 \times 10^{21}$ cluster $/ \mathrm{cm}^{3}$ based on an estimated film thickness of $700 \pm 300 \mathrm{~nm}$. The solution concentration is $0.087 \mathrm{mM}$ $\pm 1.4 \%$.

Figure 52. Integrated emission intensity $(550-850 \mathrm{~nm})$ from sol-gel film $29 \mathrm{~L}$ at room temperature, after heating at $200^{\circ} \mathrm{C}$ for the indicated time interval. See Figure 10 for cluster information.

Figure 53. Thermal dependence of the emission spectra for film 38Q cured at 200 ${ }^{\circ} \mathrm{C}$ for 30 minutes. The emission intensity is a function of temperature, but the lineshape is temperature independent. All spectra were sampled in $99.999 \%$ nitrogen environments. The cluster source was MM8 and the film concentration is $(5 \pm 1.1) \times$ $10^{20}$ clusters $/ \mathrm{cm}^{3}$ based on an estimated film thickness of $(700 \pm 300) \mathrm{nm}$.

Figure 54. Time dependent quenching measurements at $674 \mathrm{~nm}$ of sol-gel film $38 \mathrm{Q}$ alternating between a $99.999 \% \mathrm{~N}_{2}$ and $20.7 \% \mathrm{O}_{2}$ gas environment at $147{ }^{\circ} \mathrm{C}, 174{ }^{\circ} \mathrm{C}$ and $200{ }^{\circ} \mathrm{C}$. The response time of the film is fast, $\leq 1$ second. The film was pumped at $313 \mathrm{~nm}$.

Figure 55. Quenching ratio as a function of film temperature for sol-gel film $38 \mathrm{Q}$ derived from the time dependent measurements of Figure 15. The quenching ratios are relatively independent of temperature, but the magnitude itself is small.

Figure 56. Demonstration that the room temperature quenching ratio of slide $38 \mathrm{Q}$ is relatively unaffected by temperature cycling; measurements from the (1) first day, (2) one day later, following cycling to: (3) $50{ }^{\circ} \mathrm{C}$, (4) $88^{\circ} \mathrm{C},(5) 115^{\circ} \mathrm{C}$, (6) $150^{\circ} \mathrm{C}$ and $(7) 200^{\circ} \mathrm{C}$. The lowest value obtained is $1.45 \times$.

Figure 57. Micrograph of Fiber $M$

Figure 58. Fiber sensor measurements at $100{ }^{\circ} \mathrm{C}$ demonstrating quenching of $6.1 \times$ between pure nitrogen and $21 \%$ oxygen (balance nitrogen). The sensor signal is large, in the nanowatt regime with the signal magnitude in oxygen $\sim 40$ greater than the measured autofluorescence. The luminescent tip contains $\mathrm{K}_{2} \mathrm{Mo}_{6} \mathrm{Cl}_{14}$ sol-gel particles embedded in a sol-gel binder matrix, with $4 \times 10^{18}$ clusters $/ \mathrm{cm}^{3}$ (Fiber M). The coupled pump power is $295 \mathrm{~W}$ at $365 \mathrm{~nm}$ and the gas flow rate is $1000 \mathrm{sccm}$.

Figure 59. Fiber sensor measurements at $80^{\circ} \mathrm{C}$ demonstrating quenching of $6.4 \times$ between pure nitrogen and $21 \%$ oxygen (balance nitrogen) for Fiber M. The 
measurement conditions are the same as Figure 58.

Figure 60. Fiber sensor measurements at $60^{\circ} \mathrm{C}$ demonstrating quenching of $6.8 \times$ 77 between pure nitrogen and $21 \%$ oxygen (balance nitrogen) for Fiber M. The measurement conditions are the same as Figure 58.

Figure 61: Fiber sensor measurements at $41^{\circ} \mathrm{C}$ demonstrating quenching of $5.9 \times$ 78 between pure nitrogen and $21 \%$ oxygen (balance nitrogen) for Fiber M. The measurement conditions are the same as Figure 58.

Figure 62. Fiber sensor measurements while scanning the temperature from $23{ }^{\circ} \mathrm{C}$ to $76{ }^{\circ} \mathrm{C}$ and then back down to $23{ }^{\circ} \mathrm{C}$ for fiber $\mathrm{M}$. The date demonstrate that the sensor signal is relatively unaffected by the temperature ramp; the signal magnitude in $\mathrm{N}_{2}$ decreases by $5 \%$ from $23{ }^{\circ} \mathrm{C}$ to $76^{\circ} \mathrm{C}$, whereas the quenching ratio varies by $25 \%$. The measurement conditions are the same as in Figure 58.

Figure 63. Fiber sensor measurements at room demonstrating quenching of $4.4 \times$ between pure nitrogen and $21 \%$ oxygen (balance nitrogen) for Fiber M. The measurement conditions are the same as Figure 58.

Figure 64. Quenching ratio (signal intensity in $\mathrm{N}_{2}$ vs $21 \% \mathrm{O}_{2}$ ) as a function of temperature for Fiber M, from the data in Figs. $6-10$. These measurements show that in the temperature range of 50 to $100{ }^{\circ} \mathrm{C}$ the quenching ratio is relatively independent of temperature, varying by $\pm 6 \%$.

Figure 65. Photograph of Fiber 121 as fabricated and after all thermal testing.

Figure 66. Oxygen sensitivity of Fiber 121 at $42{ }^{\circ} \mathrm{C}$ during several cycles of measurement. The gas composition for each cycle was: (i) $99.999 \% \mathrm{~N}_{2}$, (ii) $2.11 \%$ $\mathrm{O}_{2}$, (iii) $4.22 \% \mathrm{O}_{2}$, (iv) $6.32 \% \mathrm{O}_{2}$, (v) $8.44 \% \mathrm{O}_{2}$, (vi) $10.6 \% \mathrm{O}_{2}$, (vii) $12.7 \% \mathrm{O}_{2}$, (viii) $14.8 \% \mathrm{O}_{2}$, (ix) $16.9 \% \mathrm{O}_{2}$, (x) $19.0 \% \mathrm{O}_{2}$ and (xi) $21.1 \% \mathrm{O}_{2}$, with the balance $\mathrm{N}_{2}$. Note during the two cycles from 6,500-10,000 s and 14,580-17,062 s the gas order was reversed going from $21.1 \% \mathrm{O}_{2}$ to $99.999 \% \mathrm{~N}_{2}$. Coupled pump power is $285 \mu \mathrm{W}$, gas flow rate is 400 and $370 \mathrm{sccm}$ at the input and output of the quartz chamber respectively, and the cluster concentration is $\sim 8 \times 10^{18}$ clusters $/ \mathrm{cm}^{3}$.

Figure 67. Stern-Volmer relationship, $\mathrm{I}_{0} / \mathrm{I}$ as a function of molar oxygen concentration, at $42{ }^{\circ} \mathrm{C}$ for Fiber sensor 121. The data are from Figure 66 and represent the average over the indicated four cycles.

Figure 68. Stern-Volmer relationship, $\mathrm{I}_{0} / \mathrm{I}$ as a function of molar oxygen concentration, at $73{ }^{\circ} \mathrm{C}$ for Fiber sensor 121 . Plotted is the average from four cycles of measurement. Coupled pump power is $285 \mu \mathrm{W}$, gas flow rate is 400 and 390 sccm at the input and output of the quartz chamber respectively.

Figure 69. Stern-Volmer relationship, $\mathrm{I}_{0} / \mathrm{I}$ as a function of molar oxygen concentration, at $102{ }^{\circ} \mathrm{C}$ for Fiber sensor 121. Plotted is the average from two 
cycles of measurements. Coupled pump power is $285 \mu \mathrm{W}$, gas flow rate is 400 and $370 \mathrm{sccm}$ at the input and output of the quartz chamber respectively.

Figure 70. Quenching ratio (intensity in $\mathrm{N}_{2} /$ intensity in $\mathrm{O}_{2}$ ) for $6 \mathrm{~N}_{2} / \mathrm{O}_{2}$ cycles at $58^{\circ} \mathrm{C}$ for Fiber Sensor 45 . The cycle-to-cycle variations correspond to a $\pm 1- \pm 15$ $\%$ uncertainty in oxygen concentration over the entire measurement range from 21.1 $-2.1 \%$ oxygen respectively. The luminescent tip contains $\mathrm{K}_{2} \mathrm{Mo}_{6} \mathrm{Cl}_{14}$ sol-gel particles embedded in an OtMOS/TEOS binder matrix, with $1.3 \times 10^{18}$ clusters $/ \mathrm{cm}^{3}$ (Fiber 45). The coupled pump power is $300 \mathrm{nW}$ at $365 \mathrm{~nm}$ and the gas flow rate is $1000 \mathrm{sccm}$. These measurements were made with the "homemade" gas switching system.

Figure 71. Sensor output signal from Fiber 45 at $60{ }^{\circ} \mathrm{C}$ as a function of oxygen concentration: $0.1 \%, 0.2 \% 0.3 \%, 0.4 \%, 0.5 \%, 0.6 \%, 0.7 \%, 0.8 \%, 0.9 \%$, and $1 \% \mathrm{O}_{2}$ (balance is nitrogen). It shows that the sensor can resolve a $0.1 \%$ change in absolute oxygen concentration in the $0.1 \%-1 \%$ range at $60{ }^{\circ} \mathrm{C}$.

Figure 72. Signal from Fiber 45 measured over a period of 23 days, at room temperature $(\square), 83{ }^{\circ} \mathrm{C}$ and $114^{\circ} \mathrm{C}(\boldsymbol{\square})$, the lower measurement is $144^{\circ} \mathrm{C}$. The measurement sequence (day 0 ) began 3 days after the sensor was fabricated. On day 17 , the sensor was measured at room temperature, $83{ }^{\circ} \mathrm{C}$ and $114{ }^{\circ} \mathrm{C}$, then left at 90 ${ }^{\circ} \mathrm{C}$ for 20.5 hours with the LED blocked. As the sensor signal at room temperature on day 18 is the same as day 17 , we conclude that high temperature excursions are not intrinsically harmful to the device. See text for explanation of the drop in signal on day 19. Note that the total UV exposure over the entire 23 days is about 22.5 hours.

Figure 73. Quenching ratio (signal intensity in $\mathrm{N}_{2}$ divided by $21 \% \mathrm{O}_{2}$ ) for the measurement sequence described in Figure 72. The data demonstrates that after about 17 days and high temperature cycling the sensor response stabilizes.

Figure 74. The side view of Fiber 45 before (day 0 ) and after 23 days of room temperature measurements as well heating at high temperature up to $114^{\circ} \mathrm{C}$. There are no external signs of delamination and the morphology of the Mo-cluster/sol-gel film does not change.

Figure 75: High temperature measurements of Fiber Sensor 70 during 13.8 hours of cycling between $99.999 \% \mathrm{~N}_{2}$ and $21.1 \% \mathrm{O}_{2}$ at $70{ }^{\circ} \mathrm{C}$. These measurements were made in a quartz gas sensor cell, with temperature stability of $\pm 1{ }^{\circ} \mathrm{C}$ for 13.8 hours. In this flow-through cell the gas exchange time is $10 \mathrm{~s}$ for a $200 \mathrm{sccm}$ flow. The gas cycling is controlled by a solenoid switch, with 3.6 min in $\mathrm{N}_{2}$ and 2.3 minutes in $\mathrm{O}_{2}$. The variations in the envelope of the sensor signal are synchronous with the temperature fluctuation. The data demonstrates that we can achieve a quenching ratio of $4 \pm 0.1$ between pure $99.999 \%$ nitrogen and $21 \%$ oxygen over 13.8 hours at $71.5 \pm 1{ }^{\circ} \mathrm{C}$. 


\section{INTRODUCTION}

Fiber optic oxygen probes are well-suited for development as micro-sensors for oxygen levels in power plant exhaust environments. Advantages of fiber sensors include the ability to probe otherwise inaccessible locations via miniaturization into small flexible probes and immunity from electrical interference. Single sensors can be placed in an array rake in the exhaust duct downstream of a combustion chamber to provide spatially localized information. The time response of fiber sensors can be less than one second which would allow for real time control and balancing of the individual combustor' operation, improve efficiency, and lower emissions.

Oxygen quenching of the fluorescence from organometallic compounds has been used to develop a number of fiber sensors. However, a major drawback of these indicators for energy plant applications is that the chromophores degrade with time, i. e. lack long range reliability, and have a limited operational temperature range, typically room temperature plus or minus $25{ }^{\circ} \mathrm{C}$. Previously, we developed a room temperature fiber optic oxygen sensor that utilizes the luminescence from hexanuclear metal halide clusters such as $\mathrm{Mo}_{6} \mathrm{Cl}_{12},{ }^{[1]}$ to detect oxygen in the $0.1 \%$ to $20 \%$ range. The organic polymers used to fabricate this device limited its operation to room temperature; we have extended our previous results to $200{ }^{\circ} \mathrm{C}$ by replacing the organic components with a porous inorganic sol-gel support that has superior thermal stability.

A schematic of the reflection mode fiber sensor is shown in Figure 1. The Mo-clusters are immobilized in an oxygen permeable matrix at the far end of a silica fiber. An ultraviolet optical source, coupled into the near end of the fiber, is used to excite the clusters (pump beam). The reflected luminescence signal is also collected from the near end of the fiber. This geometry allows for the "active" end of the fiber sensor to be immersed in a harsh environment, while the collection and excitation optics are located in a more benign environment.

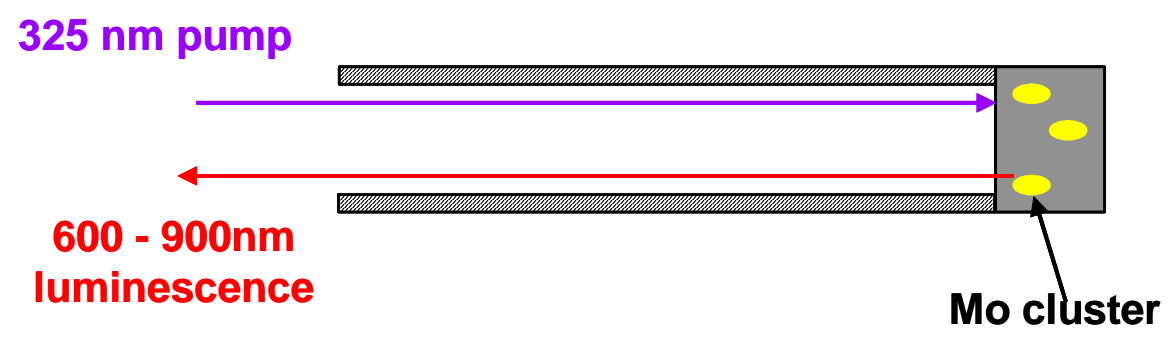

Figure 1. Schematic of the reflection mode fiber sensor.

The use of $\mathrm{Mo}_{6} \mathrm{Cl}_{12}$ clusters offer particular advantages for the construction of practical fiber optic devices. The clusters are inexpensive and their synthesis is straight-forward. The long lifetime of the cluster excited state $(>100 \mu \mathrm{s})$ and the large Stokes shifted emission (> $300 \mathrm{~nm}$ ) allows the use of simple light emitting diode (LED) pumping and $\mathrm{Si}$ photodiode detection, both of which are essential for volume fabrication of the sensor. Other advantages of the metal halide clusters are that they can withstand repeated cycling and show no signs of decomposition to temperatures to $200{ }^{\circ} \mathrm{C}$. Finally, the red luminescence emitted from the excited state of the Mo cluster is efficiently quenched by 
only ground state ${ }^{3} \mathrm{O}_{2}$. Since the ground state of all other gases typically present in power plant exhausts such as hydrogen, hydrocarbons, carbon monoxide and sulfur oxides do not have a triplet ground state; no cross-sensitivity with these species is expected.

The photophysics and physical properties of $\mathrm{Mo}_{6} \mathrm{Cl}_{12}$ and related metal halide compounds [2] are well suited for oxygen sensing schemes. The extended cluster array has a quasiperovskite structure, composed of an octahedral core of molybdenum atoms with eight face bridging chlorides and four axial chlorides, which are shared among neighboring cluster subunits. ${ }^{[3]}$ The emissive excited state is localized in the metallic core of the cluster with little ligand character. ${ }^{[4]}$ From a sensor perspective, these clusters are an ideal lumophore because their luminescence is largely unaffected by the external environment, whether that be encapsulation in a sol-gel matrix or immersion in a gaseous environment. When dissolved in solution the clusters exist in the form $\left[\mathrm{Mo}_{6} \mathrm{Cl}_{8}\right] \mathrm{Cl}_{4} \mathrm{~L}_{2}$ where $\left[\mathrm{Mo}_{6} \mathrm{Cl}_{8}\right]$ is the core of the cluster, $\mathrm{Cl}_{4}$ are exchangeable chlorides sited in axial positions, and L is either a solvent molecule or another ligand, see Figure 2. The cluster can withstand repeated cycling, without degradation of the luminescence. The intensity of the luminescence increases with decreasing oxygen concentration, following the SternVolmer equation. ${ }^{[5]}$ Under atmospheric conditions we have shown that gaseous oxygen can be detected from $0.1 \%$ to $20 \%,{ }^{[1]}$ a range which is well suited for power plant applications such as emission control and individual burner balancing.

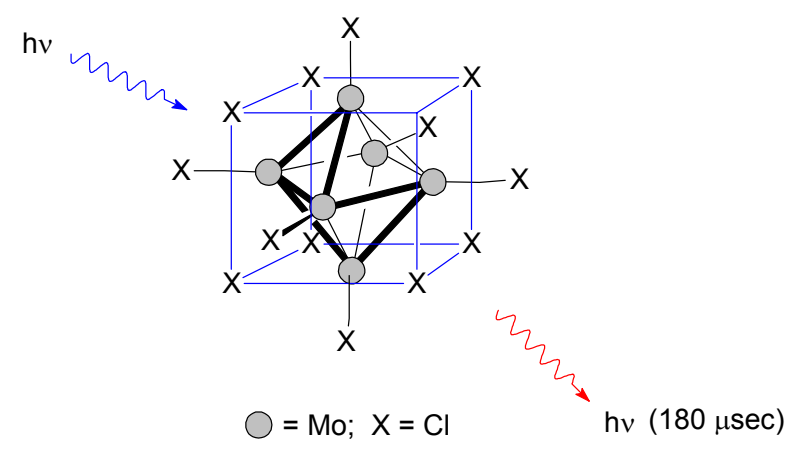

Figure 2. The $\mathrm{Mo}_{6} \mathrm{Cl}_{12}$ cluster, the basis for a versatile optical sensor for oxygen.

Shown in Figure 3 are the absorption and emission spectra of the Mo-clusters in acetonitrile. Absorption of UV photons through the broad 300-400 nm absorption band raises the cluster to an excited electronic state. Emission of red luminescence from the excited state is efficiently quenched by ground state ${ }^{3} \mathrm{O}_{2}$. Due to the large Stokes shift of $>400 \mathrm{~nm}$ we are able to separate the pump and probe signals using simple filtering techniques and then integrate all the photons in the $600-850 \mathrm{~nm}$ emission band as the sensor signal using a simple photodiode detector.

Oxygen quenching of the luminescence is demonstrated in Figure 4. The luminescence spectra are shown in two gas environments: (a) argon $(<0.005 \%$ oxygen $)$ and (b) air ( $20 \%$ oxygen). A quenching of a factor of 5.5 between argon and air was observed. 


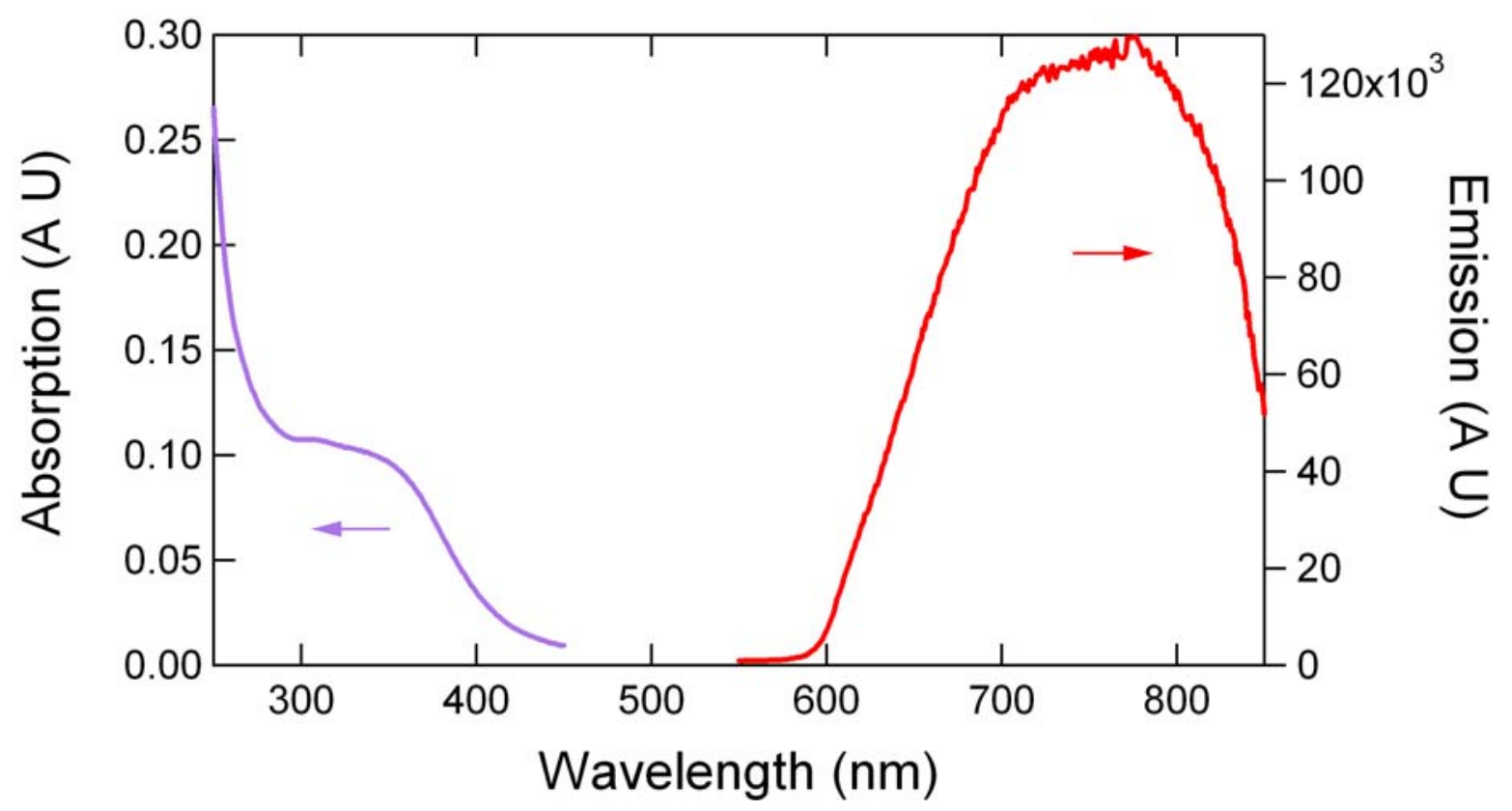

Figure 3. Absorption and emission spectra of the $\mathrm{Mo}_{6} \mathrm{Cl}_{12}$ acetonitrile complex. The absorption band extends from 300-400 nm and the emission band extends from 600$850 \mathrm{~nm}$. The large Stokes shift allows for simple LED excitation and photodiode detection, which are essential for volume fabrication of the senor.

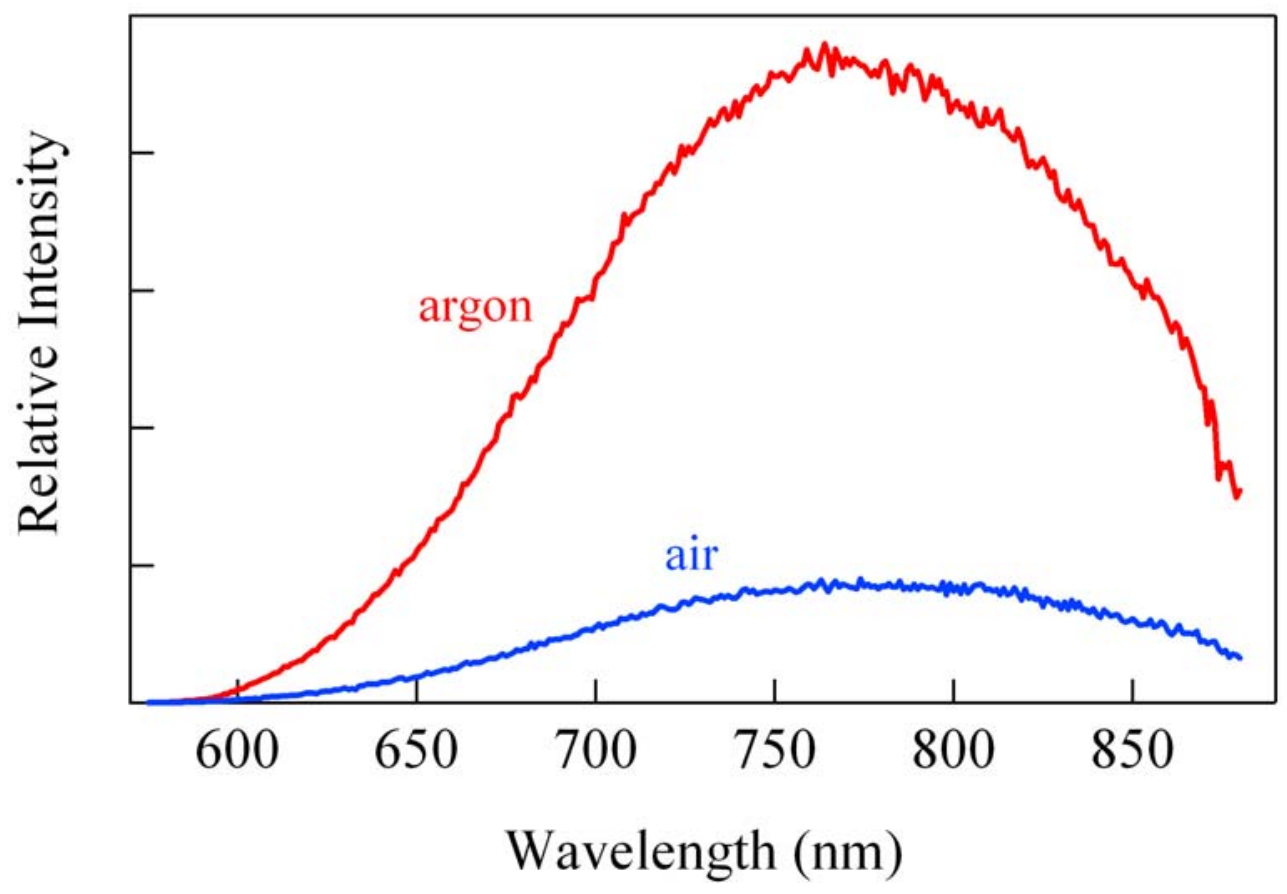

Figure 4. Luminescence spectra from the Mo-clusters demonstrating quenching by oxygen: (a) argon environment and (b) laboratory air ( $20 \%$ oxygen). 
A schematic diagram of the setup used for characterizing the fiber sensor is shown in Figure 5. Plotted in Figure 6 is output signal from the sensor in $\mathrm{nW}$ as a function of oxygen concentration from $0-20 \%$ oxygen, with nitrogen as the balance gas. Note from the error bars on the measurement points, within our $6 \mathrm{~Hz}$ measurement bandwidth the standard deviation is less than $2 \%$ of the signal. The data demonstrate that the sensor can clearly resolve changes on $0.1 \%$ absolute oxygen concentration in the $0-1 \%$ range, changes of $0.5 \%$ absolute oxygen concentration in the $1-4 \%$ range, changes of $1 \%$ absolute oxygen concentration in the $4-10 \%$ range, and changes of $2 \%$ absolute oxygen concentration in the $10-20 \%$ range. These measurements were made on a $1.5 \mathrm{~m}$ long fiber probe. The auto-fluorescence is small for this long length of fiber, demonstrating the feasibility of probing remote locations with such a fiber sensor. From the inset to Figure 6 we deduce that an upper bound to the sensor switching time is $30 \mathrm{~s}$. This is not the intrinsic response time of the sensor, which we estimate to be $1 \mathrm{~s}$. In addition we have demonstrated that the quenching of the cluster luminescence shown in the figure, obeys the Stern-Volmer equation as expected from theory. ${ }^{[1]}$

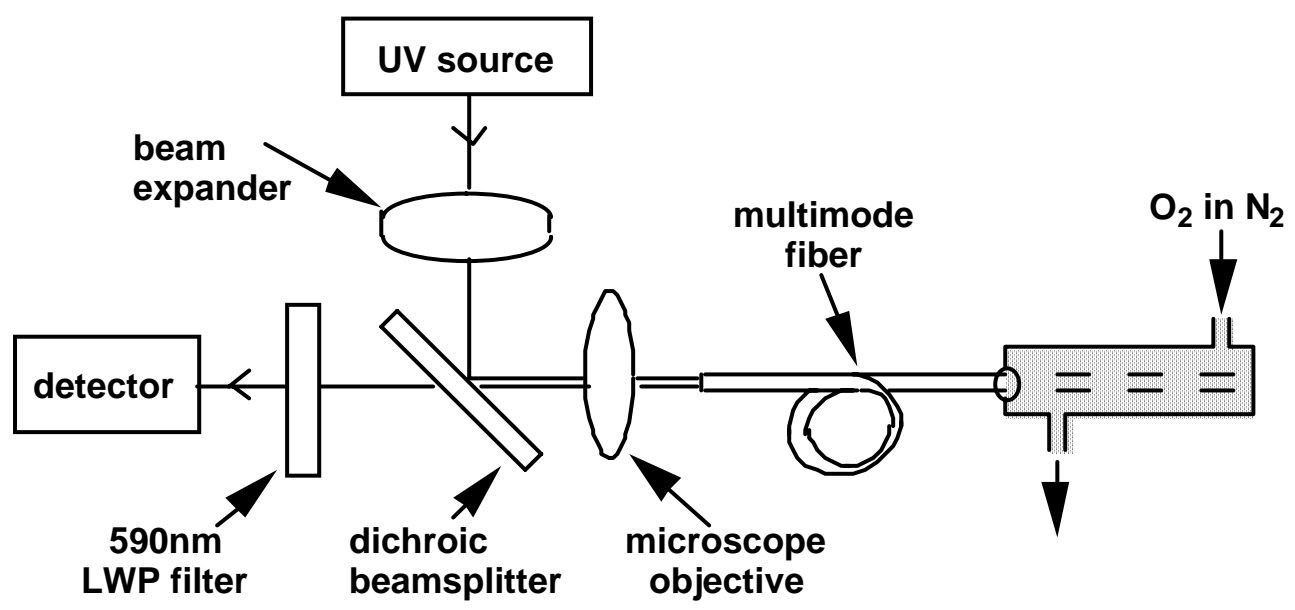

Figure 5. Optical setup for fiber sensor measurements. 


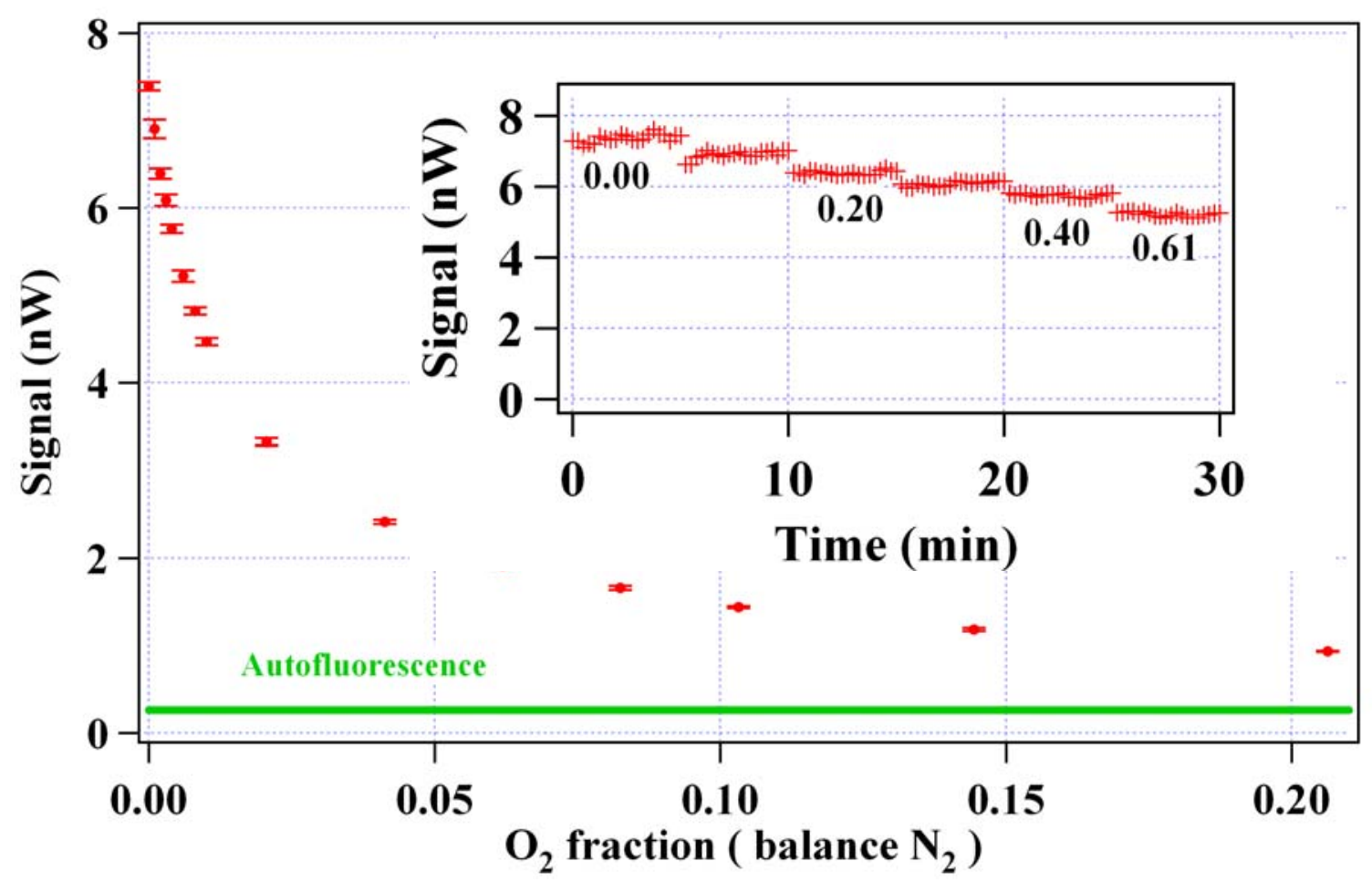

Figure 6. Output signal from the room temperature fiber oxygen probe. ${ }^{[1]}$ The sensor signal as a function of time for low oxygen concentrations is shown in the inset.

Maximizing the efficiency of the combustion process requires real-time control of the correct fuel/oxygen ratio. This requires the ability to sense oxygen levels over a broad range of concentrations with fast response times. Mussell, Newsham, and Ruud previously reported preliminary studies of the synthesis and optical properties of $\mathrm{Mo}_{6} \mathrm{Cl}_{12}$-based clusters relevant to this project ${ }^{[1,6-8]}$. Mussell described the synthesis of the molybdenum clusters, and Newsham gives a good account of the properties of neutral $\mathrm{Mo}_{6} \mathrm{Cl}_{12}$ clusters and their salts, in both solution and a sol gel matrix. Newsham's data indicate that the photophysical properties of the clusters are maintained in sol gel matrices. To prepare a fiber optic sensor based on $\mathrm{Mo}_{6} \mathrm{Cl}_{12}$, Ruud dispersed $\mathrm{Mo}_{6} \mathrm{Cl}_{12}$ in poly[1-trimethylsilyl-1-propyne] (PTMSP), and used a dipping technique to immobilize the composite at the cleaved end of a silica optical fiber. Ghosh and co-workers ${ }^{[9]}$ demonstrated a fast room temperature fiber optic sensor based on oxygen quenching of the luminescence from the PTMSP/ $\mathrm{Mo}_{6} \mathrm{Cl}_{12}$ composites. While the PTMSP support is adequate for room temperature applications, is unable to withstand the high temperatures associated with combustion in a power plant. To improve the sensor's high temperature performance, we are replacing PTMSP with a thermally stable sol gel matrix that should be able to withstand the higher temperature requirements of the power plant combustion process. The idea of using a sol gel as the support matrix for high temperature oxygen sensor application is not new. Remillard and coworkers have shown that a sol gel supported copper based oxygen sensor can be used in a combustion process ${ }^{[10]}$. With these facts in hand, we anticipate promising results from our design. 


\section{EXECUTIVE SUMMARY}

A requirement of optical sensors based on luminescence quenching is that the lumophore have a strong luminescence that is efficiently quenched by oxygen, and that oxygen has ready access to the lumophore. For a high temperature sensor, these characteristics must hold over the entire temperature range of interest.

A preliminary study of the high temperature stability of the $\mathrm{Mo}_{6} \mathrm{Cl}_{12}$ clusters in oxygenated environments revealed irreversible changes in the optical absorption spectrum at $>250{ }^{\circ} \mathrm{C}$ and a loss of the red luminescence that is characteristic of pristine clusters. Thermal aging experiments run in air and under nitrogen point to oxidation of the clusters as the cause of the change in optical properties. X-ray diffraction measurements on samples annealed at $300{ }^{\circ} \mathrm{C}$ under controlled conditions are consistent with oxidation of $\mathrm{Mo}_{6} \mathrm{Cl}_{12}$ to form $\mathrm{MoO}_{3}$ as the principal degradation product. Two open axial coordination sites on the $\mathrm{Mo}_{6} \mathrm{Cl}_{12}$ cluster lead to the polymerization of clusters through shared chlorine bridges. These open sites also are the likely source of the oxidative instability of $\mathrm{Mo}_{6} \mathrm{Cl}_{12}$. The known $\mathrm{Mo}_{6} \mathrm{Cl}_{14} \mathrm{X}_{2}$ salts, where $\mathrm{X}$ is an alkali metal cation such as $\mathrm{Na}^{+}, \mathrm{K}^{+}$, or $\mathrm{Cs}^{+}$should be more thermally robust since there is a full complement of chloride ligands and no open sites for cluster aggregation or oxidation, i.e. chlorides must be lost from the cluster for the cluster to undergo degradation.

We synthesized the potassium salt of $\mathrm{Mo}_{6} \mathrm{Cl}_{12}\left(\mathrm{~K}_{2} \mathrm{Mo}_{6} \mathrm{Cl}_{14}\right)$ and found that the alkali salts of $\mathrm{Mo}_{6} \mathrm{Cl}_{12}$ are more stable that the parent compound. Optical and thermal aging experiments show that the alkali metal salts of $\mathrm{Mo}_{6} \mathrm{Cl}_{12}$ have higher thermal stabilities and remain luminescent after long-term aging at $280^{\circ} \mathrm{C}$.

Methods were developed for the deposition of sol-gel films on planar and optical fiber substrates by dip coating and spray coating. The mechanical properties of the films depended on the thickness of the films; thin films were stable, but cracks often formed in the thicker films needed for sensors. This problem was addressed using two strategies: altering the components of the sol-gel solutions used to embed the clusters, and by devising a composite approach to sensing layers, where a slurry of fully cured sol-gel particles containing $\mathrm{K}_{2} \mathrm{Mo}_{6} \mathrm{Cl}_{14}$ in a sol-gel "binder" were deposited on substrates. The latter approach offers several advantages such as minimizing film shrinkage and hence, cracking, and the ability to use the same cluster/sol-gel source for a series of sensors leading to sensors with predictable characteristics.

The high temperature stability of the sol-gel sensing films embedded with $\mathrm{K}_{2} \mathrm{Mo}_{6} \mathrm{Cl}_{14}$, was first determined using films deposited on planar quartz substrates. The emission lineshape of the $\mathrm{K}_{2} \mathrm{Mo}_{6} \mathrm{Cl}_{14}$ containing sol-gel film, following 54 hours of heating at 200 ${ }^{\circ} \mathrm{C}$ was the same as that of the original potassium salt in acetonitrile. This demonstrates that both the process for embedding the cluster in a sol-gel matrix and long term heating to $200{ }^{\circ} \mathrm{C}$ do not have a deleterious effect on the cluster photophysics.

We have designed and built a compact high temperature fiber sensor test setup to characterize devices up to $350{ }^{\circ} \mathrm{C}$ in a gas flow through system. The setup is designed to be portable for field testing and uses an inexpensive, $\sim \$ 6.00$ ultraviolet (UV) light emitting diode (LED) as the excitation source. An automated data acquisition system has been developed to simultaneously record the sensor luminescence signal and sensor 
temperature, to $\pm 1{ }^{\circ} \mathrm{C}$. We are able to determine the sensor response time to better than $10 \mathrm{~s}$, as the gas exchange time in the chamber is $<6 \mathrm{~s}$ for a $1.5 \mathrm{~L} / \mathrm{min}$ flow.

The salient features of our home-built sensor characterization system are as follows. (1) The coupled pump power into the fiber sensor from the UV light source is $300-500 \mathrm{nW}$. (2) Since visible output from the UV LED in the emission bandwidth of the Mo-clusters, $600-800 \mathrm{~nm}$, is spectroscopically indistinguishable from the real sensor signal, it set a bound on the smallest signal we can detect. The rejection of unwanted pump power in the $600-800 \mathrm{~nm}$ emission bandwidth is $10^{-5}$. This is $1 / 160$ of the lowest sensor signal in oxygen. (3) The working end of the fiber sensor is enclosed in a heated quartz chamber that allows for true flow measurements with a measured gas exchange time of $\sim 10 \mathrm{~s}$. (4) The gas exchange is performed either using a solenoid switch to switch back and forth between two levels or with a precision manual gas divider which allows us to mix two gases in the ratio of $1: 10,2: 10 \ldots 10: 10$.

The optical properties of a large number of fiber sensors were tested up to $100{ }^{\circ} \mathrm{C}$. The best results were obtained using $\mathrm{K}_{2} \mathrm{Mo}_{6} \mathrm{Cl}_{14} /$ sol-gel composite sensing film. With Fiber $\mathrm{M}$ we demonstrated quenching of $4-6 \mathrm{X}$ between 0.001 and $21 / 1 \%$ at $23,41,60,81$ and $100{ }^{\circ} \mathrm{C}$ respectively. The sensor switches abruptly, with a time constant of better than $10 \mathrm{~s}$, between two well defined levels. From theory the quenching of the cluster luminescence by oxygen is expected to obey the Stern-Volmer relationship, which was verified by measurements of Fiber 121 at 41,73 and $102{ }^{\circ} \mathrm{C}$. One unanswered question that remains with these measurements is why the y-intercept of the Stern-Volmer plots does not equal. A possibility is that there is more than one process involved in the quenching of the excited state luminescence by oxygen, which would lead to multiple time constants. To verify this hypothesis we would need to directly measure the quenching lifetime of the Mo-cluster/sol-gel films at high temperature, unfortunately we do not have access to such a measurement system. The cycle-cycle variations for six cycles between $\mathrm{N}_{2}$ and $\mathrm{O}_{2}$ at $58{ }^{\circ} \mathrm{C}$ for Fiber Sensor 45 corresponds to an uncertainty of \pm 1 to $\pm 15 \%$ in oxygen concentration over the entire measurement range from 21.1 to 2.1 $\%$ oxygen respectively. The long-term performance of our devices was determined by cycling Fiber Sensor 70 between 0.001 and $21.1 \%$ oxygen for 14 hours. The data was stable over the entire period, the variations in sensor signal were found to be synchronous with the temperature fluctuations in the flow through cell.

The absolute magnitude of our sensor signal is very encouraging in terms of practical implementations of our device up to at least $100{ }^{\circ} \mathrm{C}$. We obtain a $\sim 3 \mathrm{nW}$ output signal for $\sim 300 \mu \mathrm{W}$ of incident pump power; $10^{-5}$ is a very reasonable power conversion efficiency for a fiber sensor. Autofluorescence or the magnitude of the signal in our measurement bandwidth due to fluorescence from a length of fiber without any cluster on the tip sets a lower bound on the smallest signal we can detect from our sensor. For our current $15 \mathrm{~cm}$ long fiber sensor, we have $0.011 \mathrm{nW}$ of autofluorescence, which is a factor of 40 smaller than the $\sim 0.4 \mathrm{nW}$ signal in oxygen.

From a project management perspective, a postdoctoral researcher, Dr. Po Zhang was involved with the spectroscopic and optical fiber sensor development portion of the program from November 2004 to July 2006. Dr. Zhang received his PhD in Electrical and Computer Engineering from Virginia Polytechnic Institute. His academic and 
industrial experience in optical fiber sensors, prior to coming to MSU, including DOE/NETL projects on optical pressure and temperature sensors for oil wells. Dr. Zhang joined Linn State Technical College in Mexico, MO in August 2006 as a Laser/Photonics Technology Instructor. D.J. Osborne, III is a Ph.D. candidate in the Chemistry Department at Michigan State University. He will complete his degree program in fall 2007.

Two patent disclosures were submitted during this project. The utility patent for "Sol-gel encapsulated hexanuclear clusters for oxygen sensing by optical techniques" was filled with the US Patent Office on January 2006. The provisional patent number for this first patent was \#60/648,367. A disclosure for "Oxygen Sensing using Composites of Hexanuclear Cluster Encapsulated in Sol-gel Particles and Binders" was submitted to the MSU intellectual property office on February 2006.

A paper entitled " $\mathrm{Mo}_{6} \mathrm{Cl}_{12}$ incorporated sol-gel for oxygen sensing applications", by D. J. Osborn, G. L. Baker and R. N. Ghosh was published in the Journal of Sol-gel Science and Technology. 36 (1), p. 5 -10 (2005). A paper entitled, " Fiber optic oxygen sensing up to $100^{\circ} \mathrm{C}$ using molybdenum chloride clusters embedded in a sol-gel matrix" by R. N. Ghosh, P. Zhang, D. J. Osborn and G. L. Baker was submitted to Sensors \& Actuators B in September 2006.

Several talks and posters were presented at international meetings on this work. (1) Dr. Ruby Ghosh, presented a poster on "Optical Detection of Oxygen at Elevated Temperatures via Molybdenum Chloride Cluster Luminescence", at the International Meeting on Chemical Sensors, Brescia, Italy, July 2006 (http://imcs11.unibs.it/onimcs/IMCS/Home.html). (2) Dr. Po Zhang, presented a talk entitled, "High Temperature Oxygen Sensing Using $\mathrm{K}_{2} \mathrm{Mo}_{6} \mathrm{CL}_{14}$ Luminescence" at the International IEEE Sensors Meeting (http://ewh.ieee.org/tc/sensors/sensors2005/), in Irvine, CA Oct. 31 - Nov. 3, 2005. His talk was in the "Optical Sensors for High Temperature \& Environmental Applications" session. (3) "High temperature optical fiber oxygen probe", by R.N. Ghosh at a Special Session on "Chemical and Physical Sensors for Extreme Environments", 2004 IEEE International Conference on Sensors, Vienna, Austria, Oct. 24 -27 (2004). (4) "Fiber Optic Oxygen Sensor for Power Plant Applications", by R. N. Ghosh in the Special Session on "Extreme Environment Chemical Sensors", IEEE International Conference on Sensors, Toronto, Canada, Oct 22-24, 2003. 


\section{EXPERIMENTAL}

\section{Materials.}

All glassware was oven-dried prior to use. Acetonitrile (Spectrum Chemical Company, HPLC grade) was dried over $\mathrm{CaH}_{2}$ and distilled prior to use. Tetraethyl orthosilicate (TEOS) (Aldrich, 98\%), trimethoxy(octyl)silane (OtMOS) (Aldrich, 96\%), ntrimethoxy(propyl)silane (PtMOS) (Gelest, 98\%), triethoxy(octyl)silane (OtEOS) (Aldrich, $\geq 96 \%$ ), (3,3,3-trifluoropropyl)trimethoxysilane (TFP-tMOS) (Gelest), and hydrochloric acid (CCI, electronics grade) were used as received. Suprasil - W1 quartz microscope slides $\left(3^{\prime \prime} \times 1 " \times 1 \mathrm{~mm}\right)$ were obtained from Heraeus Amersil and were cut into $1.25 \mathrm{~cm} \times 2.45 \mathrm{~cm}$ pieces. Slides were handled with gloves and tweezers in order to minimize surface contamination and then washed with Alconox, rinsed with distilled water, soaked in a base bath $(\sim 5 \mathrm{M} \mathrm{NaOH}$ in $95 \%$ ethanol), rinsed with distilled water, and stored in distilled water until use. Fibers were purchased from 3M (FP-1.0-UHT) and Ceramoptec (PUV 1000/1300N), and were handled with gloves in order to minimize surface contamination.

\section{Cluster synthesis.}

\section{Preparation of $\mathrm{Mo}_{6} \underline{\mathrm{Cl}_{12}} \underline{\mathbf{2}}$}

$\mathrm{MoCl}_{2}$ from City Chemical (lots $40 \mathrm{C} 65$ and 40M21 lot 30L114) was received as a yellowish-green powder with small dark-blue specks and was purified by conversion to the $\mathrm{Mo}_{6} \mathrm{Cl}_{12}$ hydrochloride salt. A representative procedure is described. $\mathrm{MoCl}_{2}(2 \mathrm{~g})$ and $800 \mathrm{~mL}$ of $6 \mathrm{M} \mathrm{HCl}$ were added to a $1 \mathrm{~L}$ Erlenmeyer flask and stirred with a Teflon coated magnetic stir bar. The solution was heated to the boiling point for several hours and the resulting bright-yellow solution was then filtered through medium-fast filter paper to remove insoluble white and metallic particles. The filtered solution was heated on a hot plate and the volume reduced to $200 \mathrm{~mL}$. The hot plate was turned off and the solution was left on the hot plate to slowly cool to room temperature. A small amount of seed crystals were added and yellow crystals formed overnight. After cooling the solution in an ice bath for 5 hours, the resulting yellow crystals of the hydrochloride salt were collected by gravity filtration through Whatman medium-fast filter paper. The crystals were then placed onto several pieces of filter paper and allowed to dry under ambient conditions for two days. Yield: $586 \mathrm{mg}$. A second crop of crystals was obtained by heating to concentrate the mother liquor to $100 \mathrm{~mL}$, filtration, and a further reduction in volume to $50 \mathrm{~mL}$. Cooling, seeding the solution as described above, and storing the solution in a freezer overnight yielded long yellow needles. Drying the needles on filter paper yielded $256 \mathrm{mg}$ of the $\mathrm{Mo}_{6} \mathrm{Cl}_{12}$ hydrochloride salt. The products were characterized using x-ray powder diffraction, UV-vis spectroscopy, fluorescence spectroscopy, and energy dispersive $\mathrm{x}$-ray spectroscopy.

\section{$\left.\underline{\text { Preparation of the acetonitrile complex of } \mathrm{Mo}_{6}} \underline{\mathrm{Cl}_{12}} \cdot \underline{\left(\mathrm{Mo}_{6}\right.} \underline{\mathrm{Cl}}_{12} \cdot \underline{2} \underline{\mathrm{CH}}_{3} \underline{\mathrm{CN}}\right)$}

The $\mathrm{Mo}_{6} \mathrm{Cl}_{12}$ hydrochloride salt was heated under vacuum at $210^{\circ} \mathrm{C}$ for 12 hours to yield $\mathrm{Mo}_{6} \mathrm{Cl}_{12}$. The resulting yellow powder was loaded into the thimble of a pre-dried Soxhlet extraction apparatus. Dry acetonitrile $(250 \mathrm{~mL})$ was added to the extractor and the receiving flask was heated to start the extraction process. After 3 days, the yellow solution was removed and concentrated to $10 \mathrm{~mL}$. The products were characterized 
using, uv-vis, and fluorescence spectroscopy. $\mathrm{Mo}_{6} \mathrm{Cl}_{12} \cdot 2 \mathrm{CH}_{3} \mathrm{CN}$ was also directly prepared from $\mathrm{MoCl}_{2}$ from City Chemical (lot40C65, ) using the same procedure.

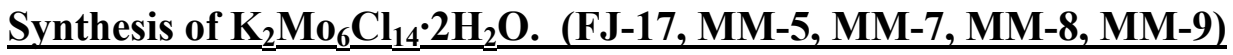

With heating, dry $\mathrm{Mo}_{6} \mathrm{Cl}_{12}$ (City Chemical, $1.0546 \mathrm{~g}, 1.055 \mathrm{mmol}$ ) was dissolved in 500 $\mathrm{mL}$ of $6 \mathrm{M} \mathrm{HCl}$ in a $1 \mathrm{~L}$ Erlenmeyer flask. The hot solution was filtered (Whatman, medium speed) to and then the volume was reduced to $250 \mathrm{~mL}$ by boiling. A saturated solution of $\mathrm{KCl}$ in $6 \mathrm{M} \mathrm{HCl}(200 \mathrm{~mL})$ was added to hot solution, and then the volume was further reduced to $150 \mathrm{~mL}$ by boiling. After cooling slowly to room temperature and an addition $24 \mathrm{~h}$ at room temperature, yellow needle-like crystals of $\mathrm{K}_{2} \mathrm{Mo}_{6} \mathrm{Cl}_{14}$ were collected by filtration. Drying under ambient conditions for three days yielded $1.0132 \mathrm{~g}$ of $\mathrm{K}_{2} \mathrm{Mo}_{6} \mathrm{Cl}_{14} \bullet \mathrm{H}_{2} \mathrm{O}$ as bright yellow crystals. The products were characterized using $\mathrm{x}-$ ray powder diffraction, uv-vis spectroscopy, fluorescence spectroscopy, and energy dispersive $\mathrm{x}$-ray spectroscopy, and thermal gravimetric analysis.

\section{Cluster characterization.}

\section{Thermal Analysis}

Isothermal aging of $\mathrm{K}_{2} \mathrm{Mo}_{6} \mathrm{Cl}_{14}$ was run in air using a Perkin Elmer TGA-7 system, which consists of a computer, TGA-7 low temperature furnace and balance module, and a TAC7/DX controller. The flow-rate of balance and sample gas was 45 and $40 \mathrm{~mL} / \mathrm{min}$ respectively. The pan, stirrup and hanger wire were made of platinum metal that was connected to a gold balance wire using a quartz hook. Samples were first equilibrated at $115^{\circ} \mathrm{C}$ for 1 hour to remove residual water, and then heated to $280{ }^{\circ} \mathrm{C}$ at a rate of $10^{\circ}$ per minute. The gas type and flow were adjusted to either nitrogen or air with a separate gas flow regulation system that was attached. . Samples were normally equilibrated at 150 ${ }^{\circ} \mathrm{C}$ to remove residual water before analysis.

\section{X-ray powder diffraction.}

Samples were prepared by using a spatula to evenly distribute a small amount of powdered sample on double-sided tape mounted on a microscope slide. After pressing gently to insure that the sample adhered to the tape, the microscope slide was gently tapped on its side to dislodge any loose powder.

\section{Elemental Analysis.}

The chemical composition of the $\mathrm{Mo}_{6} \mathrm{Cl}_{12}$ and $\mathrm{K}_{2} \mathrm{Mo}_{6} \mathrm{Cl}_{14}$ was determined by energy dispersive $\mathrm{x}$-ray spectroscopy (EDS) using a JEOL JSM-35C scanning electron microscope (SEM) equipped with a NORAN Inc. EDS detector. The analysis was conducted at accelerating voltage $20 \mathrm{kV}$ and collection time of $30 \mathrm{~s}$. The results of the elemental analysis for several crystals of each compound were averaged. The ratios were consistent with the formulas of $\mathrm{Mo}_{6} \mathrm{Cl}_{12}$ and $\mathrm{K}_{2} \mathrm{Mo}_{6} \mathrm{Cl}_{14}$, respectively. 


\section{Absorption spectroscopy.}

Samples were prepared by weighing $2-3 \mathrm{mg}$ of $\mathrm{Mo}_{6} \mathrm{Cl}_{12}$ in a small sample vial. The compound was then dissolved in a small amount of dry acetonitrile and transferred to a $10 \mathrm{~mL}$ volumetric flask. The volumetric flask was filled to the mark, stoppered, and shaken to insure a homogenous solution. Typical concentrations were $1.7 \times 10^{-4} \mathrm{M}$. Absorption spectra were measured using a Perkin-Elmer Lambda 40 series double beam $\mathrm{UV} /$ vis spectrometer. Data analysis was performed using the UV Win lab (version 2.80.03) software package supplied with the instrument and plotted using Microsoft Excel. Solutions were placed into a $1 \mathrm{~cm}$ pathlength quartz cuvette with a separate cell containing only solvent as a reference.

\section{Fluorescence spectroscopy.}

The fluorescence measurements were performed using a Fluorolog-3 instrument from Instruments S.A., Inc. The system includes a single Czerny-Turner excitation spectrometer with a $1200 \mathrm{~g} / \mathrm{mm}$ ruled grating blazed at $330 \mathrm{~nm}$ and a single CzernyTurner emission spectrometer with a $1200 \mathrm{~g} / \mathrm{mm}$ holographic grating blazed at $630 \mathrm{~nm}$. The excitation optics consists of a 450W ozone free Xe lamp, followed by a 270-380 nm bandpass filter (Oriel 1124). A Si photodiode is used to continuously monitor the lamp signal. The detection optics consists of $603.2 \mathrm{~nm}$ long wave pass filter (CVI) followed by a multi-alkali photo multiplier tube (Hamamatsu R928) with photon counting electronics. Data processing was performed using the Datamax (version 2.2) software package supplied with the instrument. Spectra were obtained by exciting at $313 \mathrm{~nm}$ and scanning the emission monochromator from 550 to $850 \mathrm{~nm}$.

Measurements of cluster fluorescence in solution were performed by placing the solution in a quartz cuvette sealed with an airtight septum. Measurements of sol-gel films were carried out similarly. Spectra were measured in laboratory air and high purity nitrogen (AGA, Inc, 99.999\%). Prior to obtaining spectra, all gases were bubbled through the solution for 10 to 15 minutes at a rate of $\sim 10 \mathrm{~mL} / \mathrm{min}$. via a glass pipette inserted through the septum. For the measurements of the potassium salts in $\mathrm{HCl}$ a glass pipette was used to bubble oxygen into the solution.

\section{Optical microscopy of clusters and films.}

Optical microscopy images were acquired using a Nikon Optiphot2-Pol equipped with a Sony Hyper HAD CCD-IRIS/RGB color video camera (model DXC-151A). The camera was connected to a PC using a Sony camera adapter (model CMA-D2). The images were viewed using a Sony Trinitron color video monitor. Images were taken using Hauppage computer works Win/TV software (version 2.4.17052). Images collected at 0 and $90^{\circ}$ to characterize the birefringence of the samples and a qualitative measure of their degree of crystallinity. A programable hot stage (Mettler FP82) was used to collect images at elevated temperatures. Images were collected every $10{ }^{\circ} \mathrm{C}$ and analyzed for mean luminosity using Adobe Photoshop, which provides a measure of the light emission from the sample over the entire visible spectrum. The mean luminosity was then plotted as a function of temperature and each sample contained approximately $4 \mathrm{mg}$ of cluster. 


\section{Dark field imaging}

Dark field optics is a low cost alternative to phase contract microscopy that allows one to readily obtain information on surface topography. In dark field the sample is illuminated from above, and only photons collected by annular apertures are collected to form the image. A perfectly flat sample with no topography will appear dark, any topographic features will be accentuated in the image. We used an Olympus BX60 optical microscope in KMF clean room, with 10X, 20X, 50X and 100X dark filed objectives and a SPOT video camera (Diagnostic Instrument model 1.3.0) with imageGear version 6.6.4 software. The particle size of sol-gel powders prepared using the small ball mill (Wig-LBug). The individual particles are $\sim 5 \mu \mathrm{m}$, with larger $50 \mu \mathrm{m}$ aggregates.

\section{Deposition of cluster-containing sol-gel films on flat substrates and fibers.}

\section{Sol-gel solutions for cluster-containing films.}

The procedure used for deposition of sol-gel films is a modified version of that described by MacCraith and coworkers. ${ }^{[11-14]}$. A typical ethanol-based stock sol-gel solution for the coating process was prepared as described below. TEOS (100 mL, $0.477 \mathrm{~mol})$ and acetonitrile $(70.3 \mathrm{~mL})$ were added to a $500 \mathrm{~mL}$ Erlenmeyer flask. With stirring, water (32.3 $\mathrm{mL}$, adjusted to $\mathrm{pH}=1$ with $\mathrm{HCl}$ ) was added and the solution was stirred for 1 hour at room temperature. The stir bar was removed from the flask and the solution was heated in an oil bath at $70{ }^{\circ} \mathrm{C}$ for 2.5 hours. The solution was then transferred to a $500 \mathrm{~mL}$ glass bottle, capped, and aged at room temperature until use. Approximately three days before dipping the slides, $25.5 \mathrm{mg}$ of $\mathrm{K}_{2} \mathrm{Mo}_{6} \mathrm{Cl}_{14} \cdot 2 \mathrm{H}_{2} \mathrm{O}$ was added to the vial, and the solution was stirred for three days to ensure complete dissolution of the complex.

\section{Sol gel films deposited on glass or quartz slides.}

Slides were handled while wearing Supreno SETM brand powder free nitrile gloves. The slides were washed with Alconox ${ }^{\mathrm{TM}}$, rinsed with distilled water, and soaked in a base bath for $\sim 6$ hours. Just prior to use, the slides were rinsed with distilled water and soaked in distilled water. Each slide was dried using a stream of house nitrogen and immediately coated by dipping the slide into the sol-gel solution at a rate of approximately $1 \mathrm{~mm} / \mathrm{sec}$. For some slides, one surface was masked using a piece of Scotch Magic ${ }^{\text {TM }}$ tape to limit the sol-gel coating to one side of the substrate. The sol gel solution vial was re-capped after each dip coat. The coated slides were either (1) placed flat on a piece of aluminum foil and the aluminum foil and placed into an oven at $70{ }^{\circ} \mathrm{C}$ for 24 hours to cure or (2) placed in a capped $20 \mathrm{~mL}$ vial laying on its side. The evaporation rate was controlled by how tightly the vial was sealed. Slow evaporation rates gave films with better adhesion and fewer cracks. When dry, the films were thermally cured in an oven in air at $70{ }^{\circ} \mathrm{C}$ for 1 to $24 \mathrm{~h}$, depending on the sample. A few slides were prepared using slight modifications of the above scheme. In some cases, the number of coatings and times between coats were varied.

A simple dip coater was built to better control the uniformity of coated slides, especially at low dipping rates $(\sim 1 \mathrm{~mm} / \mathrm{sec})$. Slides were clamped in the dip coater, dipped with no hold time and placed directly into a $20 \mathrm{~mL}$ scintillation vial and handled as described above. A dip rate of 1 to $1.6 \mathrm{~mm} / \mathrm{sec}$ gave good quality films. Loss of ethanol during 
dipping significantly changed the viscosity of the sol-gel solution. Adding ethanol to compensate for losses increased the lifetime of the solution.

\section{Spray coating planar substrates.}

Following the procedure described by Remillard et al., ${ }^{[15]}$ viscous sol-gel solutions containing $\mathrm{Mo}_{6} \mathrm{Cl}_{12}$ and $\mathrm{K}_{2} \mathrm{Mo}_{6} \mathrm{Cl}_{14}$ were plied to substrates using a Paasche double action airbrush. Fibers were supported in the barrel of a hypodermic syringe $\sim 4 \mathrm{~cm}$ from the tip of the spray coater. The fiber was coated in 1 second bursts aimed directly at the tip with 15 seconds of dry time in between each burst. The pressure of gas supplied to the airbrush was set at $10 \mathrm{psi}$, and the spray burst size was varied to determine the optimal spray conditions. Planar substrates were coated similarly. A single coat was applied to a $2.4 \mathrm{~cm} \times 1.25 \mathrm{~cm}$ quartz slide for 1 second at a distance of $4 \mathrm{~cm}$ from the airbrush tip using nitrogen gas at 10 psi. Immediately after coating the sample, it was placed into an oven and cured for 30 minutes in air at $200^{\circ} \mathrm{C}$.

\section{Fiber Coating.}

Approximately $1 \mathrm{~cm}$ of jacket and cladding were mechanically removed to expose the fiber core. The exposed core was wiped with an acetone-soaked Kimwipe to remove residual cladding material and the tip was suspended in stirred acetone and for 30 minutes. The fiber was removed, wiped with an acetone-soaked Kimwipe, rinsed with deionized water, and the fiber tip was suspended in a stirred solution of $2 \mathrm{M} \mathrm{KOH}$ for 60 minutes. The fibers were removed from the $\mathrm{KOH}$ solution, rinsed with $10 \mathrm{~mL}$ of deionized water, and re-dipped into $2 \mathrm{M} \mathrm{KOH}$ to test wetting. If necessary, the $\mathrm{KOH}$ treatment, water rinse, and wetting test were repeated until the $\mathrm{KOH}$ solution wet the fiber surface. Once wetting was satisfactory, the fiber tip was rinsed with $10 \mathrm{~mL}$ of deionized water and dried using a stream of nitrogen gas. The fibers were immediately dipped by hand into the sol gel solution at a $15^{\circ}$ angle for better coating of tip, and allowed to dry vertically for one hour under ambient conditions to maximize coating uniformity on the tip. Fibers were cured at $70^{\circ} \mathrm{C}$ for times ranging from 4 to 12 hours.

Scotch tape was used to assemble a flat bundle of five fibers with the fiber tips separated by $1 \mathrm{~mm}$. The bundle of five fibers was dipped by hand at a $15^{\circ}$ angle (for better coating of tip) into binder/particle mixtures, being careful to maintain the gap between the fiber tips. The fibers were hung vertically (tip-down) and dried under ambient conditions for one hour to promote uniform coating of the fiber tips.

\section{Preparation of composite films.}

\section{Synthesis of cluster-containing sol-gel particulates.}

Sol-gel solutions containing $\mathrm{K}_{2} \mathrm{Mo}_{6} \mathrm{Cl}_{14}$ were prepared as described above were aged for $4-7$ months at room temperature to form solid monoliths. The monoliths were then ground using a mortar and pestle and cured at $70{ }^{\circ} \mathrm{C}$ for 5 days to complete the sol-gel reaction and minimize further densification of the sol-gel matrix. Particulates were formed with a $\mathrm{K}_{2} \mathrm{Mo}_{6} \mathrm{Cl}_{14}$ concentration of $8.6 \times 10^{-3} \mathrm{M}$ and $2.1 \times 10^{-3} \mathrm{M}$. To obtain smaller particles, the particles were pulverized for 15 minutes using a small stainless steel ball mill (Wig-L-Bug) . 


\section{Binders for Sol-Gel Stock Solutions.}

TEOS based binder. The preparation of a typical TEOS-based sol-gel binder solution is described below. TEOS $(100 \mathrm{~mL}, 0.477 \mathrm{~mol})$ and acetonitrile $(70.3 \mathrm{~mL})$ were added to a $500 \mathrm{~mL}$ Erlenmeyer flask. With stirring, water $(32.3 \mathrm{~mL}$, adjusted to $\mathrm{pH}=1$ with $\mathrm{HCl})$ was added and the solution was stirred for 1 hour at room temperature. The stir bar was removed from the flask and the solution was heated in an oil bath at $70{ }^{\circ} \mathrm{C}$ for 2.5 hours. The solution was then transferred to a $500 \mathrm{~mL}$ glass bottle, capped, and aged at room temperature until use.

55\% OtMOS/TEOS based binder. The preparation of a typical 55\% OtMOS / TEOS solgel binder solution is described below. A stock solution of $55 \mathrm{~mol} \%$ OtMOS in TEOS was prepared by mixing $10.20 \mathrm{~mL}$ of OtMOS and $7.30 \mathrm{~mL}$ of TEOS while stirring. The solution was then stored in a brown glass bottle with a Teflon-lined cap until needed. The OtMOS/TEOS mixture $(1.75 \mathrm{~mL}$ ) and co-solvent (see below) were added to a $20 \mathrm{~mL}$ scintillation vial, which was then capped and stirred until clear. Once the solution became clear, $0.40 \mathrm{~mL}$ of $0.1 \mathrm{M} \mathrm{HCl}$ was added. After recapping the vial, the solution was stirred at room temperature until clear ( $\sim 15$ minutes). The solution was diluted 1:1 $\mathrm{v} / \mathrm{v}$ with additional co-solvent to decrease the viscosity of the solution and aged at room temperature until used. For binder solutions with acetonitrile as the co-solvent, dry acetonitrile $(1.70 \mathrm{~mL}, 0.352 \mathrm{~mol})$ was added. For binder solutions using ethanol as the co-solvent (1.80 mL, $0.352 \mathrm{~mol})$ was added.

$50 \%$ OtEOS/TEOS based binder. The preparation of a typical 50\% OtEOS / TEOS solgel binder solution is described below. A stock solution of $50 \mathrm{~mol} \%$ OtEOS in TEOS was prepared by adding $10.20 \mathrm{~mL}$ of OtEOS to $7.30 \mathrm{~mL}$ of TEOS with stirring. The solution was then stored in a brown glass bottle with a Teflon-lined cap until needed The OtEOS/TEOS mixture $(1.75 \mathrm{~mL}$ ) and co-solvent (see below) were added to a $20 \mathrm{~mL}$ scintillation vial, capped, and then stirred until clear. Once the solution became clear, $0.40 \mathrm{~mL}$ of $0.1 \mathrm{M} \mathrm{HCl}$ was added. The vial was recapped and the solution was stirred at room temperature until clear ( $\sim 15$ minutes). To decrease the viscosity, the solution was diluted with an additional portion of co-solvent $(1: 1 \mathrm{v} / \mathrm{v})$ and then the solution was aged at room temperature until used. For binder solutions with acetonitrile as the co-solvent, dry acetonitrile $(1.70 \mathrm{~mL}, 0.352 \mathrm{~mol})$ was added. For binder solutions using ethanol as the co-solvent $(1.80 \mathrm{~mL}, 0.352 \mathrm{~mol})$ was added.

67\% TFP-tMOS/PtMOS based binder. The preparation of a typical 67\% TFP-tMOS / PtMOS sol-gel binder solution is described below. A stock solution of $67 \mathrm{~mol} \%$ TFPtMOS in PtMOS was prepared by mixing TFP-TMOS (3.00 $\mathrm{mL}, 156.7 \mathrm{mmol})$ and PtMOS (1.40 mL, $79.3 \mathrm{mmol})$ while stirring. The solution was then stored in a brown glass bottle with a Teflon-lined cap until needed. A $4.40 \mathrm{~mL}$ portion of stock solution, $1.30 \mathrm{~mL}$ of deionized water, $\mathrm{HCl}(0.15 \mathrm{~mL}, 0.1 \mathrm{M})$, and the co-solvent (see below) were added to a $20 \mathrm{~mL}$ scintillation vial, capped, and stirred until clear. The solution was then sonicated for 1 hour while capped. For binder solutions with acetonitrile as the cosolvent, dry acetonitrile $(2.70 \mathrm{~mL}, 51.7 \mathrm{mmol})$ was added. For binder solutions using ethanol as the co-solvent $(3.00 \mathrm{~mL}, 51.4 \mathrm{mmol})$ was added.

Preparation of fiber 121 (55\% OtMOS / TEOS and wlb34g-o powder). A paste containing $\sim 54 \mathrm{w} / \mathrm{w} \%$ particles was prepared by adding $0.0652 \mathrm{~g}$ of wlb34g-o particles to $0.0536 \mathrm{~g}$ binder solution that had been aged for 5 days at room temperature. The 
resulting off-white paste was then mixed in a small vial to increase homogeneity. A clean dry fiber was then dipped into the mixture as described above. The pre-dried film was then cured at $70^{\circ} \mathrm{C}$ for 16 hours.

\section{Composite powder / sol-gel binder blends.}

A previously prepared cluster-containing sol-gel solution (composite 31) was aged at room temperature for 4 months in a sealed vial to obtain a solid monolith. The monolith was then ground by hand to a powder with particle sizes ranging from $25-250 \mu \mathrm{m}$ using a mortar and pestle. The powder was then cured for 24 hours at $70^{\circ} \mathrm{C}$ to drive the sol-gel reactions toward completion. Blends of $30,50,60$, and $80 \mathrm{w} / \mathrm{w} \%$ were prepared by adding a known mass of stock sol-gel solution to a predetermined mass of the composite 31 powder to obtain a light yellow suspension that was then mixed with gentle grinding in a small vial to maximize homogeneity.

A control for fiber sensor analysis was prepared from a stock sol-gel solution without added cluster (composite 21). After aging at room temperature for 4 months in a sealed vial, the solid monolith was ground using a mortar and pestle to a powder with particle sizes ranging from $25-250 \mu \mathrm{m}$. The powder was cured for 24 hours at $70{ }^{\circ} \mathrm{C}$ to drive the sol-gel reactions toward completion and then was pulverized for 15 minutes in a WigL-Bug (a small ball mill) to obtain a white powder with $1-2 \mu \mathrm{m}$ diameter particles. The powder also was used to assess the film quality that can be obtained from $<10 \mu \mathrm{m}$ particulates.

General for the preparation of fibers (55\% OtMOS / TEOS and wlb29 or wlb34g-o powder). A paste containing $\sim 55 \mathrm{w} / \mathrm{w} \%$ particles was prepared by adding a known mass of sol-gel particles to a binder solution that had been aged for 5 days at room temperature. The resulting off-white paste was then mixed in a small vial to increase homogeneity. A clean dry fiber was then dipped into the mixture as described above. The pre-dried film was then cured at $70{ }^{\circ} \mathrm{C}$ for 16 hours. The sol-gel binder solutions used ethanol as the cosolvent.

Preparation of fiber $M$ (TEOS binder and mp31). A paste containing $60 \mathrm{w} / \mathrm{w} \%$ was prepared by adding a known mass of TEOS-based sol-gel solution aged at room temperature for 70 days to a predetermined mass of mp31 powder to obtain a light yellow paste. The paste was then mixed with gentle grinding in a small vial to increase homogeneity. A clean dry fiber was then dipped at an angle of $15^{\circ}$ and hung vertically for 1 hour to achieve a uniform coating and pre-dry the film. The pre-dried film was the cured at $70{ }^{\circ} \mathrm{C}$ for 12 hours.

Preparation of fiber 45, (55\% OtMOS / TEOS and wlb29). A paste containing $60 \mathrm{w} / \mathrm{w} \%$ was prepared by adding a known mass of room temperature aged 55\% OtMOS / TEOS based sol-gel solution to a predetermined mass of wlb29 powder to obtain an off-white paste. The paste was then mixed with gentle grinding in a small vial to increase homogeneity. A clean dry fiber was then dipped at an angle of $15^{\circ}$ and hung vertically for 1 hour to achieve a uniform coating and pre-dry the film. The pre-dried film was the cured at $70{ }^{\circ} \mathrm{C}$ for 12 hours. 


\section{Fluorescence measurements of sol-gel films at high temperatures.}

The measurements of the $\mathrm{K}_{2} \mathrm{Mo}_{6} \mathrm{Cl}_{14}$ emission from Mo-cluster / sol-gel composite films were made in the quartz cuvette sealed with an airtight septum. Nitrogen gas with purity $99.999 \%$ was used to obtain the luminescence spectra in a non-oxygen environment. The oxygen measurements (21\% oxygen in nitrogen) were performed using $99.999 \%$ purity gas. The nitrogen and oxygen were injected bias a needle passing through the septum and allowing the gas in the cuvette to equilibrate for $10 \mathrm{~min}$. An external gas flow switch was designed and built to conveniently change the gas environment without needing to touch the spectrometer compartment. This switch allows us to be completely certain that the sample does not move during repeated gas exchange.

The in-situ measurements of the $\mathrm{K}_{2} \mathrm{Mo}_{6} \mathrm{Cl}_{14}$ and $\mathrm{Mo}_{6} \mathrm{Cl}_{12}$ emission from Mo-cluster / solgel composite films, as a function of temperature were made in the same quartz cuvette described above. A platinum microheater (part 32208172 from Heraeus Sensor Technology) was attached with a thermally conducting epoxy resin (Ther-O-Bond/1500 hardener) to the backside of the quartz slide (Figure 7). The epoxy is allowed to cure for at least four hours in air at room temperature. Electrical connection to the Pt heater was made by microwelding 5 mill thick $\mathrm{Cu}$ wire to the 5 mill thick legs of the Pt microheater. The electrical leads were then threaded through the septum. The microheater was powered with a regulated voltage supply. We determined the heater temperature by monitoring the heater resistance, and using the resistance versus temperature curves for a standard $100 \mathrm{ohm}$ Pt thermometer. The thermal impedance of the quartz slide was independently determined by gluing a Pt thermometer to the front of a quartz slide, and monitoring the temperature of the front side of the slide in the quartz cuvette under the same gas flow conditions used during spectroscopy. Thus, by monitoring the backside heater resistance we know the temperature of the front side of the slide to $\pm 5{ }^{\circ} \mathrm{C}$. The film-coated side of the quartz slide was irradiated at an angle of $\sim 66^{\circ}$ with a $90^{\circ}$ angle maintained between the excitation beam and detector. The slides were purged in-situ and care was taken not move the excitation spot between measurements in the different gas environments.

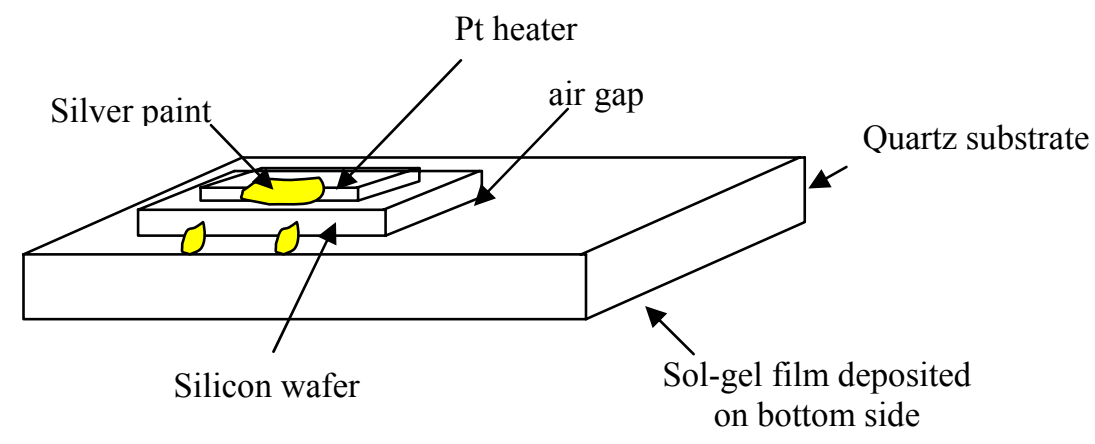

Figure 7. Diagram of the sandwich-like structure used for in-situ high temperature measurements of slides. 
Two types of spectra are presented. The "uncorrected spectra" are the raw data from the photo multiplier tube, without correcting for the spectral response function of either the PMT or emission grating. Therefore the "uncorrected spectra" do not show the true emission lineshape. The "corrected spectra" includes corrections for the spectral response of the PMT and emission grating, and represents the true emission lineshape. The "uncorrected spectra" will show a peak in the $670-680 \mathrm{~nm}$ range, and a constant background offset of $500-1000 \mathrm{cps}$, due to the PMT dark count. The "corrected spectra" have a broad peak in the $720-760 \mathrm{~nm}$ range, without any background offset.

A Newport 1815-C Power meter with and 818 UV Silicon detector was used to monitor the Xe lamp intensity at the $313 \mathrm{~nm}$ pump wavelength, before and after the fluorescence measurements. After an initial warm up time of half an hour, the lamp was found to have a stable output power better than $+/-5 \%$ for a period of several hours. These power measurements will allow us to quantitatively compare spectra obtain on different days by accounting for the diminishing output of the Xe lamp due to aging.

\section{Mechanical testing of composite adhesion.}

A qualitative test of adhesion was performed using a stream of nitrogen gas at $\sim 10$ psi directed at the coating on the fiber tip and then followed by gently tapping the distal fiber edge on the edge of the laboratory bench top. A ballistic pendulum apparatus (Figure 8) was fabricated for more quantitative measurements. Fibers were imaged and weighed before testing, and then tape was used to secure the fiber to a sewing thread. The fiber was attached to the pendulum with the length adjusted so that the metal stop impacted the fiber where the fiber jacket had been removed, $\sim 1 \mathrm{~cm}$ above the tip. The distance between the fiber impact point and the upper metal bar was $\sim 22-26 \mathrm{~cm}$. The fiber was then set to the desired angle, released, and allowed to impact the metal stop. The fibers were imaged after each test to assess changes in the film morphology. The impact force was calculated by:

$$
\mathrm{I}=2 \mathrm{~m}\left[3 \mathrm{gL}(1-\cos (\theta)]^{1 / 2}\right.
$$

where I is the impact force in $\mathrm{N} \cdot \mathrm{s}, \mathrm{m}$ is the mass of the fiber and string in grams, $\theta$ is the angle of travel in degrees, $g$ is the acceleration due to gravity $\left(9.8 \mathrm{~m} / \mathrm{s}^{2}\right)$, and $\mathrm{L}$ is the distance from the pendulum attachment point to the impact point in meters. 


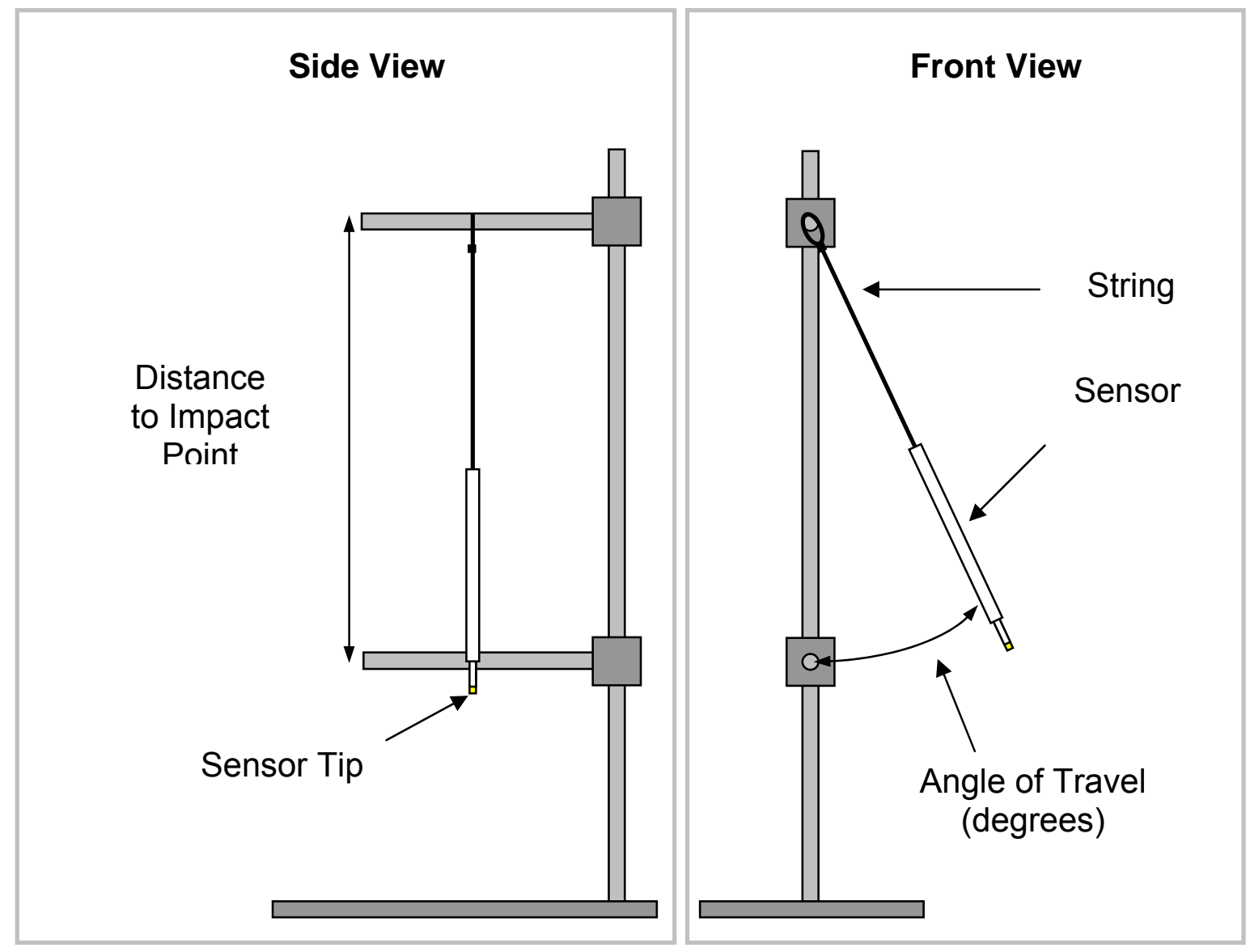

Figure 8. Ballistic pendulum apparatus fabricated for fiber coating adhesion analysis.

\section{Fiber optic oxygen sensor characterization system}

The response of Fiber sensor 121 to step changes in oxygen from 2 to $21 \% \mathrm{O}_{2}$, at 40,70 and $100{ }^{\circ} \mathrm{C}$ was measured in the flow through system shown in Fig. 5. This setup has been described in the previously, we summarize its salient features below. Major improvement we have made to the system is to install a Horiba gas divider (SGD-710C) upstream of the gas inlet into the quartz chamber for precise $( \pm \%)$ control over the oxygen concentration. The gas divider allows us to deliver a precise, within $\pm 0.5 \%$ of the component gas $\left(0.1 \% \mathrm{O}_{2}\right)$ stream to the sensor.

Our automated high temperature reflection-mode fiber optic sensor characterization setup uses a special-design quartz "furnace" to heat the tip of the fiber sensor up to $\sim 110{ }^{\circ} \mathrm{C}$ and monitor the temperature to better than $\pm 2{ }^{\circ} \mathrm{C}$ using a thermocouple placed $1-2 \mathrm{~mm}$ near sensor tips. The gas flows in this flow- through cell is $400-300 \mathrm{~mL} / \mathrm{min}$. By monitoring both the inlet $( \pm 10 \mathrm{sccm})$ and outlet $( \pm 20 \mathrm{sccm})$ flows, we estimate a gas exchange time $10 \mathrm{~s}$ for the system. We use a Labview program to simultaneously monitor the sensor signal and sensor temperature. The excitation source for the sensor measurements is about $700 \mu \mathrm{W}$, at the wavelength of $365 \mathrm{~nm}$ UV Nichia LED. Using the 
dichroic beam splitter and the UV objective lens we are able to couple around $300 \mu \mathrm{W}$ into the multimode fiber ( $\Phi 1 \mathrm{~mm}$ core diameter) by a UV objective lens. The reflected phosphorescence $(590-850 \mathrm{~nm})$ from the tip of the fiber sensor is collected by the photomultiplier tube (PMT). A $45^{\circ}$ dichroic beam splitter and a $590 \mathrm{~nm}$ long wave pass (LWP) filter are used to separate the pump and signal beams. The detection optics/electronics consists of a Hamamatsu Detector R955 and a Stanford SR570 current pre-amplifier. The typical gain of the preamplifier used is $20 \mu \mathrm{A} / \mathrm{V}$. We estimate that a 1 $\mathrm{V}$ signal at the voltmeter corresponds to $1 \mathrm{nW}$ of phosphorescence signal from the fiber sensor. In addition we estimate that the "unwanted" light in the emission bandwidth that reaches the detector to a level 1/160 of the smallest sensor signal in oxygen

The entire optical path from the UV LED to the detector is aligned on a single optical bench plate, which has the following advantages. First we are able to make meaningful long term, over several days, sensor measurements because of the stability of both the pump power coupled in the fiber sensor as well as the coupling of the output sensor signal to the detector. Secondly, we are able to remove a fiber sensor from the measurement system and reinstall it with a high degree of reproducibility (repeatability of LED to fiber coupling of better than 1\%), which allows for meaningful comparisons between one sensor and another.

Beginning at the UV source, the UV LED, the collimating lens and a UV bandpass filter were placed inside a single stackable lens tubing. This ensures the concentricity of all three components along the optical axis. The output UV beam is now collimated with a $25 \%$ variation in the beam size at a distance of $6 \mathrm{~cm}$. The purpose of the UV bandpass filter (Semorock FF01-377/50-25 351/405), which has a $93 \%$ transmission between 351$405 \mathrm{~nm}$, is to reduce the unwanted visible light from the UV LED that reaches the detector, see Figure 9. Since this visible output from the UV LED in the emission bandwidth of the Mo clusters, $600-800 \mathrm{~nm}$, is spectroscopically indistinguishable from the real sensor signal, it sets a bound on the smallest signal we can detect. From the output spectra of the UV diode, we find that the integrated power output of the LED is about $2 \mu \mathrm{W}$ in wavelength range of $600-800 \mathrm{~nm}$. Without the Semrock visible rejection filter this results in an unwanted signal of about $0.4 \mathrm{nW}$ at the PMT. Table 1 lists the transmission and reflection parameters for all the relevant optical components. As shown in Figure 10 the transmission through the Semrock bandpass filter is $93 \%$ in the UV and an average of $5 \times 10^{-5}$ for $600-700 \mathrm{~nm}$ and $3 \times 10^{-3}$ for $700-900 \mathrm{~nm}$. We calculate that the unwanted signal from LED should now be only $0.002 \mathrm{nW}$. The measured transmission through an optical fiber coated with sol-gel coating without any Mo-cluster, was measured to be about $0.01 \mathrm{nW}$. This was a PUV fiber with clusterless sol-gel particles in a TEOS/OtMOS sol-gel binder, which mimics a real sensor structure. The measured intensity in emission bandwidth that is 30 times smaller than the intensity in oxygen. A black plastic enclosure now covers the entire optical path and our signal-tonoise ratio is improved $4 \times$ compared to our original characterization system. 


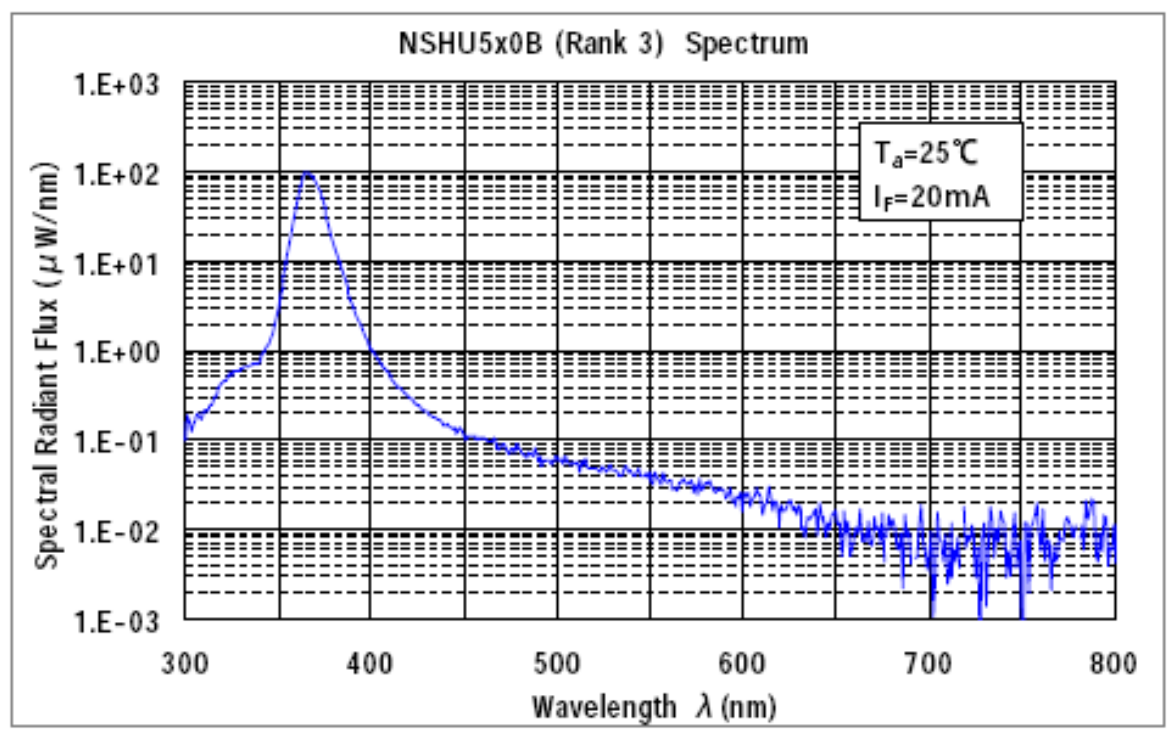

Figure 9 LED diode spectrum from Nichia company data sheet. There is 2 $\mu \mathrm{W}$ of unwanted visible signal from the LED itself in the emission bandwidth of the Mo-clusters.

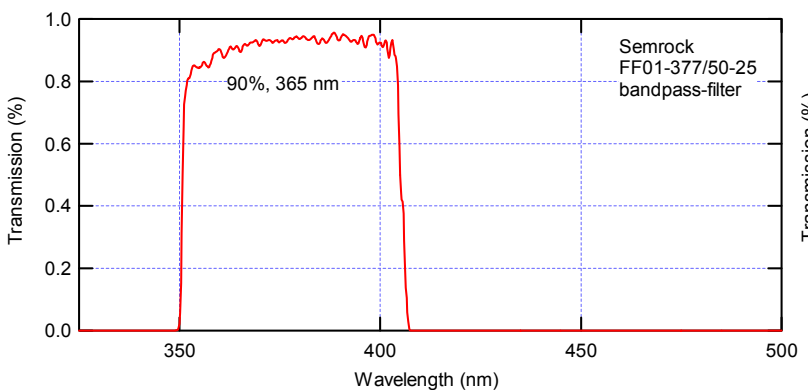

$\mathbf{a}$

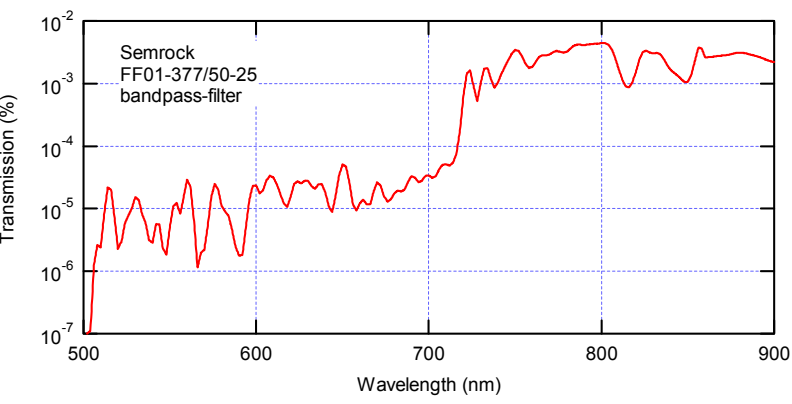

b

Figure 10 (a) Semorock (FF01-377/50-25) band-pass filter spectrum, with a UV bandwidth $352-403 \mathrm{~nm}$ and $93 \%$ transmission, (b) enlarged spectrum in the range 500-900 $\mathrm{nm}$, transmission $10^{-6}-4 \times 10^{-3}$. The filter is used to remove the visible component of the LED output. 
Table 1: Reflectance and transmission in visible range for all the optical components used in the system shown in Figure 12. For $2 \mu \mathrm{W}$ of LED power at $750 \mathrm{~nm}$, the peak luminescence wavelength, we obtain $0.002 \mathrm{nW}$ at the PMT detector.

\begin{tabular}{|c|c|c|c|c|c|c|c|}
\hline & $\begin{array}{c}\text { Band- } \\
\text { pass } \\
\text { filter } \\
(700- \\
800) \mathrm{nm}\end{array}$ & $\begin{array}{c}\text { Dichroi } \\
\text { c Beam- } \\
\text { Splitter } \\
(\sim 750 \mathrm{n} \\
\mathrm{m}) \\
(\text { Est.) }\end{array}$ & $\begin{array}{c}\text { Lens- } \\
\text { fiber } \\
\text { coupling } \\
\text { (Est.) }\end{array}$ & $\begin{array}{c}\text { Fiber } \\
\text { Fresnel } \\
\text { reflection } \\
\text { (air) } \\
\text { (Est.) }\end{array}$ & $\begin{array}{c}\text { Dichoic } \\
\text { Beam- } \\
\text { Splitter } \\
(\sim 750 \mathrm{~nm})\end{array}$ & $\begin{array}{c}\text { Fiber- } \\
\text { Lens } \\
\text { coupling } \\
\text { (Est.) }\end{array}$ & $\begin{array}{c}\text { High- } \\
\text { pass filter } \\
(>590 \mathrm{~nm})\end{array}$ \\
\hline Transmission & $3.4 \times 10^{-3}$ & -- & 0.4 & -- & 0.97 & 0.50 & 0.92 \\
\hline Reflectance & & 0.03 & & 0.04 & & & \\
\hline $\mathrm{P}=2 \mu \mathrm{W}$ & & & & & & & \\
\hline
\end{tabular}

\section{Gas Divider - SGD 710C}

In the experiment, we need to accurately determine the oxygen concentration of the flowing gas stream. The Horiba gas divider (SGD -710C) was used to mix $21.1 \%$ oxygen (component gas) with $99.999 \% \mathrm{~N}_{2}$ (dilution gas) as shown in Fig 4. The precision of the gas divider is $0.5 \%$ of the component gas, i.e. $0.1 \% \mathrm{O}_{2}$ in our case, with a repeatability of $0.2 \%$ of the component gas. The gas divider consists of 10 identical capillary tubes. A mechanical switch sets the number of capillaries used for the component and dilution gas, such that the generated gas of concentration $\mathrm{C}$, is given by $\mathrm{C}$ $=\mathrm{m} / 10 \mathrm{C}_{\mathrm{o}}$, where $\mathrm{C}_{\mathrm{o}}$ is the concentration of component gas (oxygen), and $\mathrm{m}$ is the number of capillaries in which component gas flows. The inlet pressure of the capillary tubes is controlled by a pressure regulating section which is precisely designed to allow the pressure of a component gas $\left(\mathrm{O}_{2}\right)$ to remain same as that of a $\mathrm{N}_{2}$ gas (dilution). The generated flow rate then depends upon only on the pressure of the dilution gas which we selected 5 psi. The generated flow has usually 10 psi pressure.

To make measurement between two preset oxygen levels, we replace the gas divider with a 3-way solenoid valve (Cole-Parmer Inc. EW-98302-42) to automatically switch between the two gases. The time duration of each gas pulse can be set by the switch controller. This system allows us to perform long-term gas cycling measurements with flow rate from 100 to $1000 \mathrm{sccm} /$ 


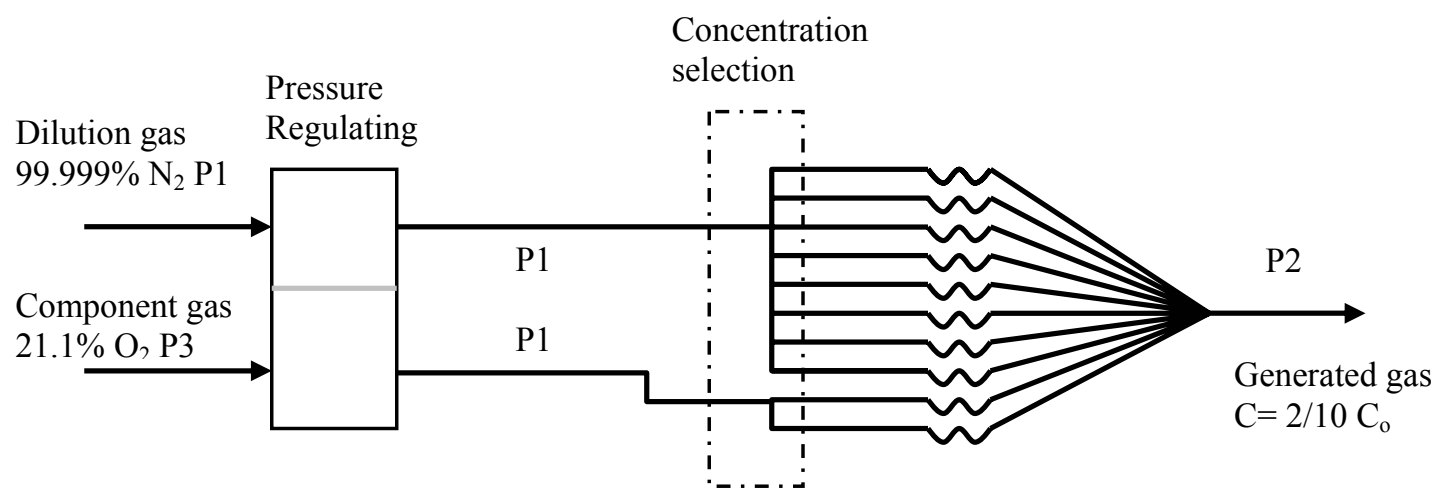

Figure 11. Schematic of gas divider SGD-710 principle

\section{$\underline{\text { Molar oxygen concentration }\left[\mathrm{O}_{2}\right]}$}

To calculate the molar oxygen concentration in the flow through cell at a given temperature $\mathrm{T}$ and pressure $p$ we use the ideal gas law:

$$
p \mathrm{~V}=\mathrm{nRT},
$$

hence, molar oxygen concentration $\quad\left[\mathrm{O}_{2}\right]=\mathrm{n} / \mathrm{V}=p /(\mathrm{TR})$

Where $\mathrm{n}$ is the number of moles of the gas, $\mathrm{R}=8.2057 \times 10^{-2} 1 \mathrm{~atm} / \mathrm{mol} / \mathrm{K}$ is universal gas constant. $\mathrm{T}$ is absolute temperature in $\mathrm{K}$,

The measured pressure $p$ in our flow through cell is 10 psi or 0.6803 atm. For a given oxygen fraction $\mathrm{F}$ (where $\mathrm{F}=1$ for $100 \%$ ) the molar oxygen concentration is

$$
\left[\mathrm{O}_{2}\right]=\mathrm{n} / \mathrm{V}=8.29 \mathrm{~F} / \mathrm{T}
$$




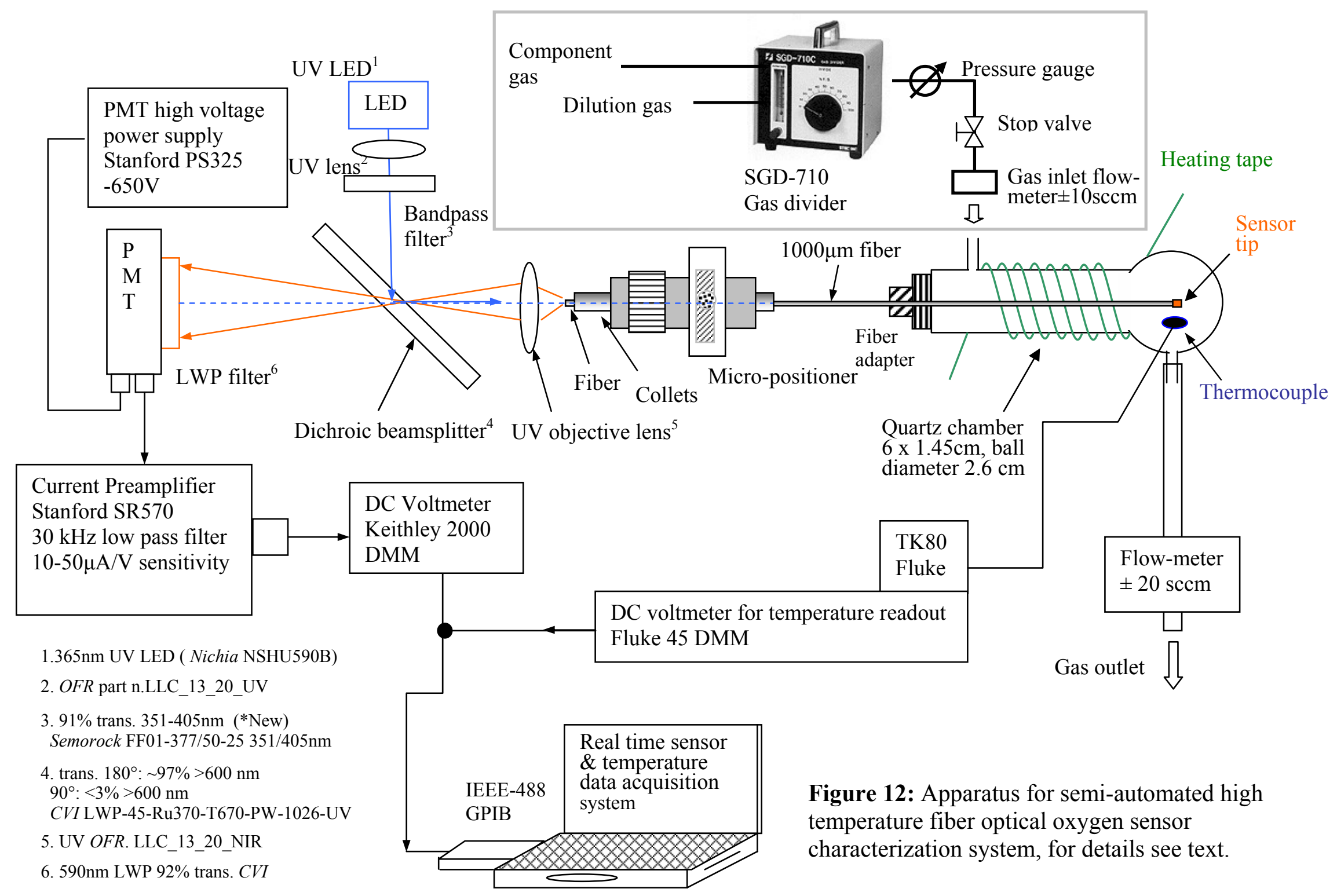


A number of measurements were performed to characterize the optical performance of the overall system. First, we evaluated the stray light level of the system. With only the PMT and current preamplifier turned on, we measured a $0.0005 \mathrm{nW}$ signal. Secondly, after turning on the pump LED, but without an optical fiber in the path, the signal increased to $0.13-0.15 \mathrm{nW}$, which sets an upper bound on the smallest sensor signal we could detect. As the UV rejection ratio of the $590 \mathrm{~nm}$ LWP filter in front of the PMT is very high, essentially none of the pump signal can be scattered back into the detector, so the $0.15 \mathrm{nW}$ signal must be due to visible fluorescence in the optical path. We are looking into potential sources of this fluorescence, in order to eliminate it. Thirdly, we measured the output signal from bare 1000- $\mu \mathrm{m}$ fibers of various lengths (no cluster on the fiber tip (see Figure 13). For a short fibers, an additional $0.07 \mathrm{nW}$ is added due to scattering from the front and back faces of the fiber. The autofluorescence of the fiber itself is low, $2.1 \times 10^{-4} \mathrm{nW} / \mathrm{cm}$. Later we describe the results for fiber sensor D operating at $100{ }^{\circ} \mathrm{C}$ where the signal to noise is $\sim 4 \mathrm{~dB}$ in $21 \%$ oxygen.

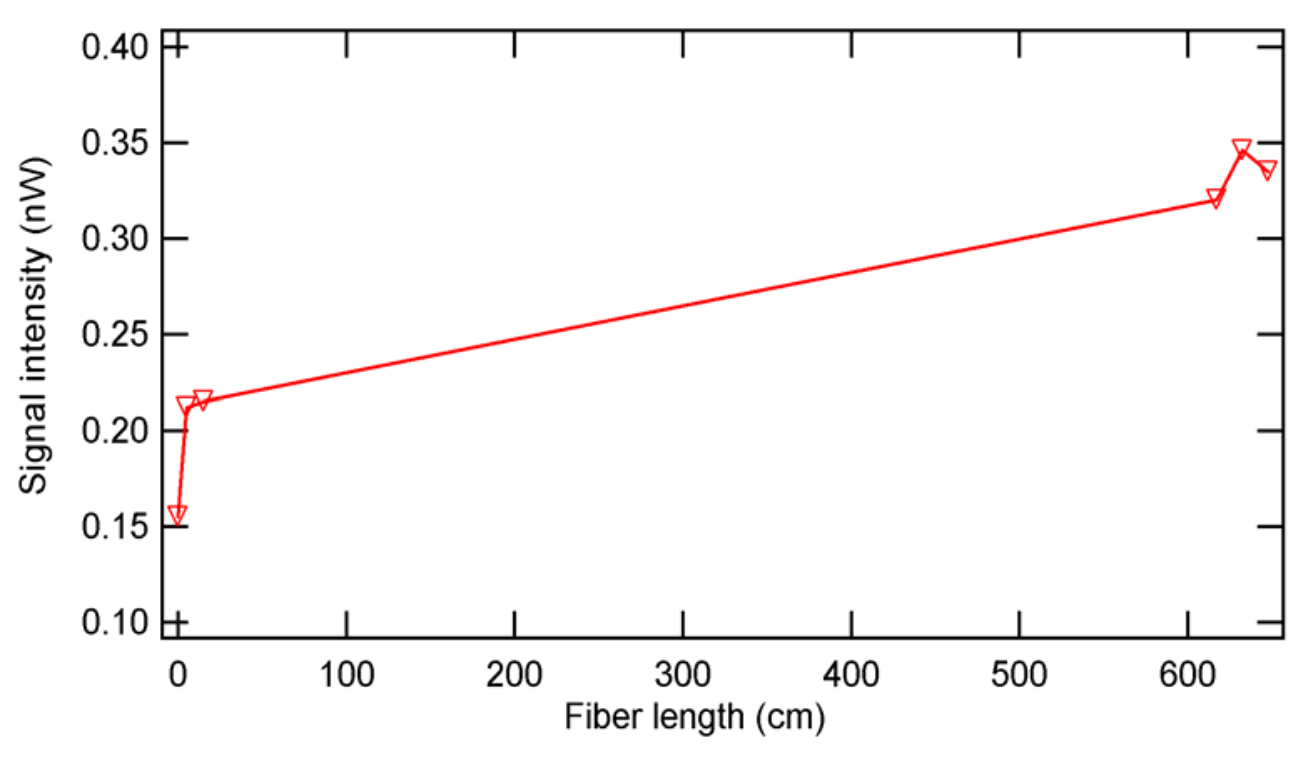

Figure 13: Signal from an uncoated optical fiber as a function of fiber length. The data show low auto-fluorescence $\left(2.1 \times 10^{-4} \mathrm{nW} / \mathrm{cm}\right)$. However, there is a $0.07 \mathrm{nW}$ signal (bandwidth: $590 \mathrm{~nm}-900 \mathrm{~nm}$ ) due to reflections off the front and back faces of the fiber 


\section{Sensor data acquisition and measurement}

For real time applications, we need a technique to monitor the signal from the fiber optic sensor as a function of both temperature and time. With Mr. Nate Vehanovitz (Troy Inc.), we developed a Labview program for sensor data acquisition and temperature monitoring. The hardware requirements are a laptop running Windows XP or 2000 equipped with a PCMCIA-GBIP card from National Instruments, a GPIB cable, a Keithley digital multimeter and Fluke 45 voltmeter (Figure 14). During fiber sensor measurements, the Keithley voltmeter monitors the sensor voltage signal (which is proportional to the luminescence intensity) while the Fluke digital multimeter (DMM) monitors the temperature output from a k-type thermocouple and 80TK readout module. The front panel of the data acquisition program is shown in Figure 15.

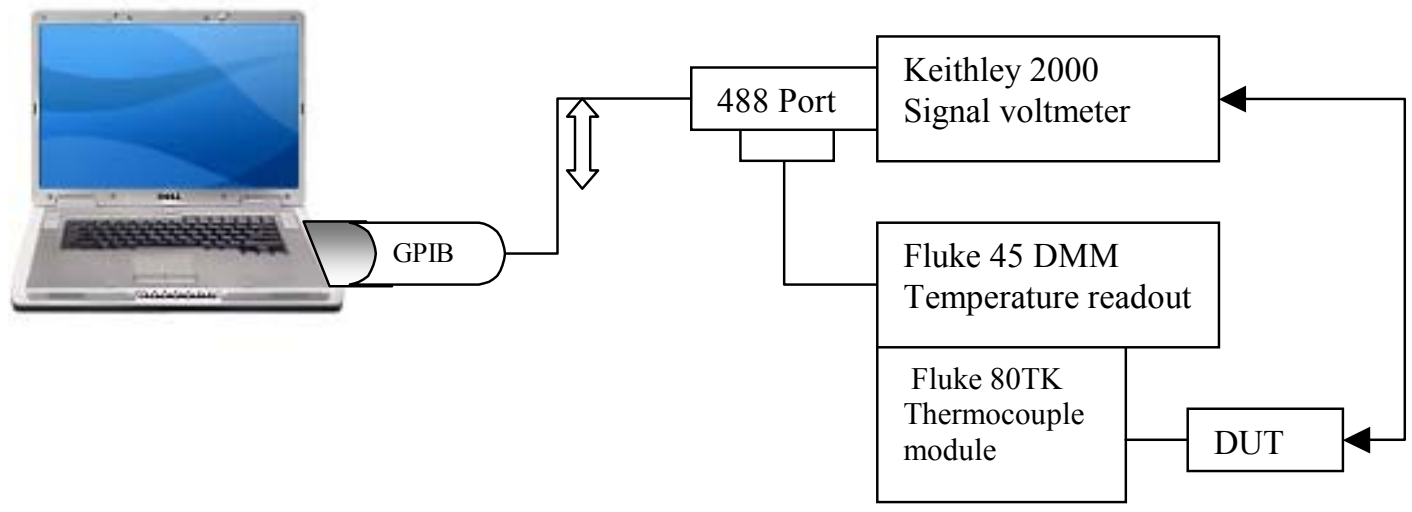

Figure 14: Block diagram of the sensor and temperature data acquisition system. 


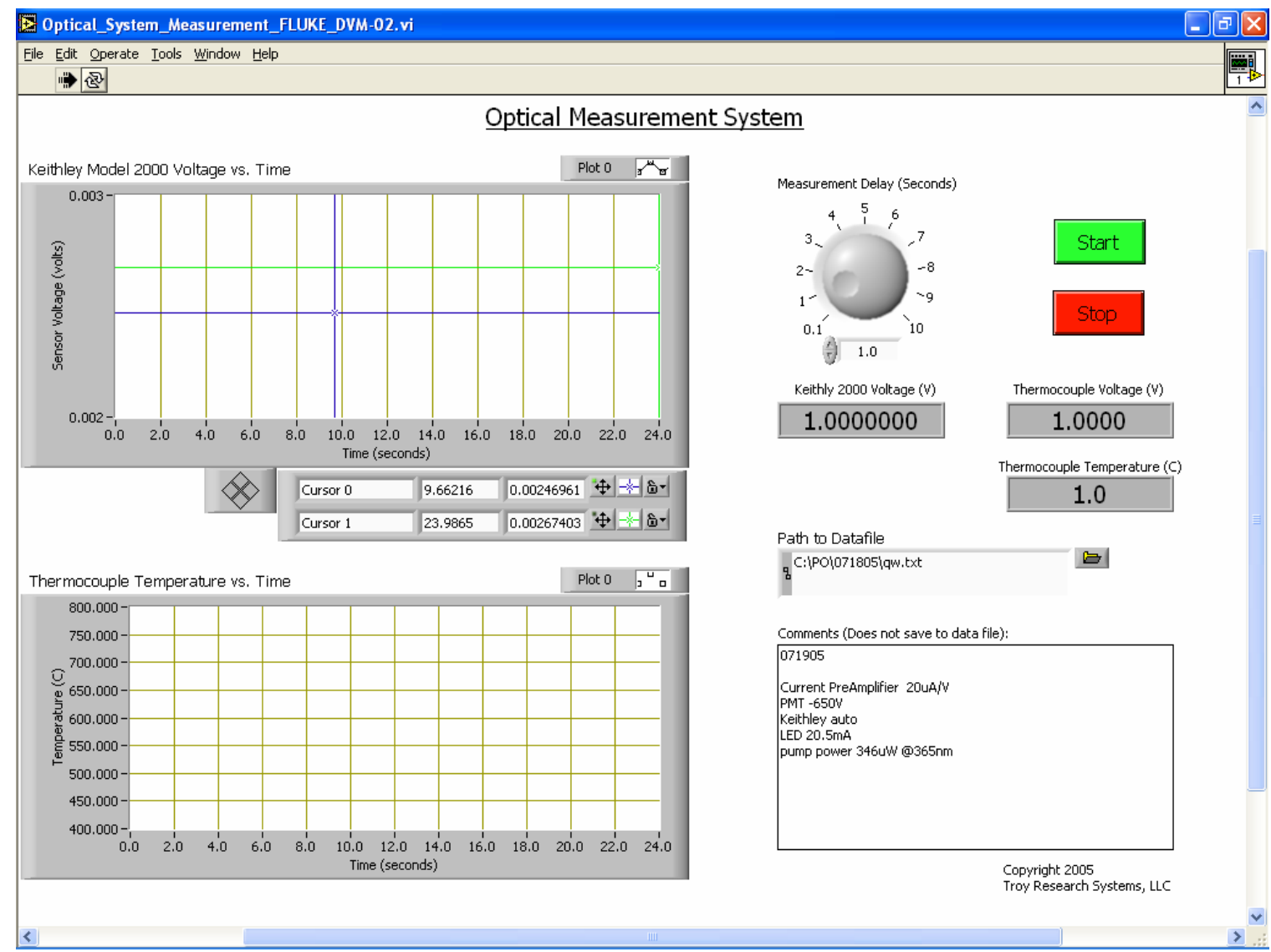

Figure 15: User interface of the automated optical sensor data acquisition software OMS_02.exe.

The data are displayed on an oscilloscope-like screen during real time measurements (see Figure 15). The user can save data to a specified data-file after popping out a Save As window. The user can also write down experimental condition in comments window and set a continual sampling rate by adjusting a knob on right-up window. Two plotting windows on the left display record the sensor signal and temperature, respectively. The cursors can be moved during the course of the measurement to provide real-time output of signal amplitude and time. The program generates one data file (.txt) with the output data in tab-separated columns 


\section{RESULTS AND DISCUSSION}

\section{Synthesis, purification, and characterization of $\mathrm{Mo}_{6} \mathrm{Cl}_{12}$}

$\mathrm{Mo}_{6} \mathrm{Cl}_{12}$ can be can be obtained from several commercial sources or directly synthesized from $\mathrm{MoCl}_{5}$ and aluminum at $800{ }^{\circ} \mathrm{C}$. As-received $\mathrm{MoCl}_{2}$ from Cerac, Inc. and City Chemical, LLC was purified by dissolution in $6 \mathrm{M} \mathrm{HCl}$ to form the hydrochloride salt $\left(\mathrm{Mo}_{6} \mathrm{Cl}_{12} \bullet 2 \mathrm{HCl}\right)$, followed by concentration of the solution and cooling to precipitate the purified clusters as a canary yellow solid. Details of the process appear in the Experimental section. Proof of structure was obtained by comparing the x-ray diffraction (XRD) pattern (Figure 16) of a collection of crystals with that of authentic samples. As shown in the Figure inset, $\mathrm{Mo}_{6} \mathrm{Cl}_{12} \bullet 2 \mathrm{HCl}$ crystallizes as an octahedral core of $6 \mathrm{Mo}$ atoms with 8 chlorides bound to each face of the octahedron. The remaining 6 chlorides are located at chemically labile axial positions, which allows for a limited number of substitution reactions. Heating the hydrochloride salt to $>200{ }^{\circ} \mathrm{C}$ drives off 2 equivalents of $\mathrm{HCl}$, converting the cluster to $\mathrm{Mo}_{6} \mathrm{Cl}_{12}$. XRD (red line in Figure 16) shows that the product is amorphous. The loss of two chlorides leaves two open coordination sites, and in solid state structures, these two sites form cluster-to-cluster bridges through chlorides. Experience has shown that $\mathrm{Mo}_{6} \mathrm{Cl}_{12}$ is hygroscopic, reversibly taking up water that presumably is coordinated to the open coordination sites.

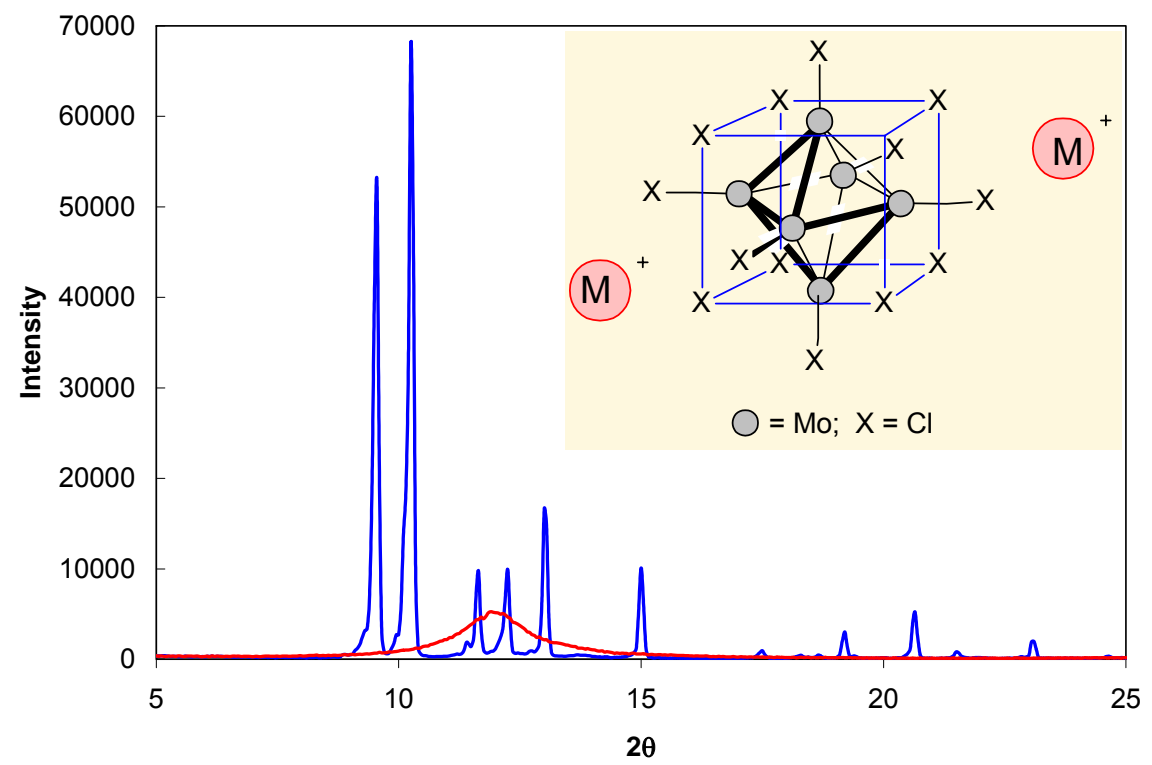

Figure 16. $\mathrm{XRD}$ patterns for $\mathrm{Mo}_{6} \mathrm{Cl}_{12} \bullet 2 \mathrm{HCl}$ (blue lines), and $\mathrm{Mo}_{6} \mathrm{Cl}_{12}$ (red line, obtained by heating the hydrochloride salt to $210^{\circ} \mathrm{C}$ under vacuum. The structure of the cluster (M $\left.=\mathrm{H}^{+}\right)$is shown in the inset.

Thermogravimetric analysis (TGA) of $\mathrm{Mo}_{6} \mathrm{Cl}_{12}$ in air (Figure 17) shows that $\mathrm{Mo}_{6} \mathrm{Cl}_{12}$ undergoes a gradual weight loss from room temperature to $250{ }^{\circ} \mathrm{C}$. The weight loss is small $(\sim 5 \%)$ and reversible, with the magnitude of the weight loss dependent on the rigor in which the compound was protected from moisture. For example, $\mathrm{Mo}_{6} \mathrm{Cl}_{12}$ that has been rigorously dried under vacuum at $200{ }^{\circ} \mathrm{C}$ shows no appreciable weight loss to 250 
${ }^{\circ} \mathrm{C}$. However, $\mathrm{Mo}_{6} \mathrm{Cl}_{12}$ heated in air to $>250{ }^{\circ} \mathrm{C}$ undergoes irreversible changes in its structure and optical properties. Isothermal aging of $\mathrm{Mo}_{6} \mathrm{Cl}_{12}$ at $300{ }^{\circ} \mathrm{C}$ for 1 hour transformed the canary yellow $\mathrm{Mo}_{6} \mathrm{Cl}_{12}$ into a gray solid. Chemical analysis of the gray material provided an empirical formula of $\mathrm{Mo}_{1} \mathrm{O}_{3.7}$; nitrogen, hydrogen, carbon, and chlorine were present at the $\leq 1 \%$ level.

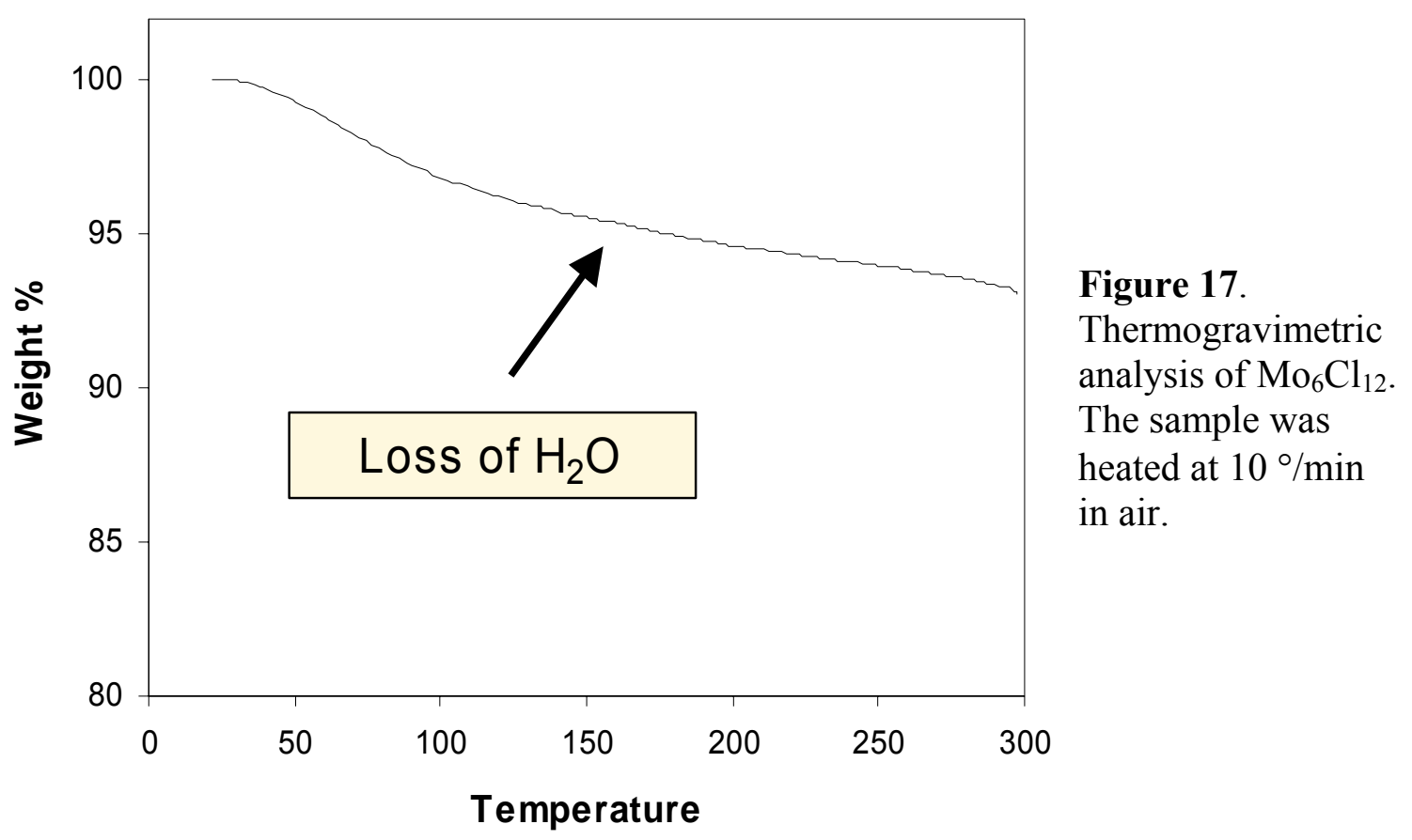

The apparent oxidation of $\mathrm{Mo}_{6} \mathrm{Cl}_{12}$ caused substantial changes in the optical properties of the clusters. An optical microscope equipped with a hot stage provided a convenient but qualitative understanding of the evolution of the optical properties of $\mathrm{Mo}_{6} \mathrm{Cl}_{12}$ with temperature. A sample of pristine $\mathrm{Mo}_{6} \mathrm{Cl}_{12}$ was heated in a hot stage at $10 \% \mathrm{~min}$ in air, and images of $\mathrm{Mo}_{6} \mathrm{Cl}_{12}$ were concurrently captured and evaluated using commercial imaging software. Shown in Figure 18 is a plot of the "luminosity" (i.e. reflected light) from three independent $\mathrm{Mo}_{6} \mathrm{Cl}_{12}$ samples as a function of temperature. Results for a TGA experiment run under the same conditions are included for comparison. The data show that decreases in luminosity and weight track each other up to $250{ }^{\circ} \mathrm{C}$. These changes are reversible. At $\mathrm{T}>250{ }^{\circ} \mathrm{C}$, the evolution in the optical properties change irreversibly, and isothermal aging at $300{ }^{\circ} \mathrm{C}$ leads to further changes in the luminosity and weight loss. These thermally-induced changes were measured quantitatively by isothermal aging of pristine samples of $\mathrm{Mo}_{6} \mathrm{Cl}_{12}$ for 1 hour at various temperatures, and after cooling to room temperature, measuring their properties by UV/vis and fluorescence spectroscopy. As shown in Figures 19 and 20, aging $\mathrm{Mo}_{6} \mathrm{Cl}_{12}$ at $\mathrm{T}<250{ }^{\circ} \mathrm{C}$ caused negligible changes in the optical properties of the clusters. However the absorption spectra of samples aged at $\mathrm{T}>250^{\circ}$ showed substantial changes, most importantly, a large decrease in luminescence compared to pristine $\mathrm{Mo}_{6} \mathrm{Cl}_{12}$. 


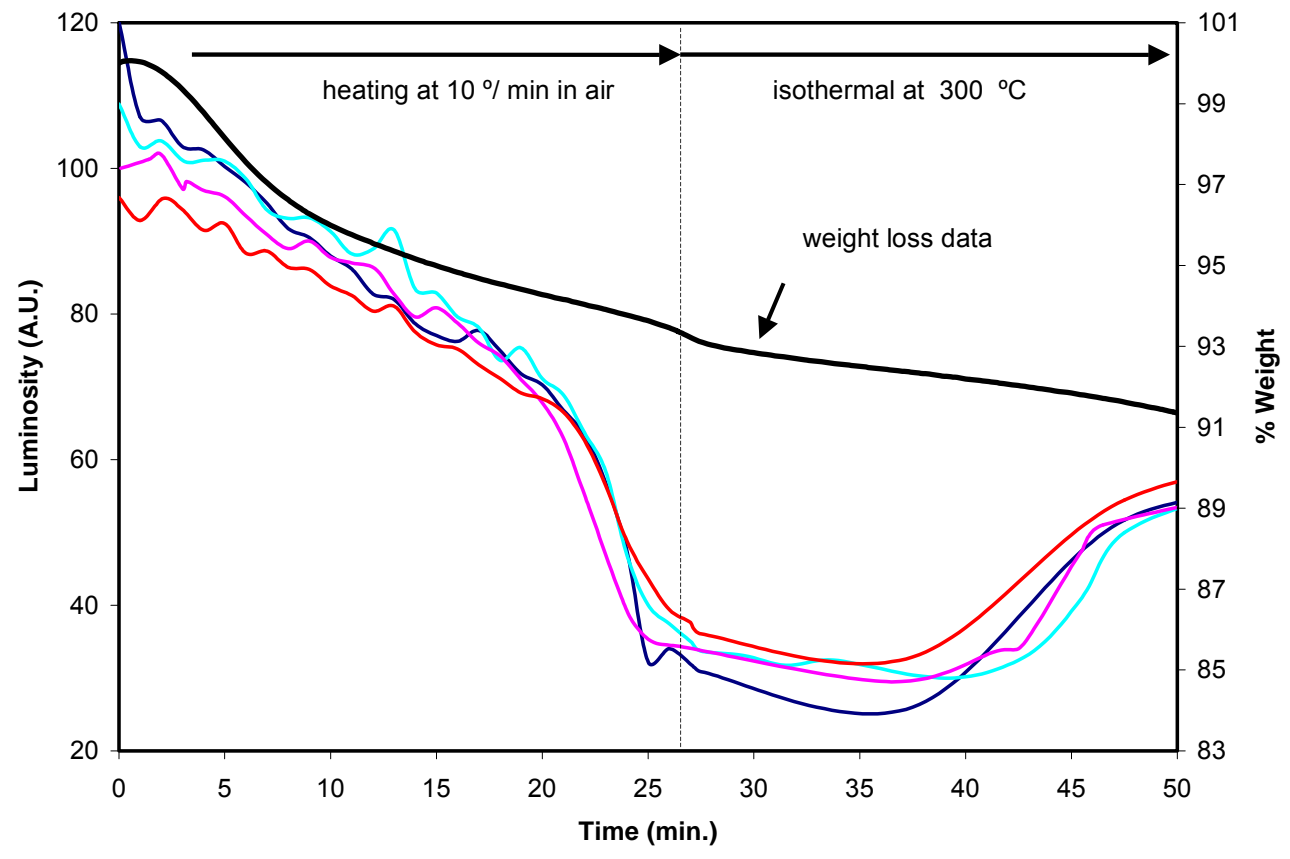

Figure 18. Changes in the luminosity of $\mathrm{Mo}_{6} \mathrm{Cl}_{12}$ caused by heating in air. Weight loss data measured under the same heating protocol are shown for comparison.

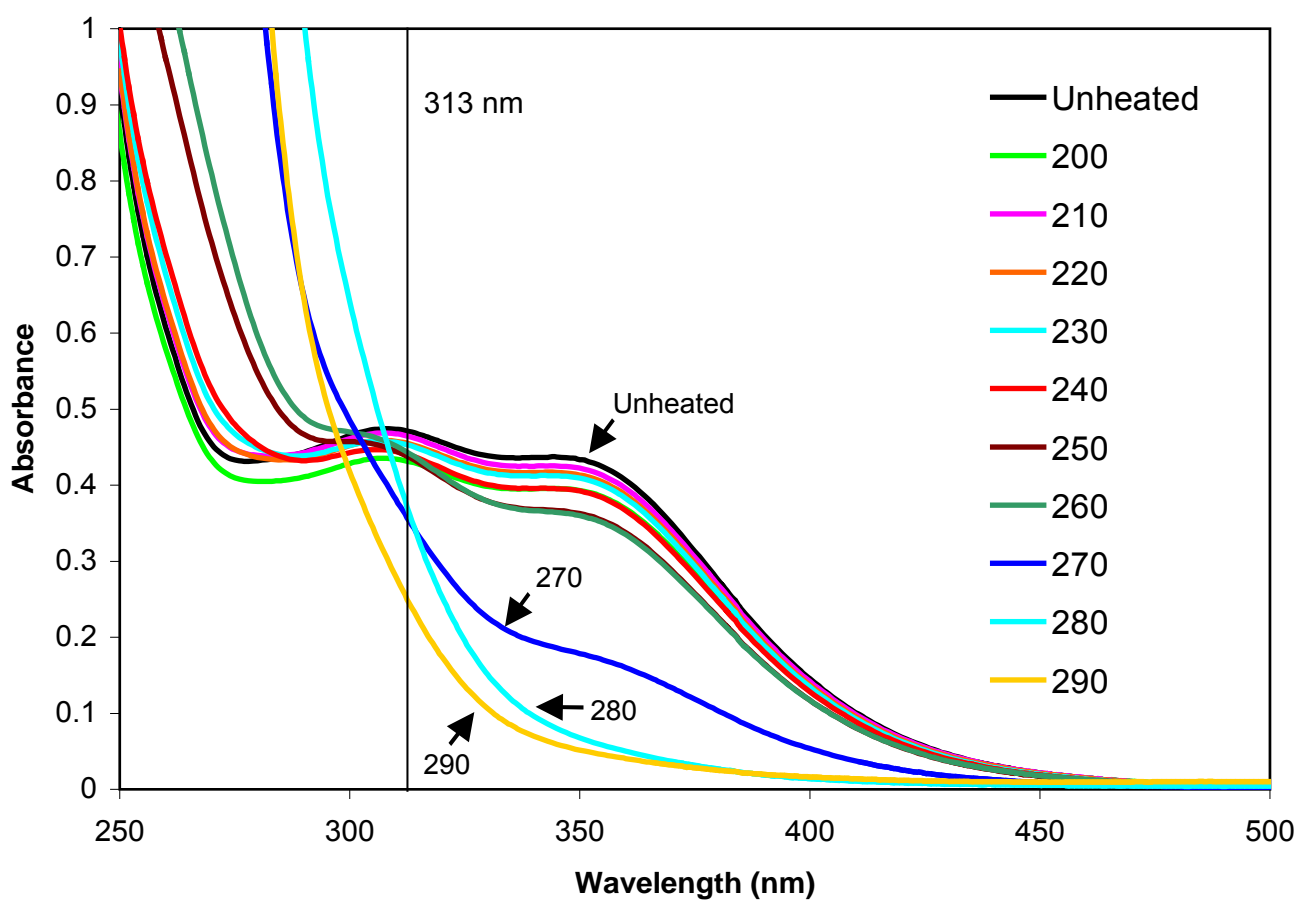

Figure 19. UV/vis spectra of $\mathrm{Mo}_{6} \mathrm{Cl}_{12}$ clusters after isothermal aging at the indicated temperatures. The spectra were run in $6 \mathrm{M} \mathrm{HCl}$. 


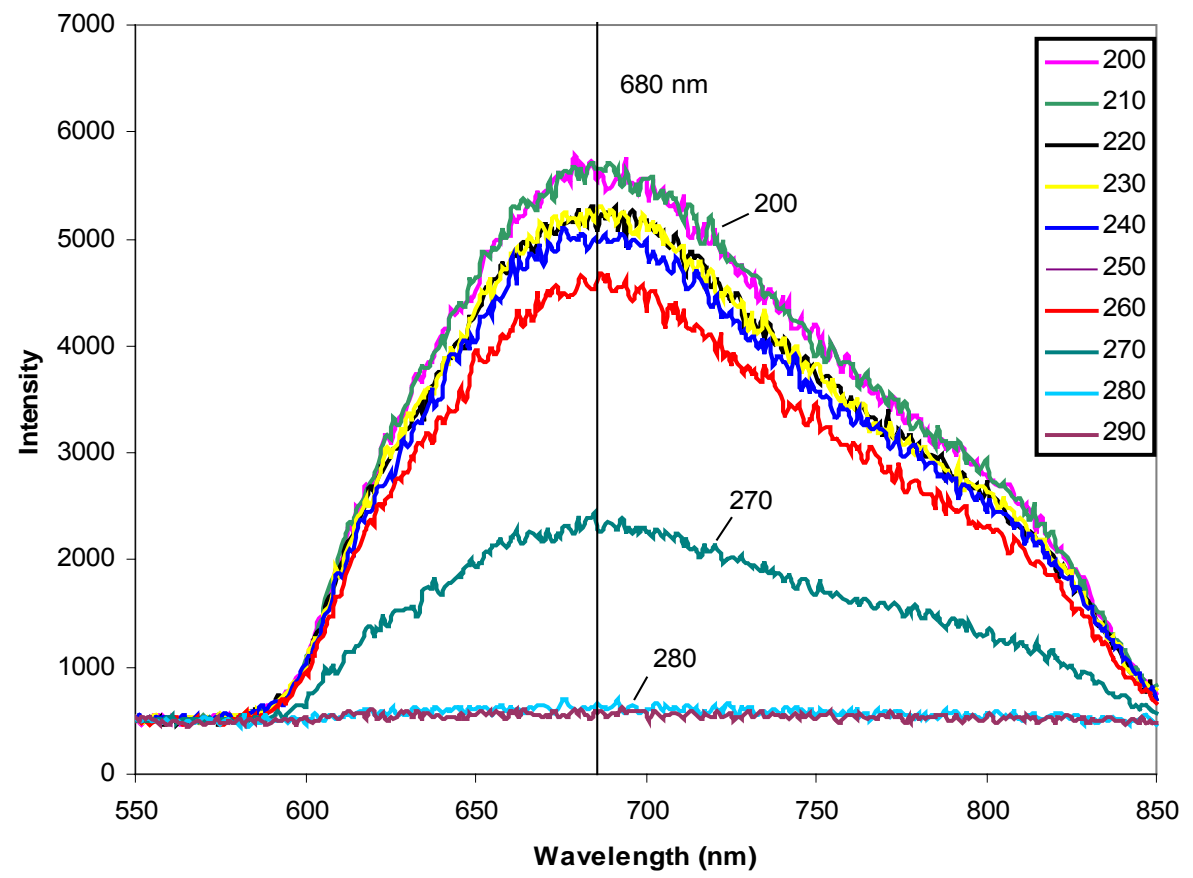

Figure 20. "Uncorrected" luminescence spectra of $\mathrm{Mo}_{6} \mathrm{Cl}_{12}$ solutions in $6 \mathrm{M} \mathrm{HCl}$ after heating to the indicated temperature.

To confirm the nature of the oxidation product, $\mathrm{Mo}_{6} \mathrm{Cl}_{12}$ was aged in air at $300{ }^{\circ} \mathrm{C}$ for 1 hour, and the resulting gray powder was analyzed by powder X-ray diffraction. The gray powder had a fairly simple diffraction pattern, and a comparison of the diffraction pattern with that of $\mathrm{MoO}_{3}$ shows that the two are nearly identical, consistent with $\mathrm{Mo}_{6} \mathrm{Cl}_{12}$ degrading via oxidation to $\mathrm{MoO}_{3}$.

While $250{ }^{\circ} \mathrm{C}$ appears to be the upper limit of stability for $\mathrm{Mo}_{6} \mathrm{Cl}_{12}$ in air, samples tolerate cycling at slightly lower temperatures. For example, the luminescence spectra in Figure 21, demonstrate that heat cycling to $200{ }^{\circ} \mathrm{C}$ does not affect the cluster photophysics. In the figure the emission spectra of (i) our previously synthesized clusters $^{[1]}$ is compared to (ii) the present material that has been cycled in air three times from room temperature to $200{ }^{\circ} \mathrm{C}$. The spectra are taking in a $0.001 \%$ oxygen environment. The data show no change in the line shape (the divergence at shorter wavelengths is due to the use of a different high pass filter for the two experiments) confirming the stability of the clusters up to $200{ }^{\circ} \mathrm{C}$. 


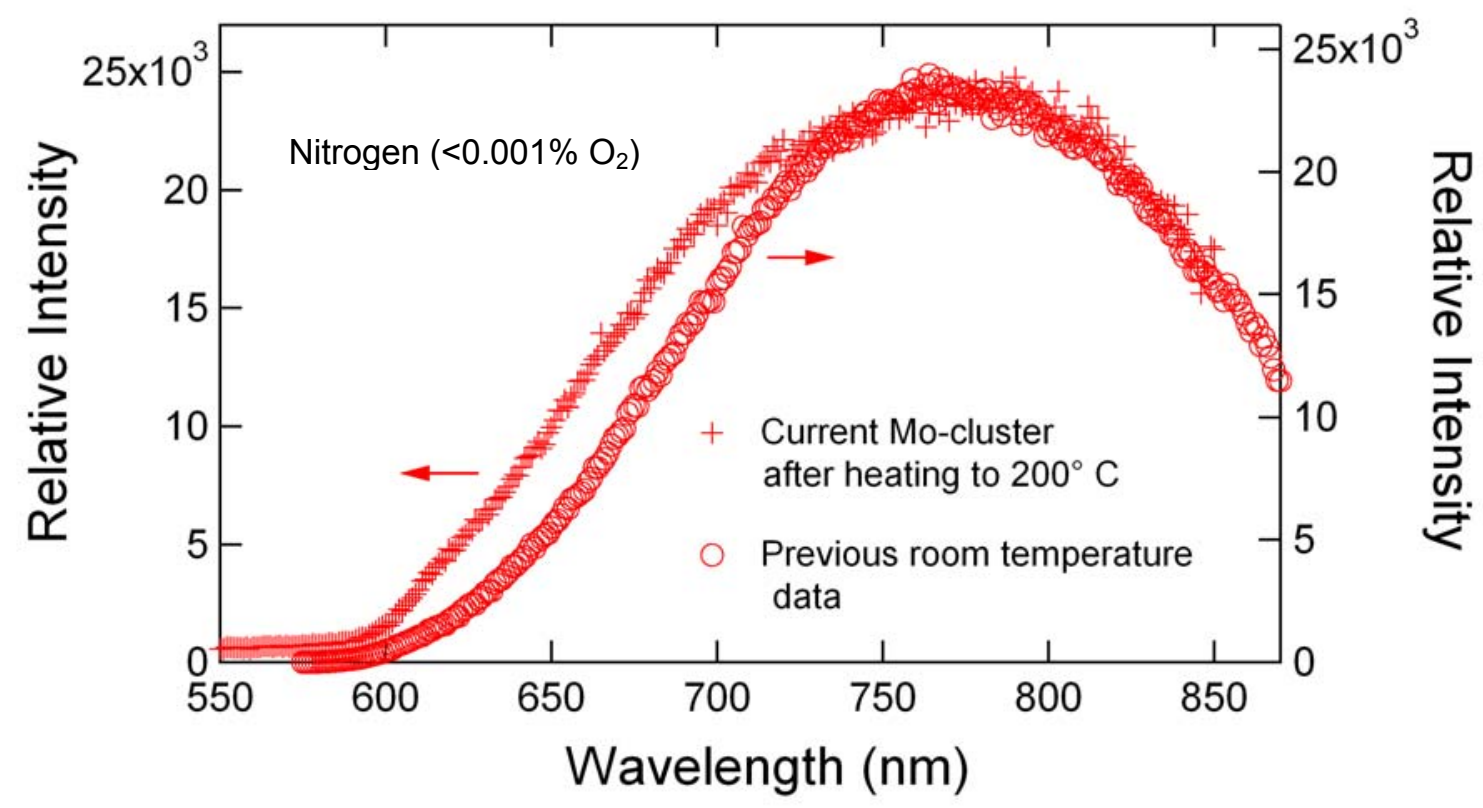

Figure 21. Emission spectra from our current Mo cluster compound after thermal cycling to $200 \mathrm{C}$ and previous results from Ghosh et al. ${ }^{[1]}$ Both spectra were taken in a $0.001 \%$ oxygen environment. 


\section{Immobilization of $\mathrm{Mo}_{6} \mathrm{Cl}_{12}$ in sol-gel matrices}

Developing a high temperature oxygen fiber sensor based on $\mathrm{Mo}_{6} \mathrm{Cl}_{12}$ luminescence quenching requires a scheme for embedding the clusters in a matrix while retaining their unique optical properties. In addition, the matrix must have high oxygen permeability and adhere strongly to the optical fiber. These requirements can be satisfied by using a sol-gel matrix to immobilize the clusters at the tip of high temperature silica fibers, such as a commercially available gold clad silica fiber rated for long term operation up to 750 ${ }^{\circ} \mathrm{C}{ }^{[16]}$. The silanol terminated surface of the fiber ensures excellent adhesion to the matrix, and prior work has shown that the oxygen permeability of sol-gel matrices can be tailored by appropriate choice of reaction conditions.
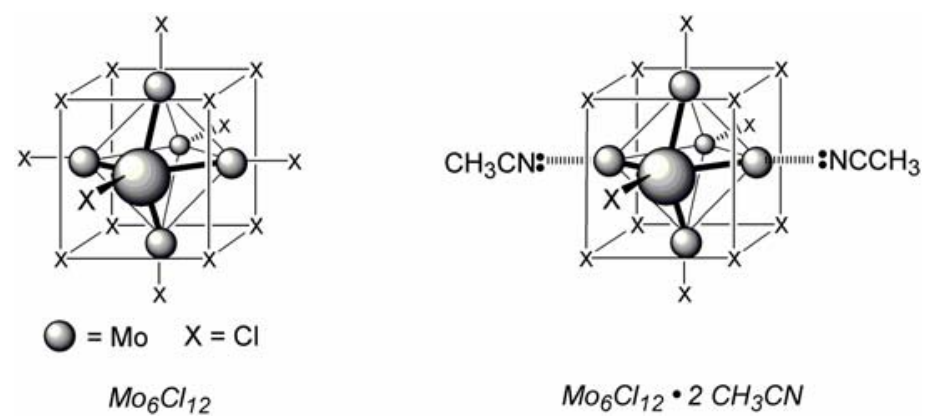

Figure 22. Luminescent molybdenum clusters.

The process for embedding the luminescent clusters must be compatible with the solubility and chemical reactivity of $\mathrm{Mo}_{6} \mathrm{Cl}_{12}$. There are two open coordination sites in the hexanuclear $\mathrm{Mo}_{6} \mathrm{Cl}_{12}$ structure (Figure 22). In the solid state, both sites are occupied by bridging chlorides from adjacent clusters resulting in a polymeric structure. In polar solvents such as ethanol or $6 \mathrm{M} \mathrm{HCl}$, solvent displaces the bridging chlorides and the clusters dissolve to give the monomeric complexes. Since both ethanol and $\mathrm{HCl}$ strongly affect sol-gel processing, we used the acetonitrile complex of $\mathrm{Mo}_{6} \mathrm{Cl}_{12}\left(\mathrm{Mo}_{6} \mathrm{Cl}_{12} \cdot 2\right.$ $\left.\mathrm{CH}_{3} \mathrm{CN}\right)^{[17]}$ in sol-gel syntheses since acetonitrile has been used successfully as a cosolvent in sol-gel syntheses. While stirring $\mathrm{Mo}_{6} \mathrm{Cl}_{12}$ in acetonitrile for several days eventually yields concentrated orange-yellow solutions of the acetonitrile complex, we found that the complex is more conveniently prepared by loading $\mathrm{Mo}_{6} \mathrm{Cl}_{12}$ into the thimble of a Soxhlet extractor and exhaustively extracting with dry acetonitrile. The use of dry solvent is important as it minimizes formation of less soluble oxygen-bridged complexes.

The spectroscopic features of the acetonitrile complex are shown in Figure 23. Excitation of $\mathrm{Mo}_{6} \mathrm{Cl}_{12}$ clusters in the UV $(\lambda<400 \mathrm{~nm})$ leads to a long lived triplet state, which decays to the ground state with emission of red luminescence centered at $\sim 750 \mathrm{~nm}$. The large Stokes shift of the emission (>300 $\mathrm{nm}$ ) greatly simplifies the design of a reflection mode fiber sensor since photons over the entire emission band can be collected and the UV pump signal can be removed using simple band pass filters. In addition, the near unity quantum yield allows simple sources such as mercury pen lamps to be used as the UV source. Excitation spectra were obtained by pumping at $313 \mathrm{~nm}$ while scanning the emission from 550 to $850 \mathrm{~nm}$. The absorbance of the solutions used for these experiments were adjusted to $\sim 0.1$ at $313 \mathrm{~nm}$ in order to minimize self-quenching effects. Using 


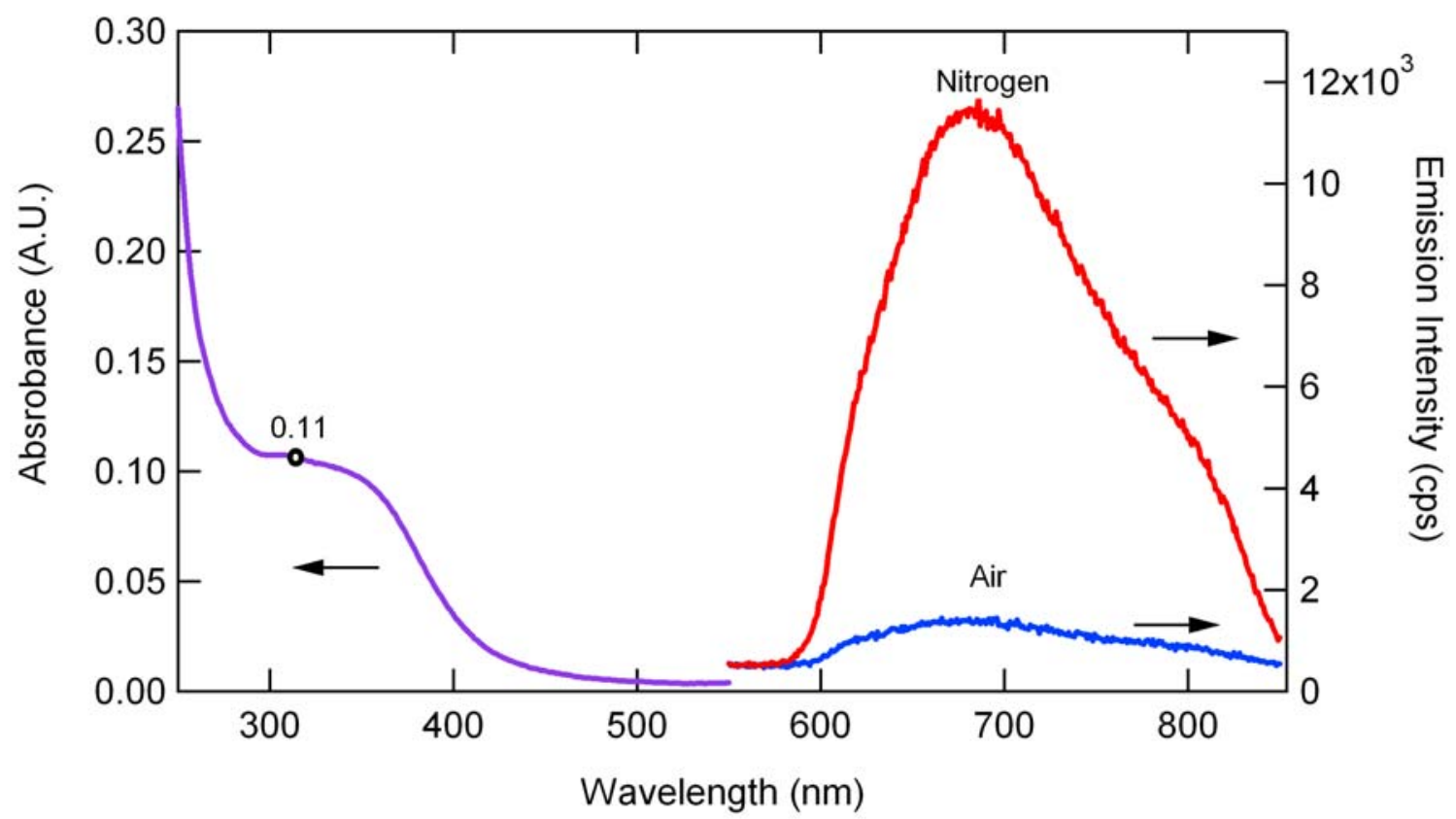

Figure 23. Absorbance and emission spectra of the acetonitrile complex of $\left(\sim 5 \times 10^{-4}\right.$ $\mathrm{mol} / \mathrm{L}$ ). The emission is the "uncorrected" raw data, taken with an excitation wavelength of $313 \mathrm{~nm}$. Quenching of $\sim 12 \times$ is observed between nitrogen $(<0.001 \%$ oxygen) and air ( $20 \%$ oxygen).

reported extinction coefficients for $\mathrm{Mo}_{6} \mathrm{Cl}_{12}$ clusters $\left(\varepsilon=3000 \mathrm{~L} \mathrm{~mol}^{-1} \mathrm{~cm}^{-1}\right){ }^{[18]}$, we estimate the concentrations to be $4 \times 10^{-5} \mathrm{M}$. A concern is whether the clusters in the matrix exist as isolated species or as aggregates. Having the former is important to avoid decreases in luminescence due to self-quenching. We believe that in solution, $\mathrm{Mo}_{6} \mathrm{Cl}_{12} \cdot 2$ $\mathrm{CH}_{3} \mathrm{CN}$ is monomeric since the luminescence intensity and quenching behavior of its solutions are comparable to those of molybdenum clusters (e.g. $\mathrm{Mo}_{6} \mathrm{Cl}_{14}{ }^{2-}$ ), which are known to be monomeric. In addition, the luminescence intensities scale linearly with changes in concentration.

The excited states of $\mathrm{Mo}_{6} \mathrm{Cl}_{12}$ clusters are efficiently quenched by oxygen. Spectra for $\mathrm{Mo}_{6} \mathrm{Cl}_{12} \cdot 2 \mathrm{CH}_{3} \mathrm{CN}$ solutions measured in room air and under nitrogen are shown in Figure 23. The data show a quenching factor of 12, with the luminescence intensity and lineshape returning to their original values upon equilibration with room air. Luminescence quenching data for $\mathrm{Mo}_{6} \mathrm{Cl}_{12}$ clusters typically follows the Stern-Volmer equation, $\mathrm{I} / \mathrm{I}_{0}=1 /\left(1+\mathrm{K}_{\mathrm{sv}}\left[\mathrm{O}_{2}\right]\right)$, where $\mathrm{I}$ and $\mathrm{I}_{0}$ are the luminescence intensity in the presence and absence of oxygen of concentration $\left[\mathrm{O}_{2}\right]$ and $\mathrm{K}_{\mathrm{sv}}$ is the Stern-Volmer constant ${ }^{[9]}$.

The process used to embed the acetonitrile complex in a sol-gel matrix is outlined in Figure 24. The process is based on the controlled hydrolysis and condensation of tetraethyl orthosilicate where ethoxy groups are lost in the form of ethanol, and new Si$\mathrm{O}-\mathrm{Si}$ bonds form to generate the silica matrix. By carrying out the reaction in the presence of the clusters, $\mathrm{Mo}_{6} \mathrm{Cl}_{12}$ is entrapped the in the final matrix. Because of its high 


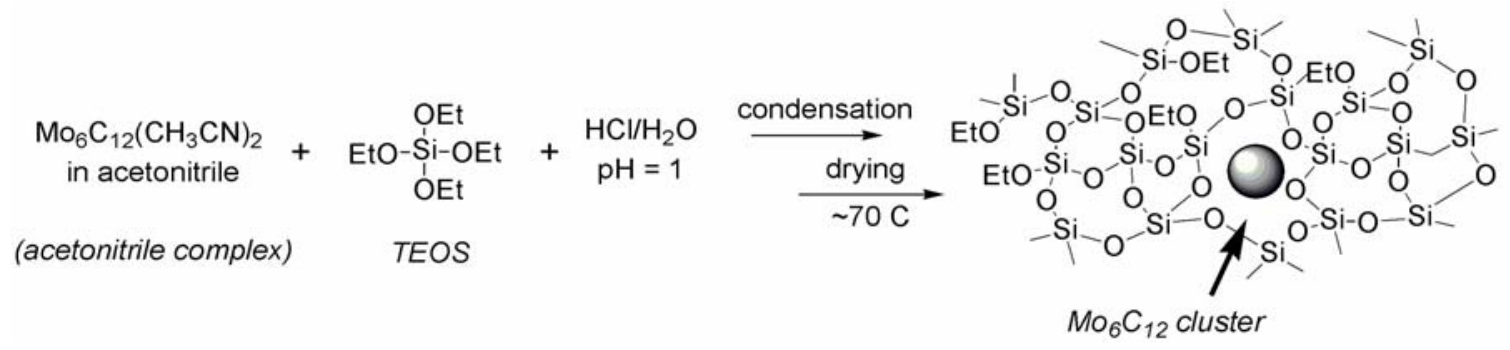

Figure 24. Synthetic route to sol-gel immobilized clusters.

solubility in the reactants, the acetonitrile complex of $\mathrm{Mo}_{6} \mathrm{Cl}_{12}$ is particularly useful for obtaining sol gel matrices that contain an appreciable concentration of $\mathrm{Mo}_{6} \mathrm{Cl}_{12}$. A requirement is that the sol-gel film be sufficiently porous to allow rapid diffusion of oxygen through the matrix. A series of experiments that lead to sol-gel matrices with different oxygen permeabilities have been reported ${ }^{[19]}$. Using those conditions as a starting point, we prepared a solution of TEOS, $\mathrm{Mo}_{6} \mathrm{Cl}_{12} \cdot 2 \mathrm{CH}_{3} \mathrm{CN}$ dissolved in acetonitrile and aqueous $\mathrm{HCl}$, and then aged the solution at $70{ }^{\circ} \mathrm{C}$ for 2.5 hours. Since acetonitrile is known to increase the rates of sol-gel reactions, we monitored the change in the viscosity of the solution and dip-coated clean quartz substrates at regular intervals. Drying at room temperature for $\sim 1$ week followed by heating at $70^{\circ} \mathrm{C}$ for 24 hours gave clear films that adhered strongly to the substrate. These films glow brightly when illuminated with a hand held UV lamp, and the emission lineshape of $\mathrm{Mo}_{6} \mathrm{Cl}_{12} 2 \mathrm{CH}_{3} \mathrm{CN}$ embedded in the sol-gel matrix matches that of the cluster in $\mathrm{CH}_{3} \mathrm{CN}$

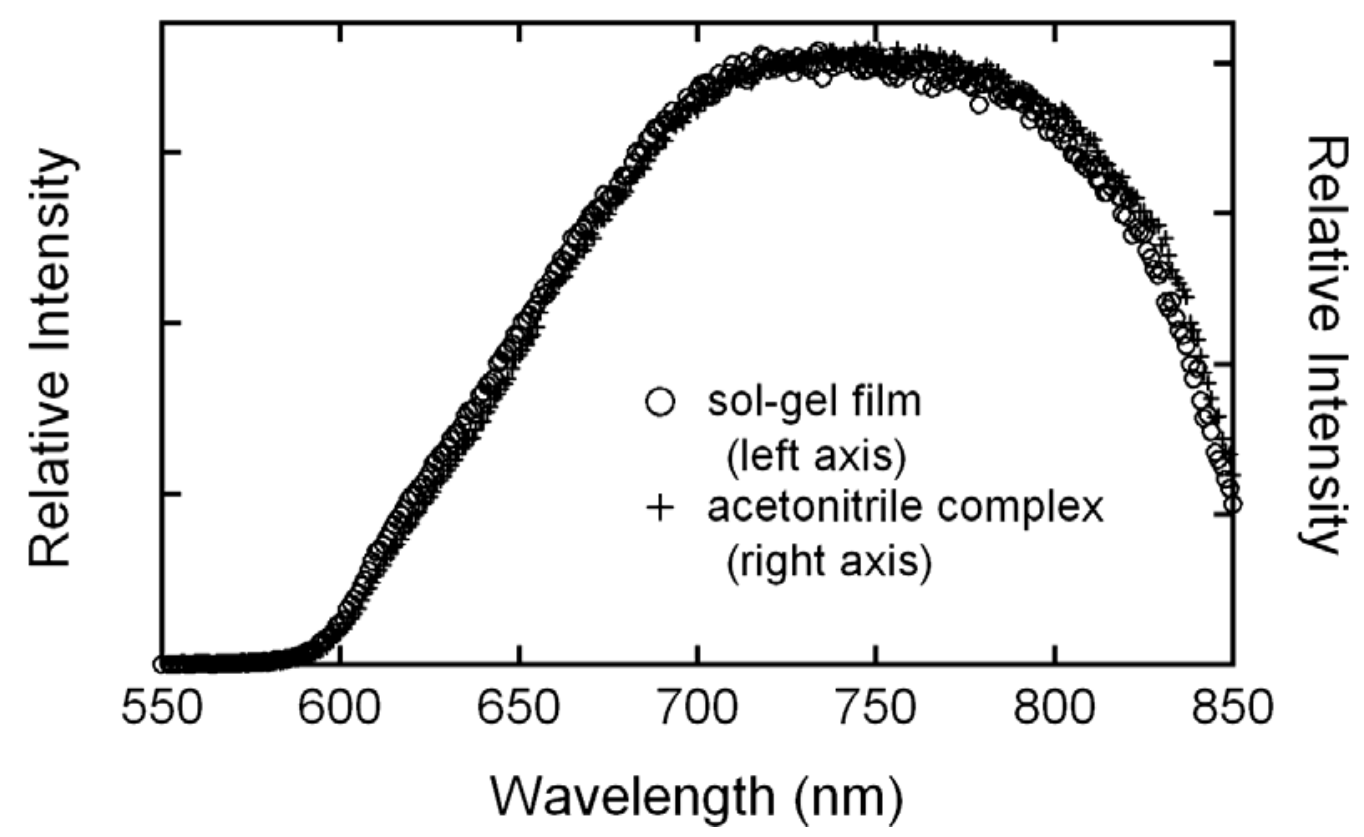

Figure 25. Emission spectra of $\mathrm{Mo}_{6} \mathrm{Cl}_{12} \cdot 2 \mathrm{CH}_{3} \mathrm{CN}$ demonstrating no change in the cluster lineshape between the $\mathrm{CH}_{3} \mathrm{CN}$ solution and the sol-gel matrix. 


\section{Film Deposition Techniques}

Coating quartz substrates with $\mathrm{K}_{2} \mathrm{Mo}_{6} \mathrm{Cl}_{14}$ clusters embedded in sol-gel films is a key prerequisite for studying the temperature dependent photophysics of $\mathrm{K}_{2} \mathrm{Mo}_{6} \mathrm{Cl}_{14}$ clusters relevant to oxygen sensing based on luminescence quenching. The film requirements are high optical clarity (absence of cloudiness or substantial cracking), mechanical stability (good adhesion), uniformity in thickness and a sufficient concentration of clusters to support luminescence and quenching measurements over a broad range of temperatures. We used hand dipping and a mechanized dipping process to coat to coat planar substrates. The apparatus used for mechanized dipping, shown in Figure 26, allows more precise control over the rate at which substrates are drawn from sol-gel solutions. Using constant dipping rates resulted in improved film quality as evidenced by smooth films with decreased frequency of cracks and films.

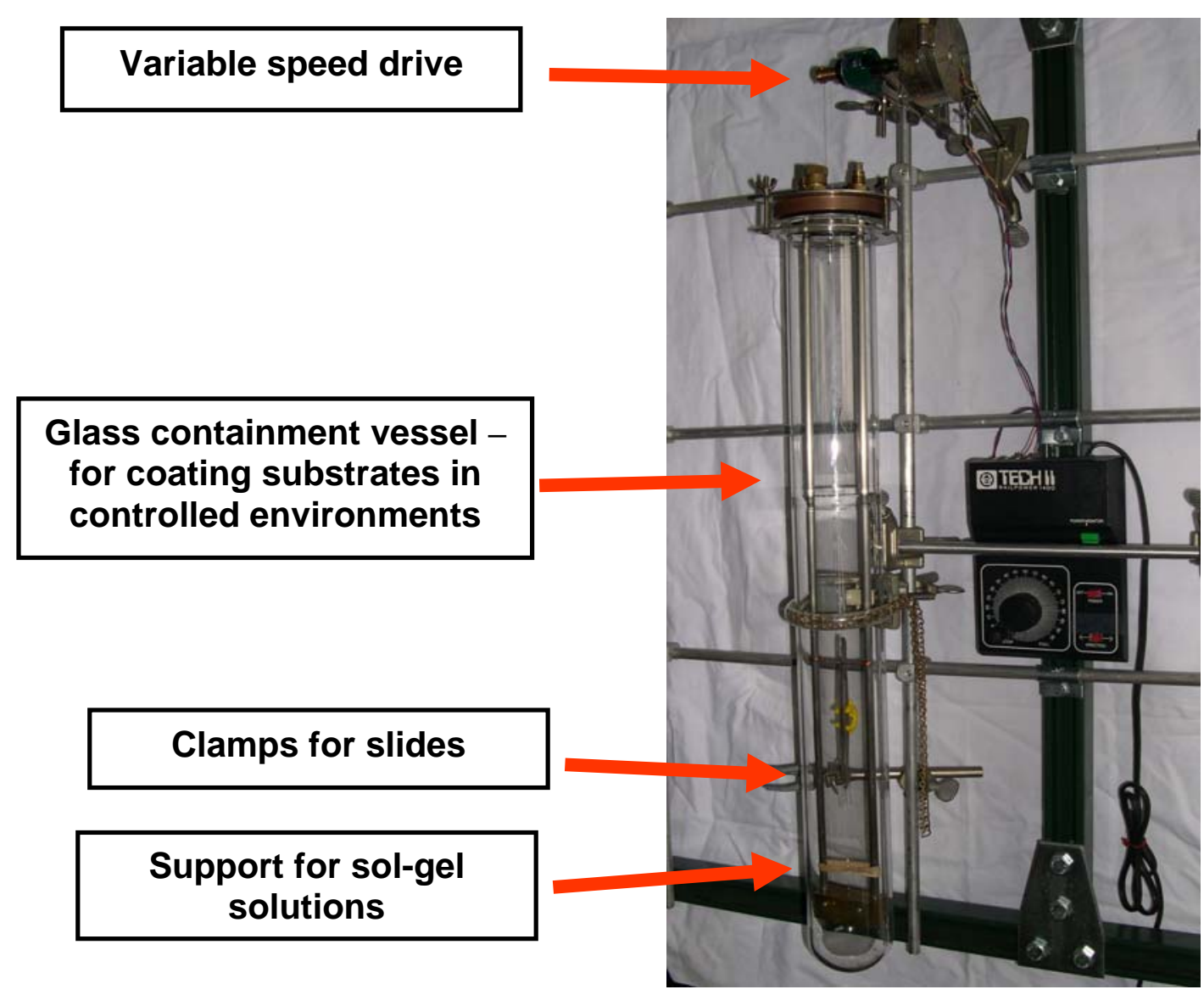

Figure 26. Apparatus used for controlled coating of planar substrates. The overall height is of the apparatus is approximately one meter. 
A second technique suitable for deposition of films on substrates is spray coating. Advantages of spray coating include the ability to deposit thin films uniformly and rapidly on surfaces, rapid drying times, and high throughput. A disadvantage of spray coating is that the resulting films generally are quite thin, often on the order of $1 \mu \mathrm{m}$. A convenient way of applying films in the laboratory scale is to use the commercial airbrush. Shown in Figure 27 is a simple rig for spray deposition on planar substrates and at the tips of fibers. The target and the spray apparatus can be enclosed to control the evaporation rate of the solvent. Since the films are thin, significant cracking characteristic of thicker films is avoided. These films are suitable for spectroscopic measurements of the clusters embedded in the matrix. However multiple coats need to be deposited to obtain thicker films so that the signal from the lumophores is sufficiently strong for simple optical detection of the luminescence quenching.

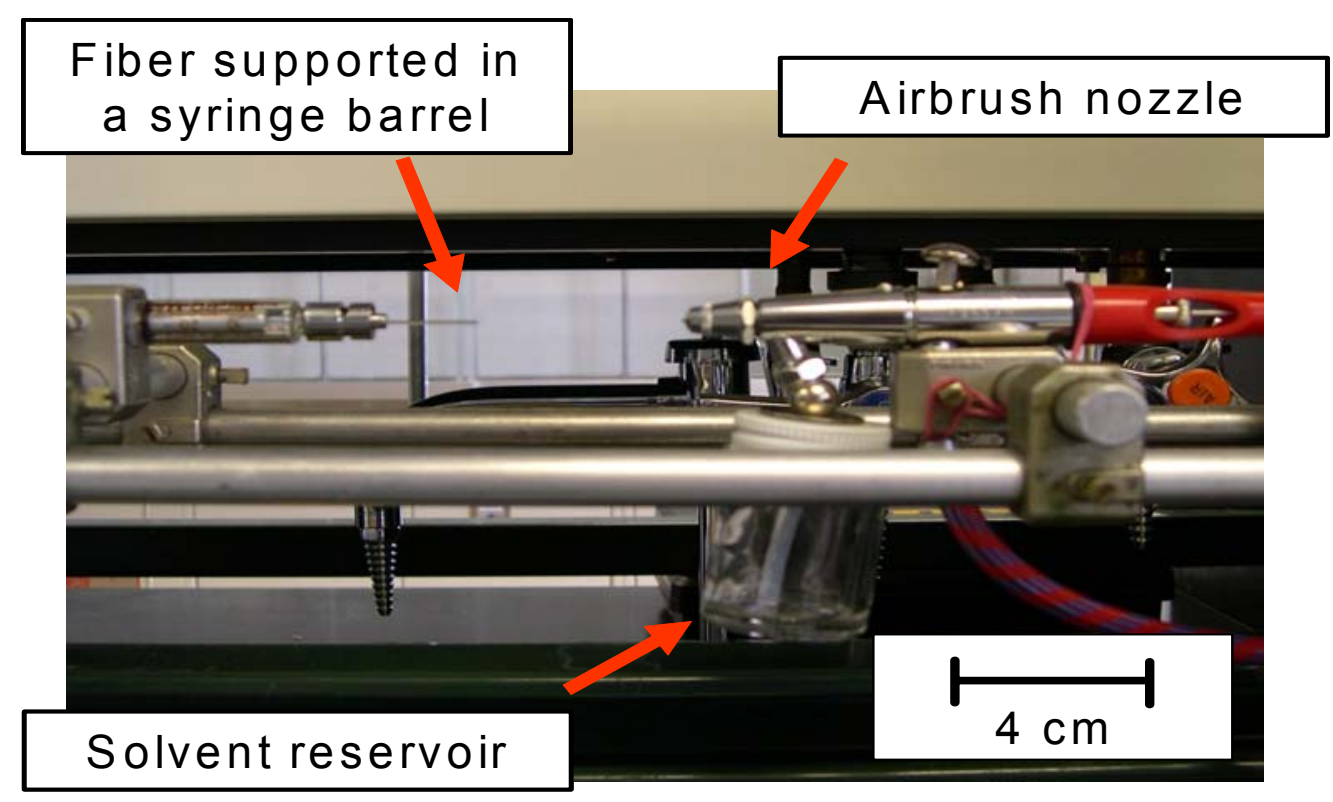

Figure 27. Apparatus used for spray coating of high temperature optical fibers

Deposition of sol-gel films on fibers is more challenging. Our spray coating results were disappointing in that we have been unable to apply multiple coatings to build up thick films and at the same time avoid cracking. A typical spray coating result is shown in the optical micrographs in Figure 28. Cracking in the sol-gel film spray coated on the surface of a high-temperature optical fiber is conspicuous. In addition the thinness of the film translates into a low absolute number of clusters available for sensing. Simply increasing the concentration of clusters in the sol-gel solution is limited to the low solubility of clusters in the acetonitrile solvent. Another disadvantage of spray coating with clusters dissolved in a sol-gel solution is that the sol-gel matrix undergoes a large decrease in volume as the sol-gel matrix cures. The large internal stress in such films exacerbates potential cracking problems. 

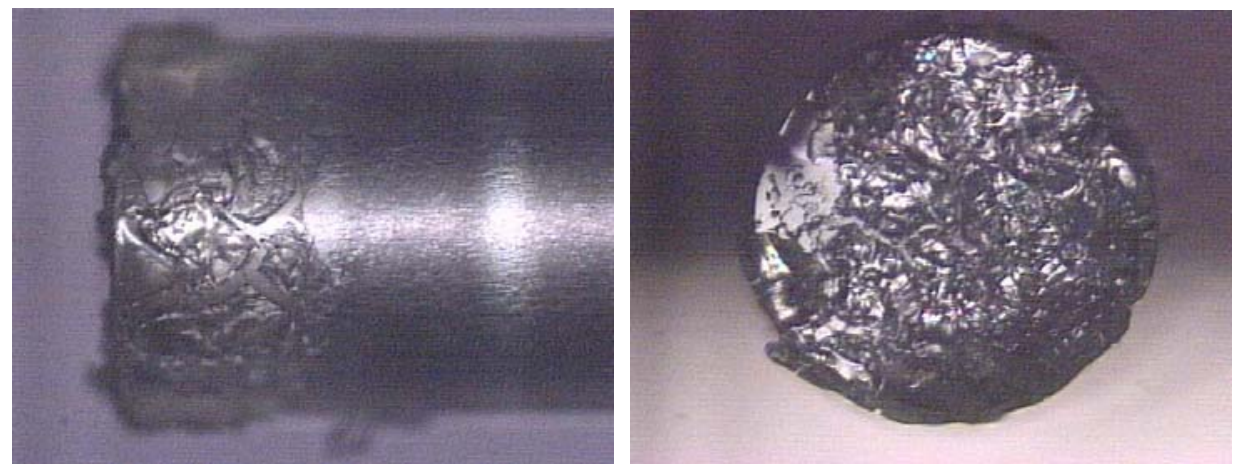

Figure 28. Typical results for multilayer deposition of sol-gel solution by spray coating showing obvious cracking. The fiber diameter is $1000 \mu \mathrm{m}$.

\section{Controlling the morphology of sol gel films on surfaces and fibers.}

One problem characteristic of materials prepared by sol gel synthesis is their propensity to fracture during curing. This problem can be understood by considering the changes in the structure of sol gel matrices as they cure. The chemistry of the sol gel process involves the condensation of tetraethoxysilane (TEOS) in the presence of either an acid or a base catalyst and solvent. As TEOS hydrolyzes and loses ethanol, the silanols generated by hydrolysis condense to form the "sol". At some point in the process, the sol solution is spread on the surface of a substrate by dip or spray coating. Solvent evaporation plus the hydrolysis and condensation of residual alkoxysilanes complete the process. If the substrate is non-adhesive, the film (often termed a monolith if it is too thick to be considered to be a film) shrinks both laterally and in thickness, and if done under near-equilibrium conditions where the rates of condensation and evaporation are uniform throughout the material, the film or monolith is transformed into a homogeneous solid. Thin films deposited on fibers or planar substrates for optical experiments must have good adherence to the substrate. For these cases, condensation and drying develops substantial strain in the material, often exceeding the yield stress of the material. Such films crack, and upon release of the strain, delaminate from the surface. The likelihood of such failures increases as the films are made thicker.

To obtain high quality films for optical experiments, we carried out a systematic evaluation of cleaning and deposition procedures that lead to high quality films. We examined a range of surface preparation techniques and found that the choice of surface preparation did not correlate with the likelihood of a film cracking. However, film thickness did correlate with cracking, with thinner films far less likely to crack. An interesting example of this phenomenon is shown in a series of slides prepared by dip coating clean slides into a sol gel solution. The sol gel film was deposited on both sides of the substrate and then the substrates were stored horizontally in small vials and allowed to dry. All of the films on the top side of the substrate (see Figure 29) cracked within 24 hours, while those on the bottom of slide did not. The crucial difference was that the film on the bottom face of the substrate was in contact with the walls of the vial allowing a portion of the film to flow from the slide to the wall, effectively thinning the film. These slides are shown in the micrographs in Figure 29. 

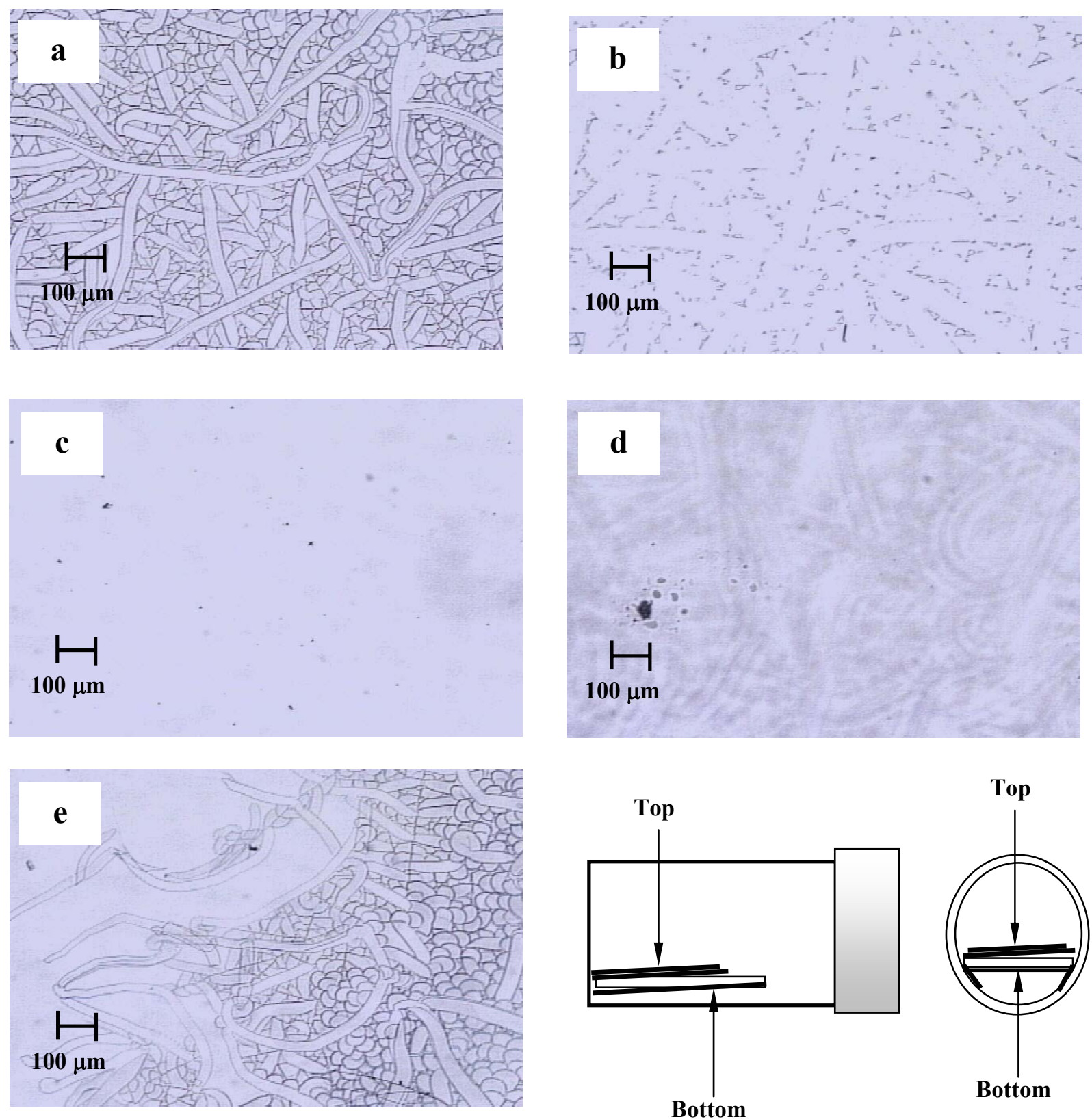

Figure 29. Optical micrographs of the surfaces of slides coated with sol gel films. (a) Top face of a slide showing the characteristic cracking pattern of thick films. (b) Top face after applying and removing tape. Note that while nearly all of the film has been removed, the original pattern can be inferred from residual fragments of the sol gel film. (c) Bottom face of the same slide showing no cracking. The film on the top face was removed by tape as in panel b. (d) The same face after applying and removing tape. This micrograph was taken in an area of the film where the top film was not removed. The unfocussed image of the top film (cracked) can be seen in the background. (e) Cracking pattern seen at the extreme edges of the film showing the evolution of cracking. The schematic at the bottom left defines the orientation of the film while drying. 
Panel a shows the dried film deposited on the top side of the substrate. During the drying process, the stress induced by the drying led an interesting and extensive pattern of cracking. The cracked film has poor adhesion to the surface. As shown in panel b, applying tape to the surface followed by peeling the tape from the surface removes nearly all of the sol gel film. Carrying out the same experiment on the bottom side of the film led to strikingly different results. The film, initially clear with no visible cracks, is unaffected by the tape test indicating excellent adhesion. Only the extreme edges of the film showed any sign of delamination (panel e). These observations suggest that under identical drying conditions, film thickness is the primary variable that determines film quality. We confirmed this hypothesis by dip coating a series of slides and orienting them vertically during the drying process. In this case, both sides of the film were crack free, with cracking seen only for the bottom edge of the film which had the highest thickness.

Similar effects can be seen in experiments on optical fibers. The fibers used were standard optical fibers - suitable for testing film deposition and adherence, but not rated for UV. Approximately twenty fibers were dip coated and after drying, they were subjected to a simple adhesion test, snapping the end of the fiber with a finger. Fibers with thick coatings generally failed with the sol gel matrix fracturing and often dislodged from the fiber. In contrast, those fibers with thin coatings passed the test and showed no fractures. Figure $\mathbf{3 0}$ shows two such fibers, one having a thin uniform coating, and a second example showing a fracture developed in the deposited sol gel film.
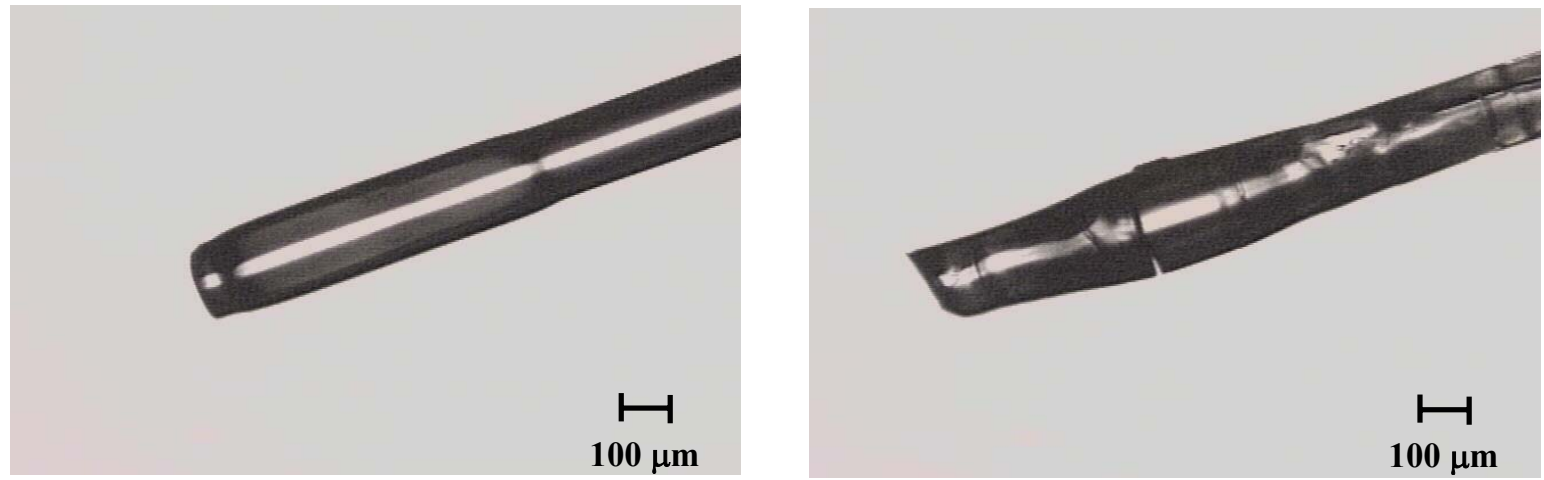

Figure 30. Optical micrographs of optical fibers coated with a sol-gel matrix containing $\mathrm{Mo}_{6} \mathrm{Cl}_{12}$ clusters. Note the cracking for the thick film on the right. 


\section{Optical properties of $\mathrm{Mo}_{6} \mathrm{Cl}_{12}$.}

Using the process described in the Experimental section, thin films of the Mo-cluster/solgel composite were deposited on quartz slides and allowed to cure. The emission spectra of the Mo-cluster / sol-gel films were measured, and then the samples were heated to 200 ${ }^{\circ} \mathrm{C}$ for one hour. Depending on the thickness of the film and the details of the preparation, the films developed a network of cracks forming domain size on the order of 100 microns after curing that was largely unchanged by the heating process. Since the core diameter of the high temperature optical fiber is $\sim 100$ microns, this process should provide crack free Mo-cluster/sol-gel composite films that completely coat the end of the fiber. The adhesion of the films to the substrates is excellent; attempts to scratch the film to measure thickness using a surface profilometer were not successful.

Oxygen quenching of the luminescence from the Mo-cluster/sol gel film $15 \mathrm{~F}$ after heating to $200{ }^{\circ} \mathrm{C}$ are shown in Figure 31. The film was heated to $200{ }^{\circ} \mathrm{C}$ for one hour prior to the measurement. Note that the clusters immobilized in the sol-gel matrix after heat treatment have the same emission lineshape as the isolated clusters in solution (Figure 25). This indicates that neither the sol-gel chemistry nor heating to $200^{\circ} \mathrm{C}$ have adverse effects on the cluster photophysics. We believe that the lower degree of oxygen quenching in the sol-gel matrix as compared to the solution results is related to the porosity of the sol-gel matrix, which can be controlled by aging time and the inclusion of porogens in the sol-gel process.

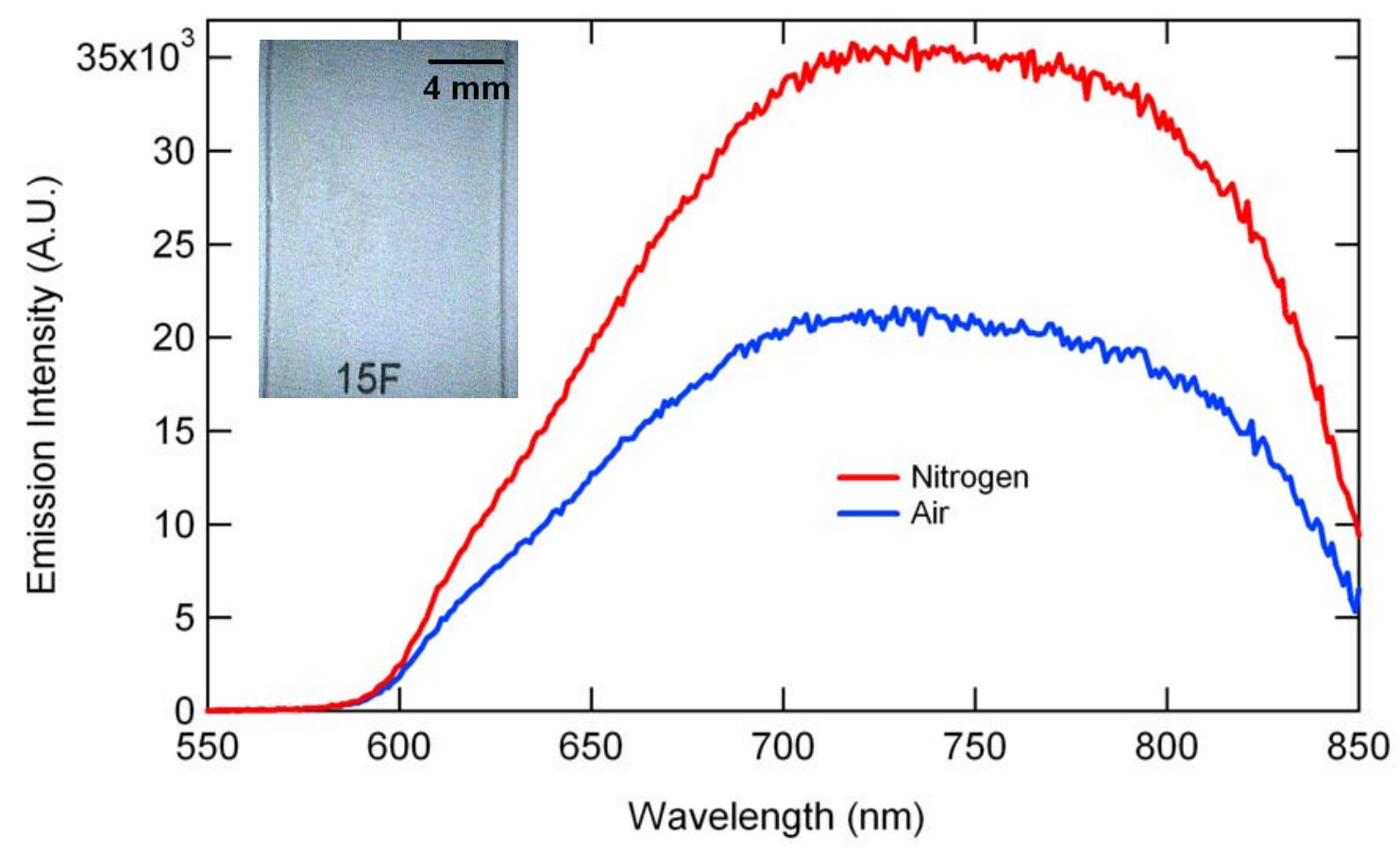

Figure 31. Emission spectra of Mo-cluster / sol-gel composite film 15F (inset), after heating to $200{ }^{\circ} \mathrm{C}$ for one hour. Quenching of $1.7 \times$ is observed between nitrogen $(<0.001 \%$ oxygen) and air ( $20 \%$ oxygen). Excitation wavelength is $313 \mathrm{~nm}$. 


\section{Measurement of $\mathrm{Mo}_{6} \mathrm{Cl}_{12}$ luminescence as a function of temperature.}

One of the critical parameters in a high temperature sensor based on luminescence quenching is the stability of the lumophore, and the temperature dependence of the luminescence, i.e. having enough photons at high temperatures to enable practical sensing. We obtained luminescence data for Mo-cluster/sol-gel film 15F from room temperature to $230{ }^{\circ} \mathrm{C}$ in flowing $\mathrm{N}_{2}$ ( purity $99.999 \%$ ), and have tested the long term stability of the lumophore. The data, shown in Figure 3, are the integrated signal intensity (i.e. integrating all the luminescent photons in the $580-850 \mathrm{~nm}$ emission band from a sol gel film containing $\mathrm{Mo}_{6} \mathrm{Cl}_{12}$. The data were collected non-sequentially, i.e., the film was not simply heated and the data collected, but instead the temperature of the sample was varied in a somewhat random fashion. As described earlier, sample heating was carried out by attaching platinum heaters to the back face of the substrate. The measured luminescence intensity follows an approximately $1 / \mathrm{T}$ relationship from room temperature to $150{ }^{\circ} \mathrm{C}$, and then declines more slowly at higher temperatures. At the highest temperature measured, $\left(230^{\circ} \mathrm{C}\right)$ the absolute number of photons leads to a signal to noise ratio $>5$, ensuring that no special optics will be required fiber based detection of oxygen at high temperatures.

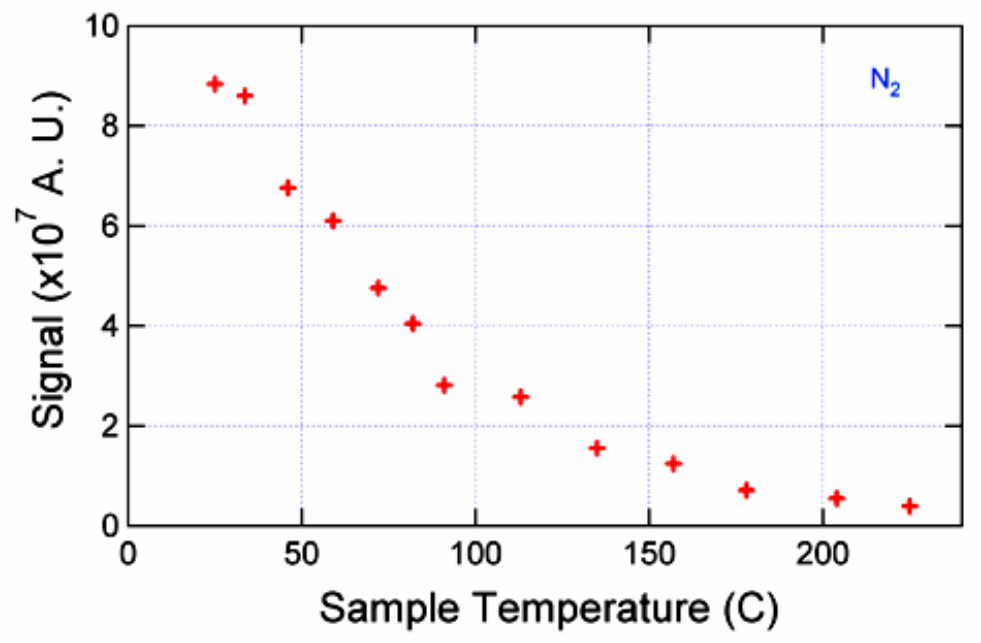

Figure 32. Integrated luminescence intensity $(580-850 \mathrm{~nm})$ of Mo-cluster/sol gel composite film $15 \mathrm{~F}$ as a function of temperature. The measurements were taken in flowing nitrogen $(99.999 \%)$. The data were collected non-sequentially with respect to temperature.

We estimate that the UV power density of the excitation source at our sample is about 1 $\mathrm{mW} / \mathrm{cm}^{2}$. Our previous room temperature fiber sensor measurements ${ }^{[1]}$ were made with an incident power density of $9 \mathrm{~mW} / \mathrm{cm}^{2}$, and the cross sectional area of the fiber sensor was roughly a factor 10 smaller than the illumination spot during our current measurements. The signal to noise measurements shown in Figure 33 confirm that despite the decrease in the integrated signal intensity with temperature, there are 
sufficient luminescent photons to develop a fiber optic based sensor using Mo-cluster / sol-gel composite films similar to that of sample $15 \mathrm{~F}$.

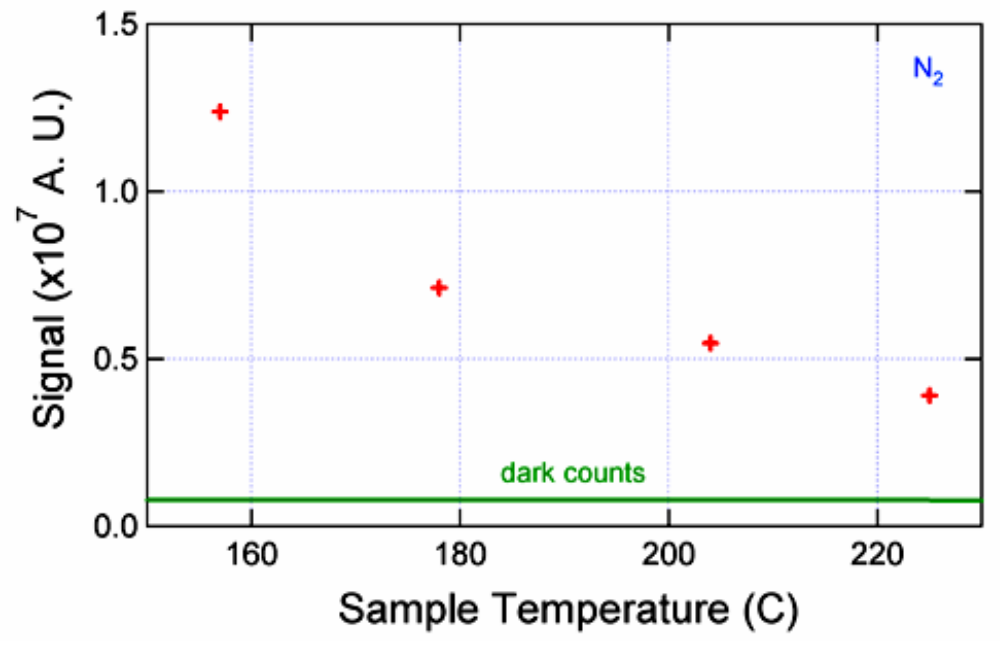

Figure 33. Data of Figure 32, expanded to show the high temperature signal intensity. The dark counts from the photomultiplier, shown in green, leads to a signal to noise ratio $>5$.

Of note is that the measurements were made on a film that was $\sim 1$ year old that had been thermally cycled to $\mathrm{T} .>200^{\circ}$ several times. Despite the repeated cycling, the luminescence intensity of the film had not diminished, but instead had increased. While the reason for the change in luminescence is not certain, it is likely related to the continued evolution of the sol gel matrix. 


\section{Evaluation of alkali metal salts of $\mathrm{Mo}_{6} \mathrm{Cl}_{12}$ for improved thermal stability.}

As the synthesis of $\mathrm{Mo}_{6} \mathrm{Cl}_{12}$ is carried out at $\mathrm{T}>600^{\circ} \mathrm{C}$, the inherent thermal stability of $\mathrm{Mo}_{6} \mathrm{Cl}_{12}$ is high. However, as described earlier, our experiments showed that the canary yellow $\mathrm{Mo}_{6} \mathrm{Cl}_{12}$ clusters undergo oxidation in oxygenated environments at $\mathrm{T}>250{ }^{\circ}$ to form a gray solid that does not luminesce. Elemental analysis indicates a chemical composition of $\mathrm{MoOx}$, consistent with oxygenation. Two open axial coordination sites on the $\mathrm{Mo}_{6} \mathrm{Cl}_{12}$ cluster lead to the polymerization of clusters through shared chlorine bridges. These open sites also are the likely source of the oxidative instability of $\mathrm{Mo}_{6} \mathrm{Cl}_{12}$. The known $\mathrm{Mo}_{6} \mathrm{Cl}_{14} \mathrm{X}_{2}$ salts, where $\mathrm{X}$ is an alkali metal cation such as $\mathrm{Na}^{+}, \mathrm{K}^{+}$, or $\mathrm{Cs}^{+}$ should be more thermally robust since there is a full complement of chloride ligands and no open sites for cluster aggregation or oxidation, i.e. chlorides must be lost from the cluster for the cluster to undergo degradation. ${ }^{[20]}$

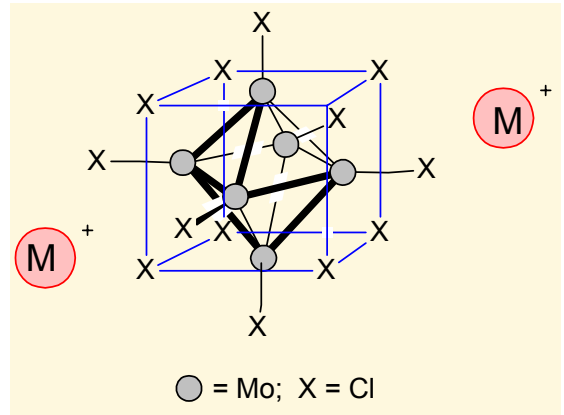

The potassium salt of $\mathrm{Mo}_{6} \mathrm{Cl}_{12}(\mathrm{M}=\mathrm{K})$

We initially synthesized the $\mathrm{K}^{+}$salt via a high temperature $\left(800^{\circ}\right)$ metathesis reaction. In addition to being cumbersome, the product contained substantial amount of impurities. On the advice of Prof Maverick at Louisiana State University, we switched to a simple solution-based synthesis. $\mathrm{Mo}_{6} \mathrm{Cl}_{12}$ dissolved in $\mathrm{HCl}$ and treated with a large excess of $\mathrm{KCl}$. The $\mathrm{K}_{2} \mathrm{Mo}_{6} \mathrm{Cl}_{14}$ complex precipitated from solution and was collected by filtration. The $\mathrm{K}^{+}$salt was characterized by powder x-ray diffraction, uv-vis, and fluorescence

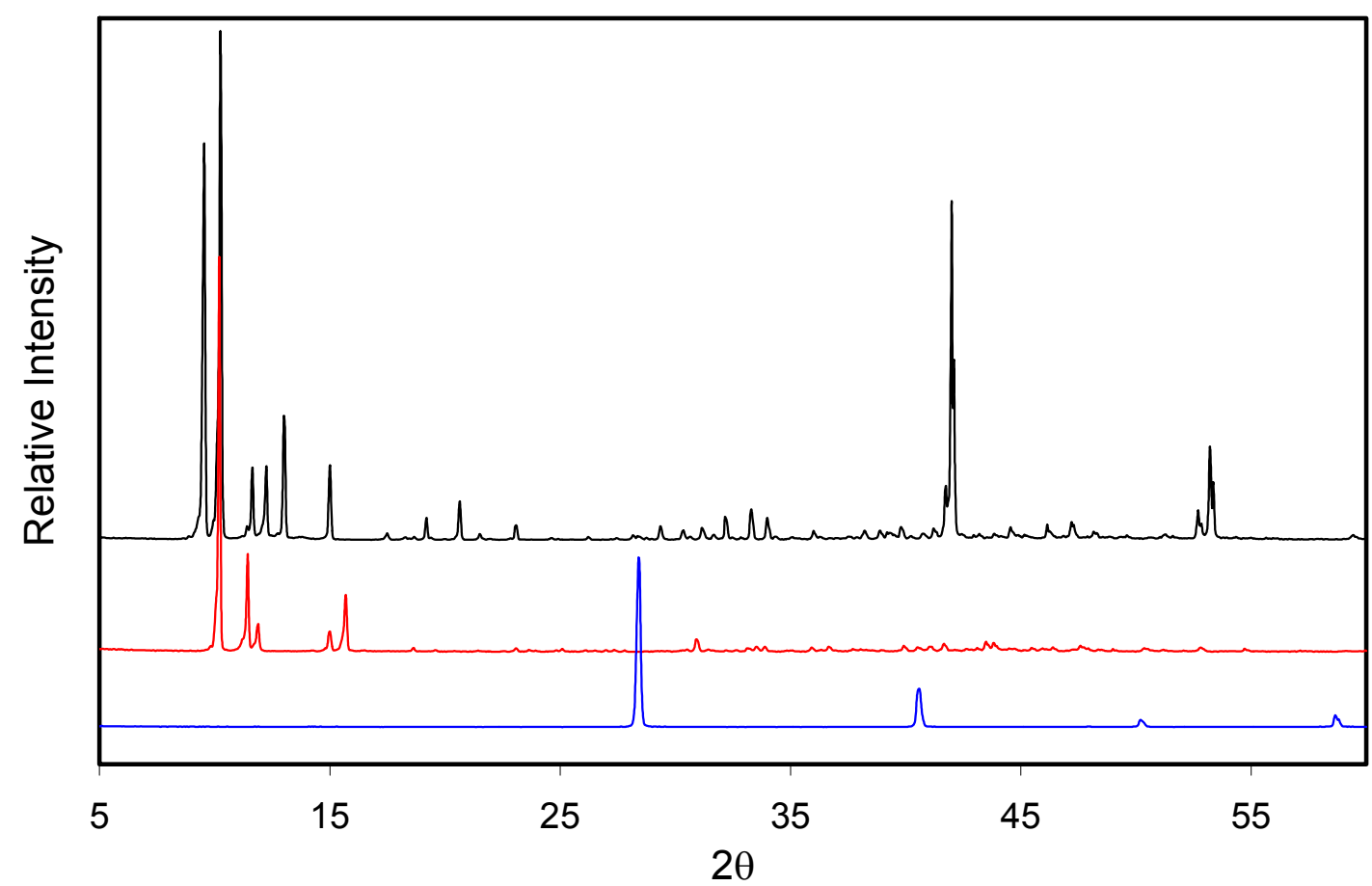

Figure 34. Powder $\mathrm{x}$-ray diffraction patterns for (top) $\mathrm{Mo}_{6} \mathrm{Cl}_{12}$, (middle) $\mathrm{K}_{2} \mathrm{Mo}_{6} \mathrm{Cl}_{14} \cdot 2 \mathrm{H}_{2} \mathrm{O}$, and (bottom) $\mathrm{KCl}$. 
spectroscopy. As shown in Figure 36, the powder x-ray diffraction pattern shows the transformation of the hydrochloride salt to the more stable potassium salt. The optical data also are consistent with successful synthesis of the salt, but the similarity of the optical properties of $\mathrm{Mo}_{6} \mathrm{Cl}_{12}$ and the $\mathrm{K}^{+}$salt makes it difficult to conclude that there was no contamination by $\mathrm{Mo}_{6} \mathrm{Cl}_{12}$.

Thermal analysis of the resulting complex shows improved thermal stability compared to $\mathrm{Mo}_{6} \mathrm{Cl}_{12}$. TGA measurements run in air at $10^{\circ} / \mathrm{min}$ (Figure 37) showed reduced weight losses, and more importantly, after 2 hours at $280{ }^{\circ} \mathrm{C}$ the samples still luminesced. $\mathrm{Mo}_{6} \mathrm{Cl}_{12}$ run under the same conditions were optically dead. The color of the salt complex evolved from yellow to a greenish hue. For reasons noted above, we are unsure whether the color change resulted from partial degradation of the cluster, or is due to contamination by $\mathrm{Mo}_{6} \mathrm{Cl}_{12}$. $\mathrm{Mo}_{6} \mathrm{Cl}_{12}$ and its potassium salt, $\mathrm{K}_{2} \mathrm{Mo}_{6} \mathrm{Cl}_{14} \cdot 2 \mathrm{H}_{2} \mathrm{O}$, were heated to $280{ }^{\circ} \mathrm{C}$ in air for 1 hour, and after cooling to room temperature, both were dissolved in $6 \mathrm{M} \mathrm{HCl}$.. The uv-vis spectra of the resulting solutions were measured. The data of Figure 38 clearly show the enhanced thermal stability of the potassium salt. The intensity of the $\mathrm{K}_{2} \mathrm{Mo}_{6} \mathrm{Cl}_{14}$ spectrum is $\sim 2 / 3$ of that for unheated $\mathrm{Mo}_{6} \mathrm{Cl}_{12}$ while that for heat treated $\mathrm{Mo}_{6} \mathrm{Cl}_{12}$ (run at a $23 \times$ higher concentration) shows none of the characteristics of the original complex.

The previous data show that $\mathrm{K}_{2} \mathrm{Mo}_{6} \mathrm{Cl}_{14}$ has superior thermal stability compared to $\mathrm{Mo}_{6} \mathrm{Cl}_{12}$. We devised two analytical tests for qualifying new syntheses of $\mathrm{K}_{2} \mathrm{Mo}_{6} \mathrm{Cl}_{14}$, isothermal aging in air at $280^{\circ} \mathrm{C}$, and measuring the optical properties before and after

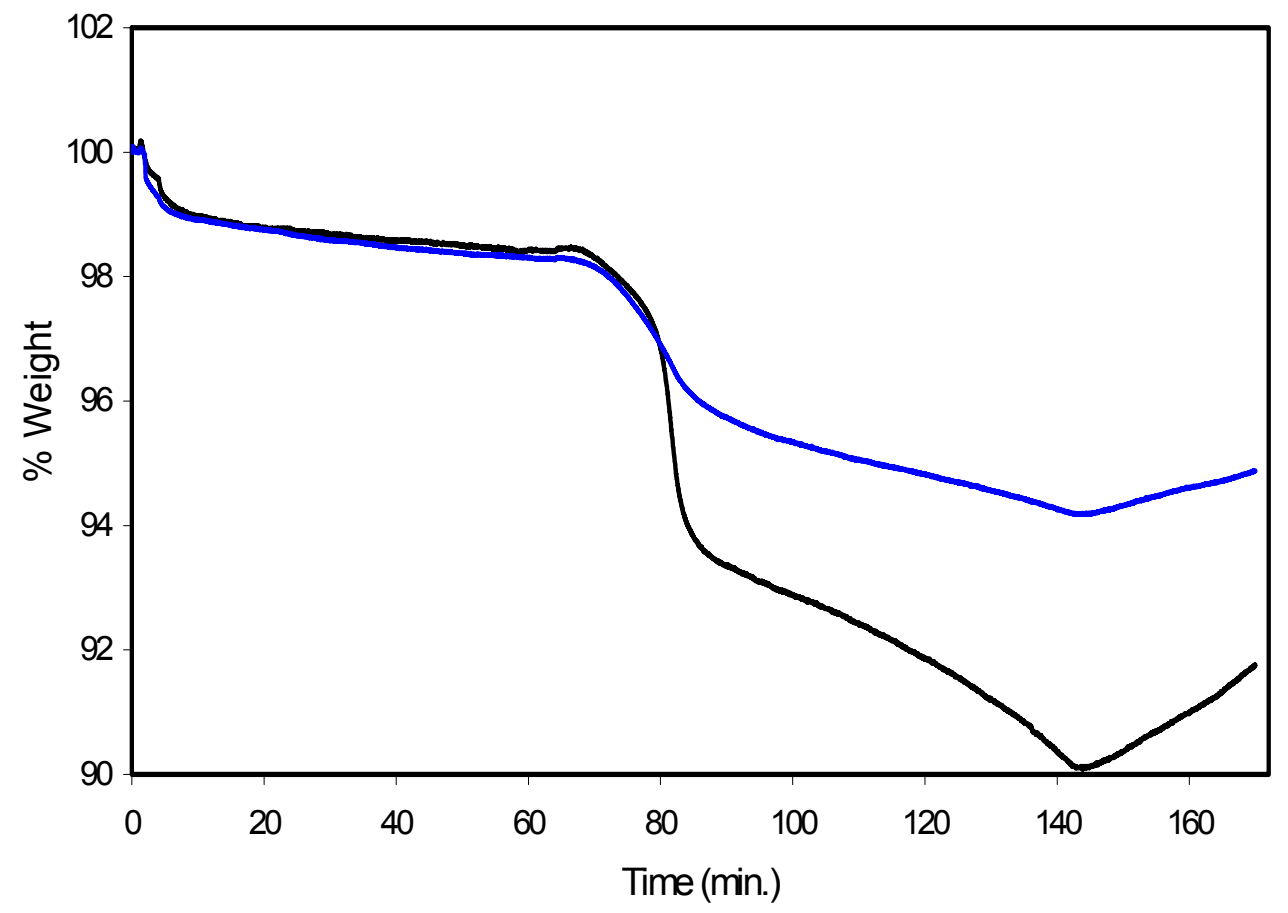

Figure 35. Thermal Gravimetric Analysis in air of (-) $\mathrm{Mo}_{6} \mathrm{Cl}_{12}$ and (-) $\mathrm{K}_{2} \mathrm{Mo}_{6} \mathrm{Cl}_{12}$. The samples were (1) heated to $120{ }^{\circ} \mathrm{C}$ at $30 \% \mathrm{~min}$, (2) held at $120^{\circ}$ for $1 \mathrm{~h}$, (3) heated to $280{ }^{\circ} \mathrm{C}$ at $10 \% \mathrm{~min}$, (4) held at $280{ }^{\circ} \mathrm{C}$ for 1 hour, and (5) cooled to $40{ }^{\circ} \mathrm{C}$ at $10 \% \mathrm{~min}$. 


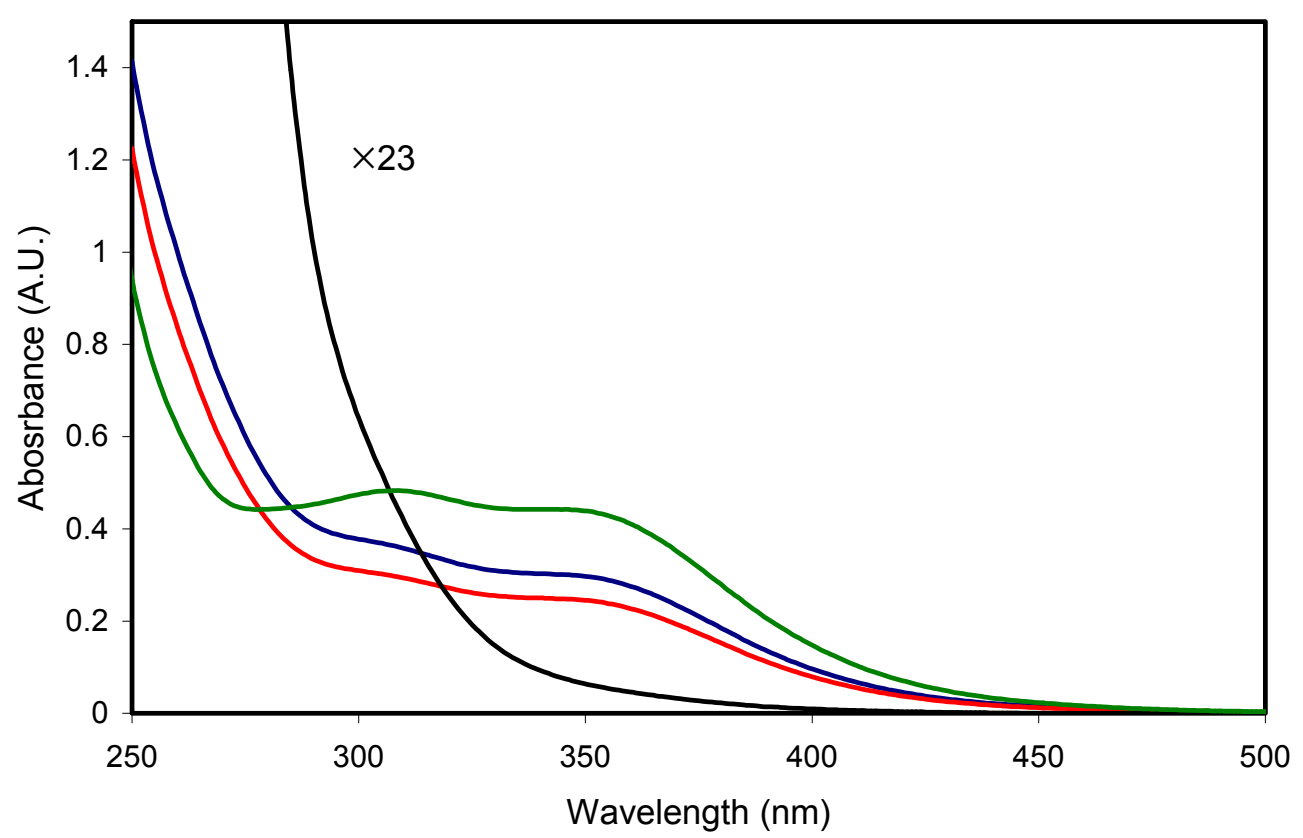

Figure 36. Absorption spectra for cluster samples heated at $280{ }^{\circ} \mathrm{C}$ for 60 minutes and then dissolved in $6 \mathrm{M} \mathrm{HCl}$. Samples shown are $(-) \mathrm{K}_{2} \mathrm{Mo}_{6} \mathrm{Cl}_{14}$, heated in air in the TGA apparatus and (-)in a microscope hot stage, $(-) \mathrm{Mo}_{6} \mathrm{Cl}_{12}$ heated in a hot stage, and (-) unheated $\mathrm{Mo}_{6} \mathrm{Cl}_{12}$. The concentrations of each solutions were $0.17 \mathrm{~g} / \mathrm{L}$, except for the heated $\mathrm{Mo}_{6} \mathrm{Cl}_{12}$ sample, which was 23 times higher $(4 \mathrm{~g} / \mathrm{L})$.

thermal aging. The potassium salt shows at most a few percent weight loss during four hours of isothermal aging, but samples contaminated with $\mathrm{Mo}_{6} \mathrm{Cl}_{12}$ degrade significantly and lose substantial weight early in the analysis. We prepared two large scale batches of the potassium salt, MM-7 and MM-8, and measured their isothermal aging characteristics. As shown in Figure 37, their thermal degradation profiles are nearly identical to FJ-17, one of the first syntheses of $\mathrm{K}_{2} \mathrm{Mo}_{6} \mathrm{Cl}_{14}$. The profile of $\mathrm{MM}-5$, prepared at approximately the same time as FJ-17, shows a significant weight loss early in the run, and we conclude from its similarities to the weight loss profile of $\mathrm{Mo}_{6} \mathrm{Cl}_{12}$ that MM-5 is contaminated by the less stable $\mathrm{Mo}_{6} \mathrm{Cl}_{12}$. While characterizing the weight loss profile of a candidate salt is a rapid assay for the purity of the salt, a more rigorous test is measurement of the optical properties of the lumophore. Solutions of MM-7, MM-8, and FJ-17 were prepared in acetonitrile and their luminescent properties were measured. Data measured at room temperature shown in Figure 38, demonstrate that both the line shape and luminescence intensity of for all three samples are nearly identical and are consistent with the notion that the lumophores in FJ-17, MM-7 and MM-8 are identical. Samples of the same salts were then heated to $200{ }^{\circ} \mathrm{C}$ for four hours, cooled to room temperature, and again solutions of the salts in acetonitrile were prepared and their luminescent properties were measured. The results again are consistent with the conclusion from the isothermal aging experiments, that the clusters from all three batches are identical. Note that the as expected the emission intensity scales linearly with cluster concentration. 


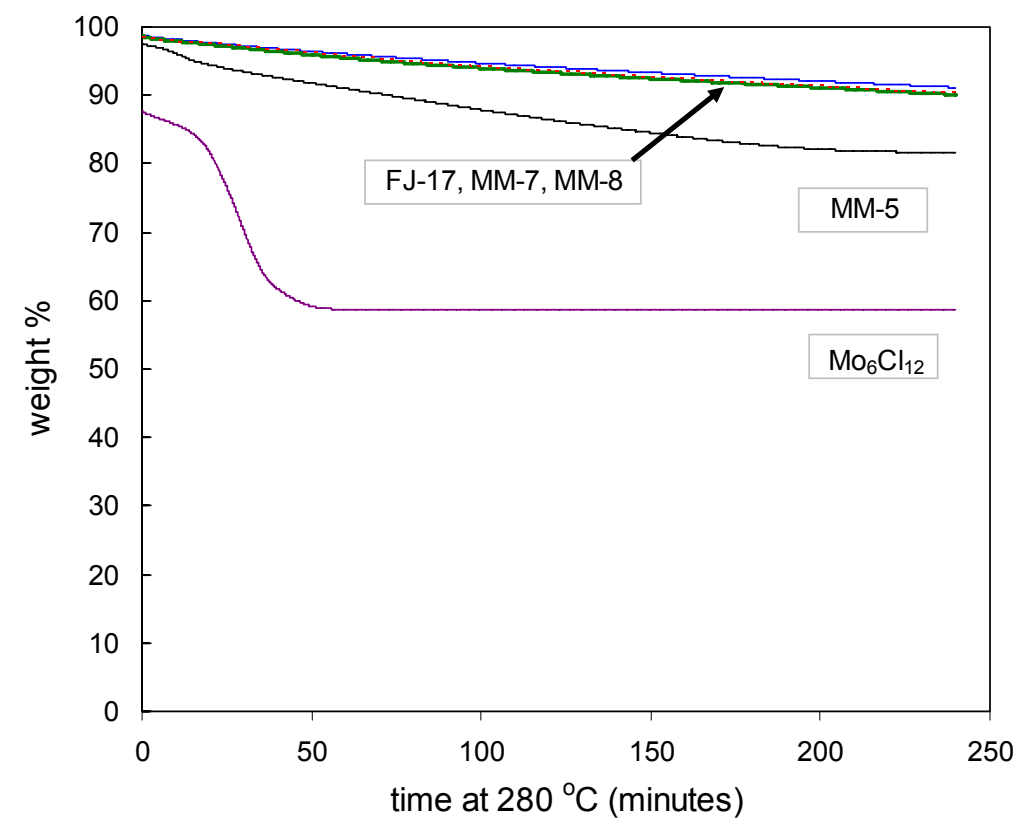

Figure 37. Isothermal aging tests of four preparations of $\mathrm{K}_{2} \mathrm{Mo}_{6} \mathrm{Cl}_{14}$ (FJ-17, MM-5, MM-7, and MM- 8 at $280^{\circ} \mathrm{C}$ in air, showing the consistent thermal profiles of recently prepared batches of $\mathrm{K}_{2} \mathrm{Mo}_{6} \mathrm{Cl}_{14}$ The corresponding data for $\mathrm{Mo}_{6} \mathrm{Cl}_{14} \bullet 2 \mathrm{HCl}$

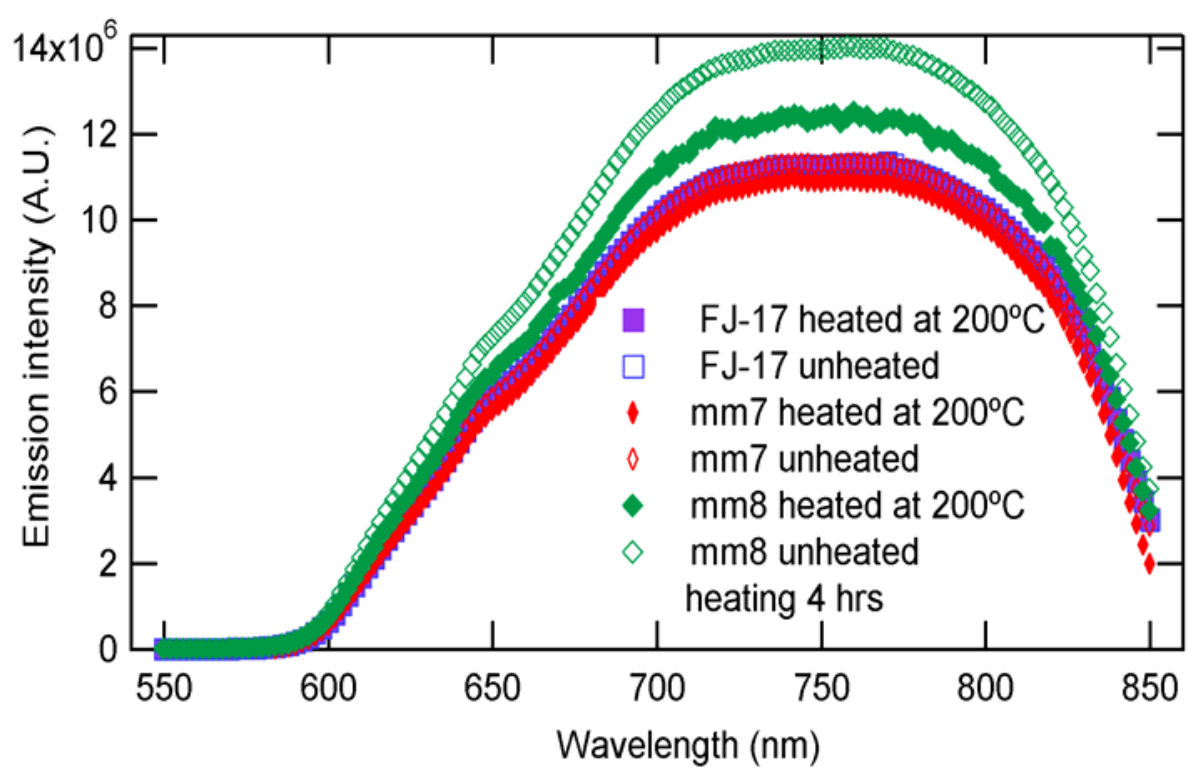

Figure 38. A comparison of the emission spectra from three different preparations of $\mathrm{K}_{2} \mathrm{Mo}_{6} \mathrm{Cl}_{14}, \mathrm{FJ}-17$, MM-7, and MM-8. Data are shown for as-prepared samples, as well as samples that have been heated to $200^{\circ}$ for 4 hours, illustrating that both lineshape and intensity are conserved. Solution concentrations: MM-8: $0.118 \mathrm{mM} \pm 1.4 \%$ and $0.115 \mathrm{mM}$ $\pm 1.4 \%$ after heating; MM-7: $0.0959 \mathrm{mM} \pm 1.4 \%$, and FJ-17: $0.087 \mathrm{mM} \pm 1.4 \%$. Within the error bars of the measurement the emission intensity scales with concentration. 
While the data presented above emphasize the similarity of the three different batches of potassium salt, UV/vis data suggest that there may be a silent impurity present in all three samples. UV/vis spectra were taken of the three salts as solutions in acetonitrile. As shown in Figure 39 the spectra have similar but not identical line shapes. While the low energy side of the absorption envelope $(>350 \mathrm{~nm})$ for all three salts appear to be identical, the spectra of the three salts differ at shorter wavelengths. The data suggest an additional absorbance feature centered at $300 \mathrm{~nm}$ for MM-7 and MM-8. Additional experiments on FJ-17 confirms that this feature is present in all three samples, and its intensity is related to the age of the solution. Since the absorption envelope for $\lambda>350 \mathrm{~nm}$ remains unchanged in intensity and shape as the $300 \mathrm{~nm}$ grows in, we speculate that the increase in absorption at $300 \mathrm{~nm}$ is due to a nanoparticulate impurity that is not removed by filtration during purification of the salts. When dispersed in acetonitrile, the impurity apparently dissolves to give a soluble Mo complex with an absorption peak at $300 \mathrm{~nm}$. Since the luminescence spectra do not show the same effect (Figure 40), the impurity is apparently non-luminescent and does not interfere with the luminescence quenching of $\mathrm{K}_{2} \mathrm{Mo}_{6} \mathrm{Cl}_{14}$.

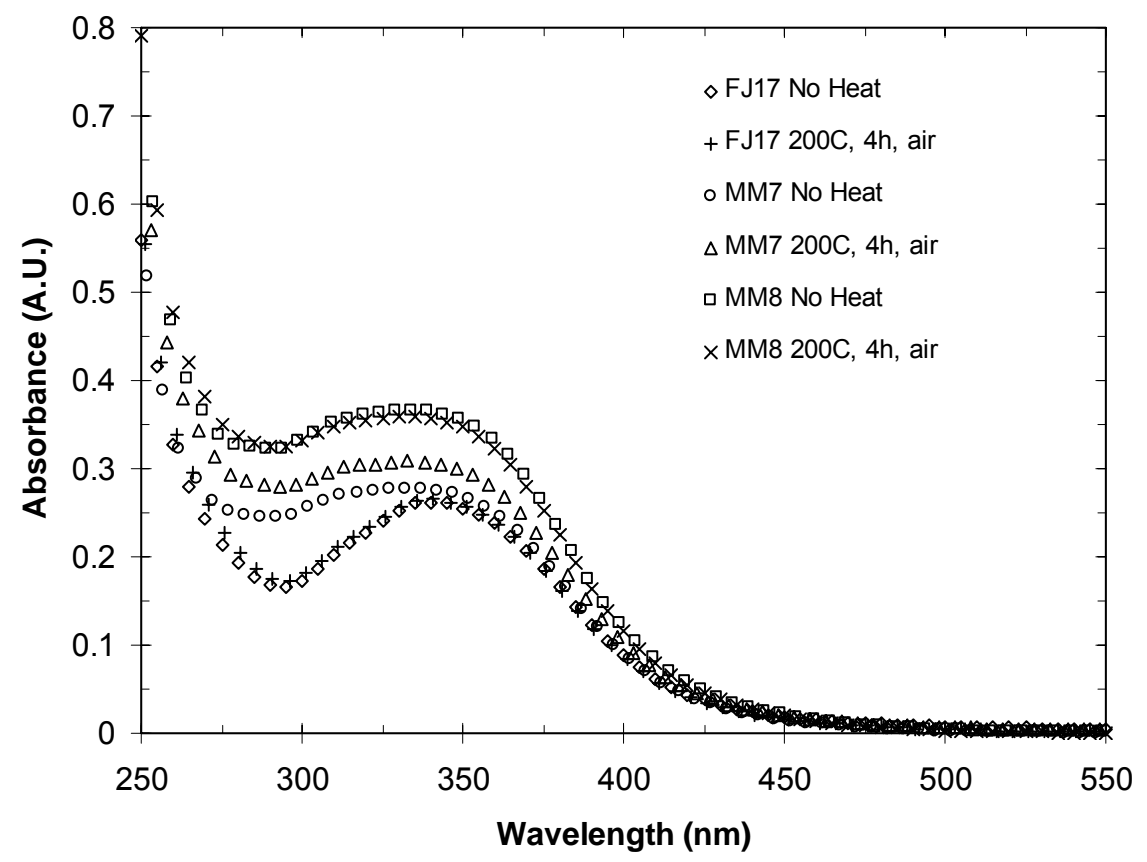

Figure 39: UV/vis spectra from three different preparations of $\mathrm{K}_{2} \mathrm{Mo}_{6} \mathrm{Cl}_{14}, \mathrm{FJ}-17, \mathrm{MM}-7$, and MM-8. Data are shown for as-prepared samples, as well as samples that have been heated to $200{ }^{\circ} \mathrm{C}$ for 4 hours. The intensity of the "excess" absorption centered at $300 \mathrm{~nm}$ correlates with the age of the solutions. Solution concentrations: MM-8: $0.118 \mathrm{mM} \pm 1.4 \%$ and 0.115 $\mathrm{mM} \pm 1.4 \%$ after heating; MM-7: $0.0959 \mathrm{mM} \pm 1.4 \%$, and FJ-17 $0.087 \mathrm{mM} \pm 1.4 \%$. 


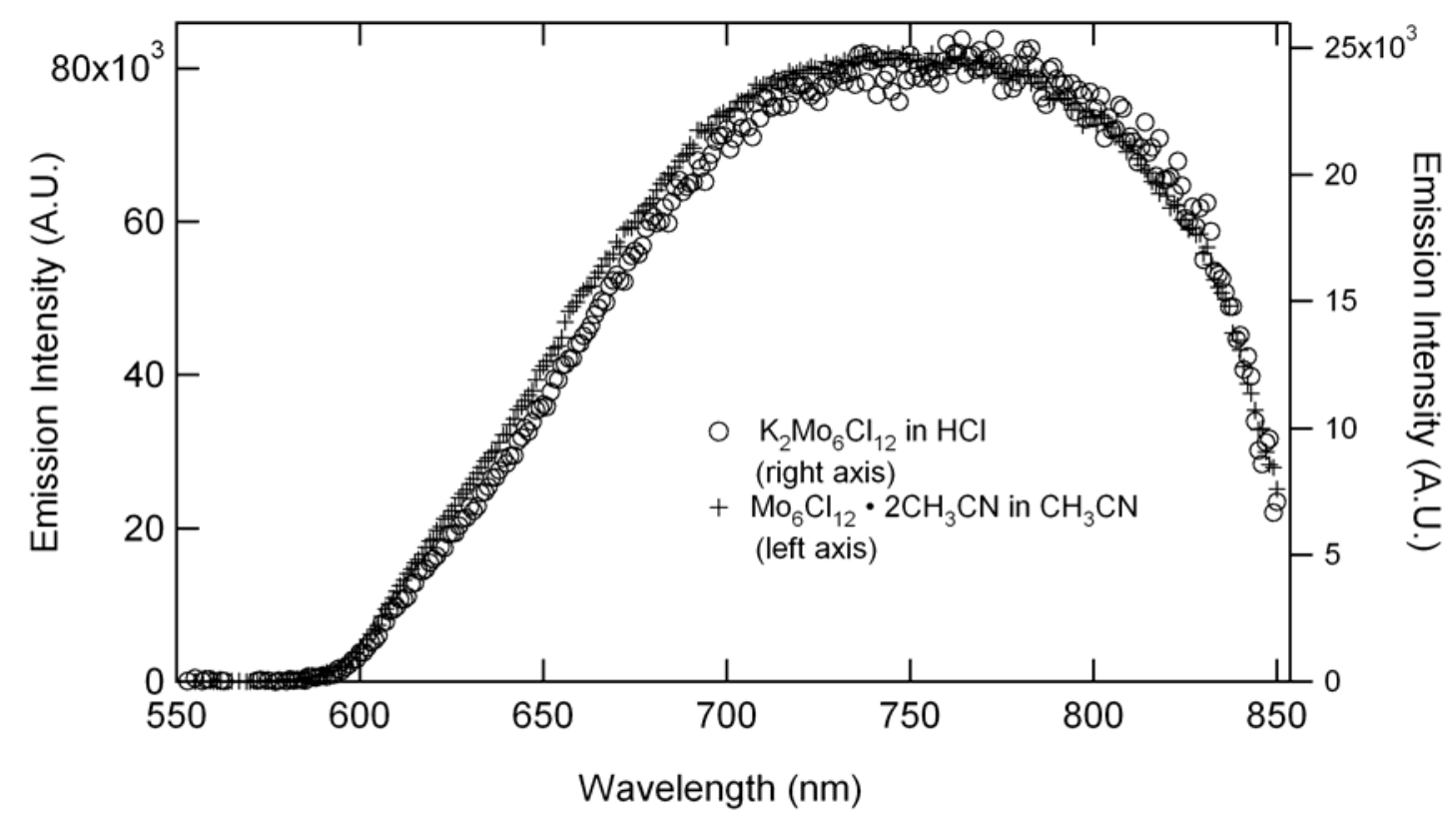

Figure 40: Emission spectra in $99.999 \%$ nitrogen of (i) $\mathrm{K}_{2} \mathrm{Mo}_{6} \mathrm{Cl}_{14}$ and (ii) $\mathrm{Mo}_{6} \mathrm{Cl}_{12}$ $2 \mathrm{CH}_{3} \mathrm{CN}$ in $\mathrm{CH}_{3} \mathrm{CN}$, demonstrating that the cluster photophysics is not affected by ligand substitution. Note that the potassium salt has been heat cycled to $280{ }^{\circ} \mathrm{C}$ for one hour. 


\section{The composite material approach to sensing layers.}

To realize a practical sensor based on $\mathrm{K}_{2} \mathrm{Mo}_{6} \mathrm{Cl}_{14}$, the molybdenum clusters must be immobilized at the end of high-temperature optical fibers using methods that ensure high luminescence intensity from the clusters and strong quenching of the luminescence in the presence of oxygen. Previously we discovered that despite long aging and drying times, films deposited on substrates continued to evolve when they were tested at high temperatures. In general the quenching ratio decreased, which is consistent with densification of the sol-gel matrix. Our hypothesis is that in these materials, the limiting factor in the quenching process is the diffusion of oxygen to the molybdenum clusters, and that the oxygen diffusivity in the heat-treated sol-gel matrices was low. Both the change in the physical parameters of the sol-gel matrix and the low quenching ratio are problems that must be solved in any practical sensor.

We developed a composite material approach that involves embedding molybdenumcontaining sol-gel particles in a binder that essentially glues the particles to the substrate (Figure 41). This approach offers several advantages that overcomes some of the limitations encountered when depositing a homogeneous solution of the cluster in a solgel solution. First, by using a preformed and fully equilibrated cluster containing sol-gel matrix, issues related to the long-term aging of the sol-gel matrix are avoided. Second, the use of small particle sizes should lead to large quenching ratios since in the limit of infinitely small particles the diffusivity of oxygen should be dominated by the permeability of the binder. We expect that the binder will be a minority component of the matrix, filling the void space between the particles, and that curing the binder will lead to little if any change in the volume of the composite. The net result is that the binder should have a low density, high oxygen permeability, and that the composite matrix should have an enhanced quenching ratio compared to sol-gel monoliths. Third, the composite material approach allows us to use the same cluster/sol-gel source for a series of sensors leading to sensors with predictable characteristics.

To that end we selected a monolith previously prepared from a sol-gel solution containing molybdenum clusters (MM5). Figure 42 shows a micrograph of the MM5 containing sol-gel and the particle size achieved by grinding the monolith into a fine powder using a standard mortar and pestle. A freshly prepared sol-gel solution was

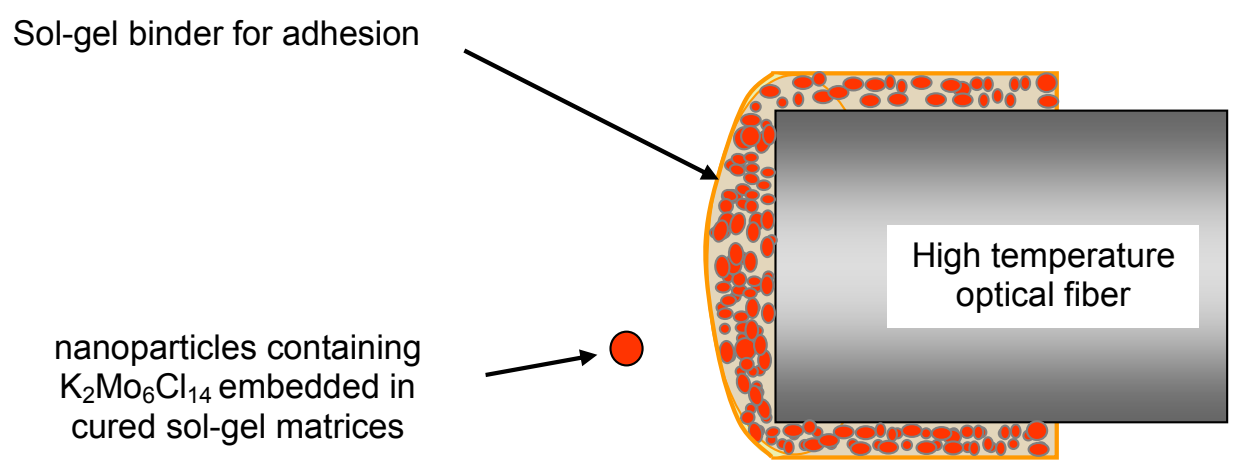

Figure 41. Schematic showing the expected morphology resulting from dip or spray coating a slurry of particles in a sol-gel binder solution. The particles correspond to pre-cured sol-gel particles containing $\mathrm{K}_{2} \mathrm{Mo}_{6} \mathrm{Cl}_{14}$ clusters. 
added to give a paste-like material composed of either 50 or $60 \mathrm{w} / \mathrm{w} \%$ particles and the remainder binder. While the viscosity of the paste proved to be too high for effective spraying, reduction of the particle size seems to be the logical approach for reducing the viscosity since diluting the particles with more sol-gel solution would reduce the net luminescence of the matrix. Coating slides and fibers using a hand-dipping procedure gave films that strongly luminesced.
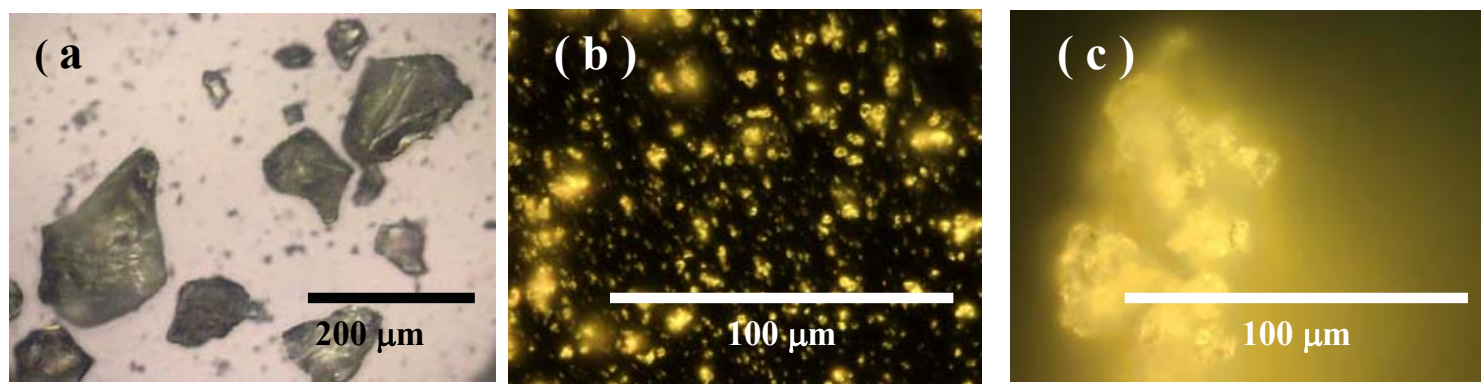

Figure 42. Optical micrographs of sol-gel particles (a) bright field image $(10 \times)$ showing a sol-gel monolith containing MM-5 pulverized using a mortar and pestle, 25 - $250 \mu \mathrm{m}$ particle size, (b) a sol-gel monolith (no clusters), $1-2 \mu \mathrm{m}$ particle size, and (c) dark field image $(100 \times)$ showing a sol-gel monolith containing MM-5 pulverized via ball milling, $2-8 \mu \mathrm{m}$ particle size.

A closer examination of films deposited on fibers (Figure 43) shows that the particle sizes are relatively large, between 25 and $150 \mu \mathrm{m}$ for fibers $\mathbf{C}, \mathbf{D}$, and $\mathbf{E}$. As noted above, smaller particles are desired to achieve better quenching ratios and more uniform deposition. Using a ball milling technique reduced the particles to $\sim 5 \mu \mathrm{m}$ with a significantly tighter size distribution 1-8 $\mu \mathrm{m}$ (see Figures 44b and 44c). The films prepared from these materials are more uniform and smooth, (fiber H (Figure 43). Using a monolith with the same room temperature aging time ( 7 months), cluster source (FJ17), and cluster density $\left(1 \times 10^{-18}\right.$ cluster/ $\left.\mathrm{cm}^{3}\right)$, we used the ball milling technique to prepare particles of roughly the same size (wlb34g-o, $1-8 \mu \mathrm{m}$, Figure 44). 
Clean Uncoated

Fiber

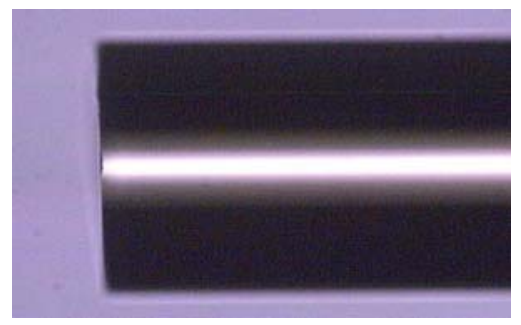

Fiber D - 60 w/w\%

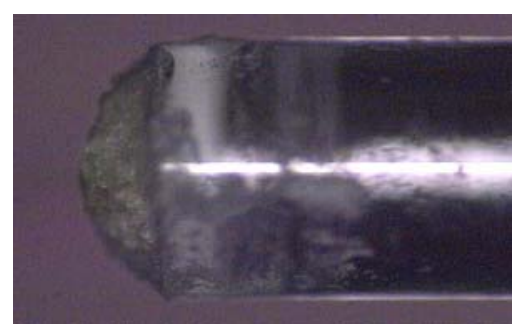

Fiber E - $\mathbf{5 0}$ w/w\%

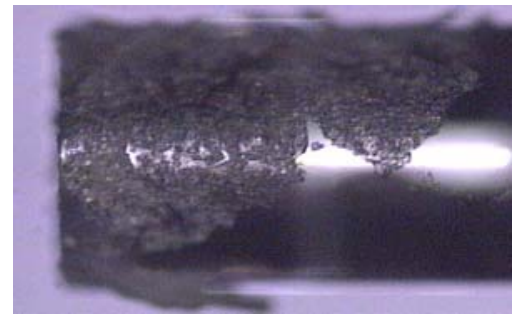

Fiber C - 60 w/w\%

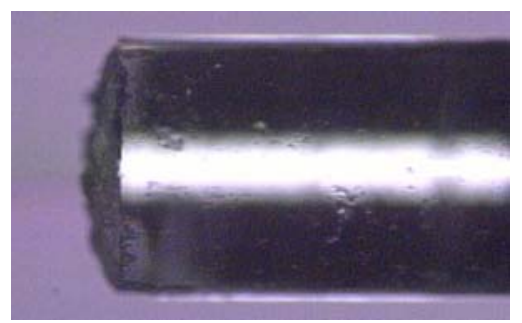

Fiber D - 60 w/w\%

after testing

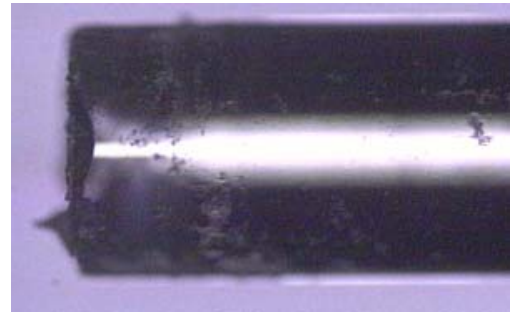

Fiber $\mathrm{H}-60 \mathrm{w} / \mathrm{w} \%$

Wig-L-Bug

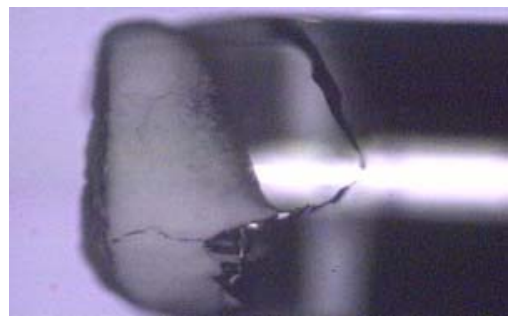

Figure 43. Typical dip coating results for deposition of composite / sol-gel binder blends $1000 \mu \mathrm{m}$ diameter fibers.
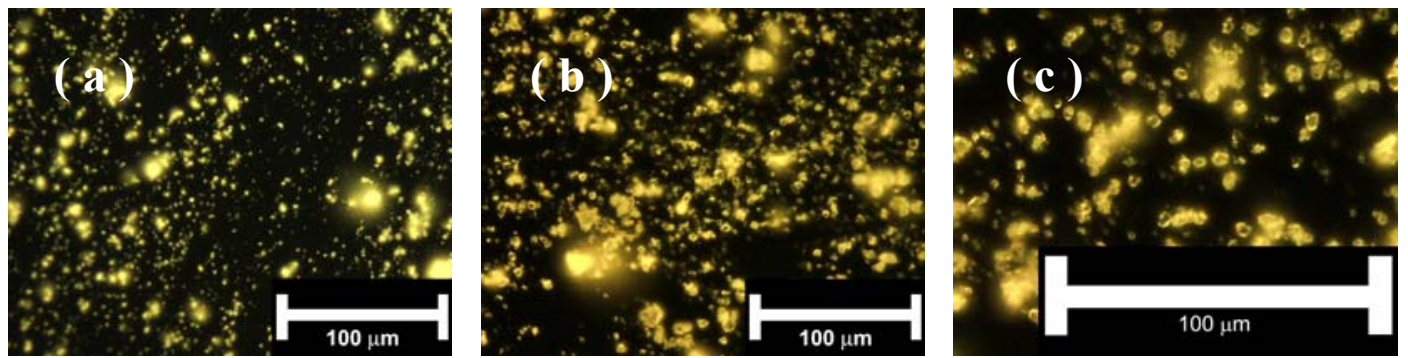

Figure 44. Dark field optical micrographs of $1-8 \mu \mathrm{m}$ sol-gel particles (cluster source FJ17) prepared by ball milling (a) previously prepared wlb29 (50×), (b) wlb34g-o, $(50 \times)$ and (c) wlb34g-o, dark field $(100 \times)$. 
The materials we generated by this approach are promising in that the quenching ratios for some fibers coated with a composite material were $>5 \times$. In addition the optical fibers have more stable properties using the particle in binder approach. One problem was not solved by this approach; the adhesion of the composite material to the tip of the fiber was poor, and the fibers that were produced by this method are probably too fragile for most applications. There was a common failure mode for these fibers, after thermal cycling the composite was completely dislodged from the fiber tip. Close analysis of the fibers after failure suggests that in many cases there was a thin sol-gel layer still adhering to the surface. We believe that the failure stems from the shrinkage of the sol-gel binder that leads to a large stress at the interface and eventually catastrophic failure.

The obvious solution to this problem is to remove the source of stress and/or strengthen the mechanical properties of the binder itself. We investigated two approaches. In the first we altered the chemistry used in the sol-gel binder to reduce binder shrinkage during curing. Minimizing shrinkage should improve adhesion by reducing the stress at the interface between the composite and the fiber. In the second, we took a somewhat unusual approach and briefly investigated the possibility of using commercial adhesives to glue the sol-gel particles to the fiber surface. If successful, this would simplify sensor fabrication since most glues cure rapidly.

We elected to use a commercial cyanoacrylate adhesive (super glue) to test the notion that the sol-gel particles could be glued directly to the end of the fiber. This process simply requires coating the tip of the optical fiber with glue and then depositing the solgel particles containing the molybdenum complex onto the surface of the fiber. Curing is completed in minutes. The resulting fibers are quite interesting and not surprisingly, there is excellent adhesion of the glue and particles to the surface of the fiber. As shown in Figure 45, the particles appear to cover the surface although the uniformity of the coating is poor, partly due to the use of large particles.

The uniformity of the coating seems inferior to the control sample shown in the top panel. The luminescence intensities from these fibers in nitrogen and oxygen yield high quenching ratios that approach those of solutions. However, there are two significant

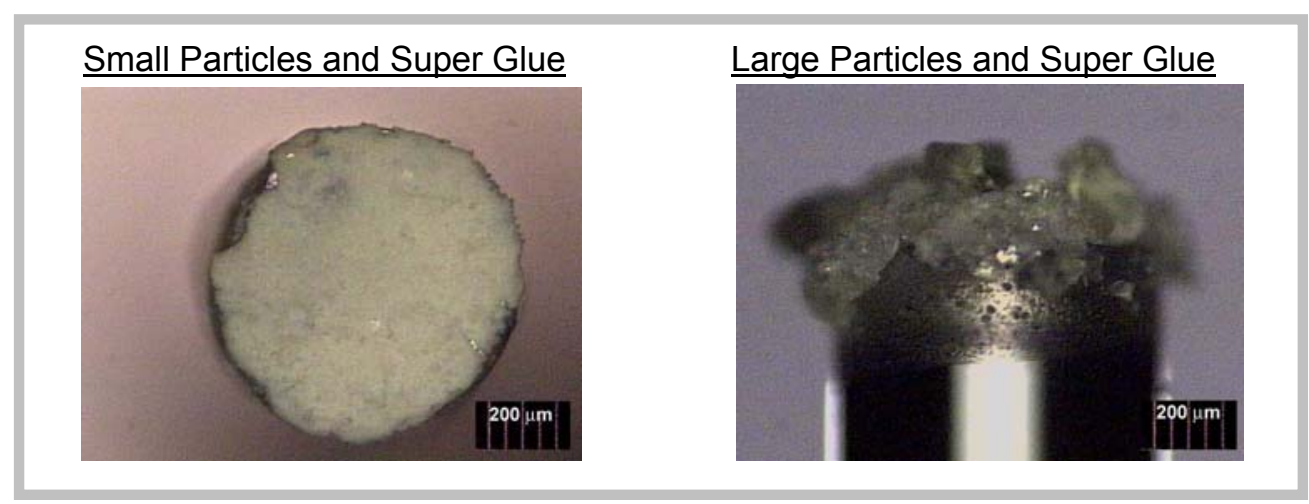

Figure 45. Images showing the range of results using super glue as a binder. Large particles are $25-250 \mu \mathrm{m}$ and small particles are 1-8 $\mu \mathrm{m}$. 
problems with this approach. The first is that the fiber-particle interface is a thin layer of glue, and particle-particle adhesion is poor. Not surprisingly, the composite material at the tip of the fiber was easily abraded from the surface. Using more glue resulted in a high luminescence intensity and quenching ratio, but the luminescence from the composite degraded over time, suggesting a deleterious chemical interaction between the glue and the clusters. The latter result prompted us to reconsider sol-gel binders.

We found that a reliable way to increase the adhesion of the composite to the fiber tip is to use a sol-gel binder that undergoes minimal shrinkage as it cures. Such materials can be prepared by replacing a portion of the TEOS in the sol-gel recipe with alkyltriethoxysilanes such as octyltrimethoxysilane (OtMOS). Reducing the number of functional groups from four to three plus the addition of the alkyl group directly bonded to silicon reduces the cross-link density in the resulting sol-gel matrix and decreases the shrinkage that occurs during curing. Cleaned fibers were coated with a mixture of sol-gel particles and the new binder formulation with ethanol as the co-solvent, cured, and then evaluated by microscopy and by luminescence measurements. These fibers (Figure 46) showed improved uniformity, and their adhesion to the tip of the fiber also was improved. Figure 47 shows further examples of this modified approach, contrasting the use of acetonitrile and ethanol as co-solvents. All of the samples used finely powdered sol-gel particles and all show excellent coating and adhesion to the fiber surface.

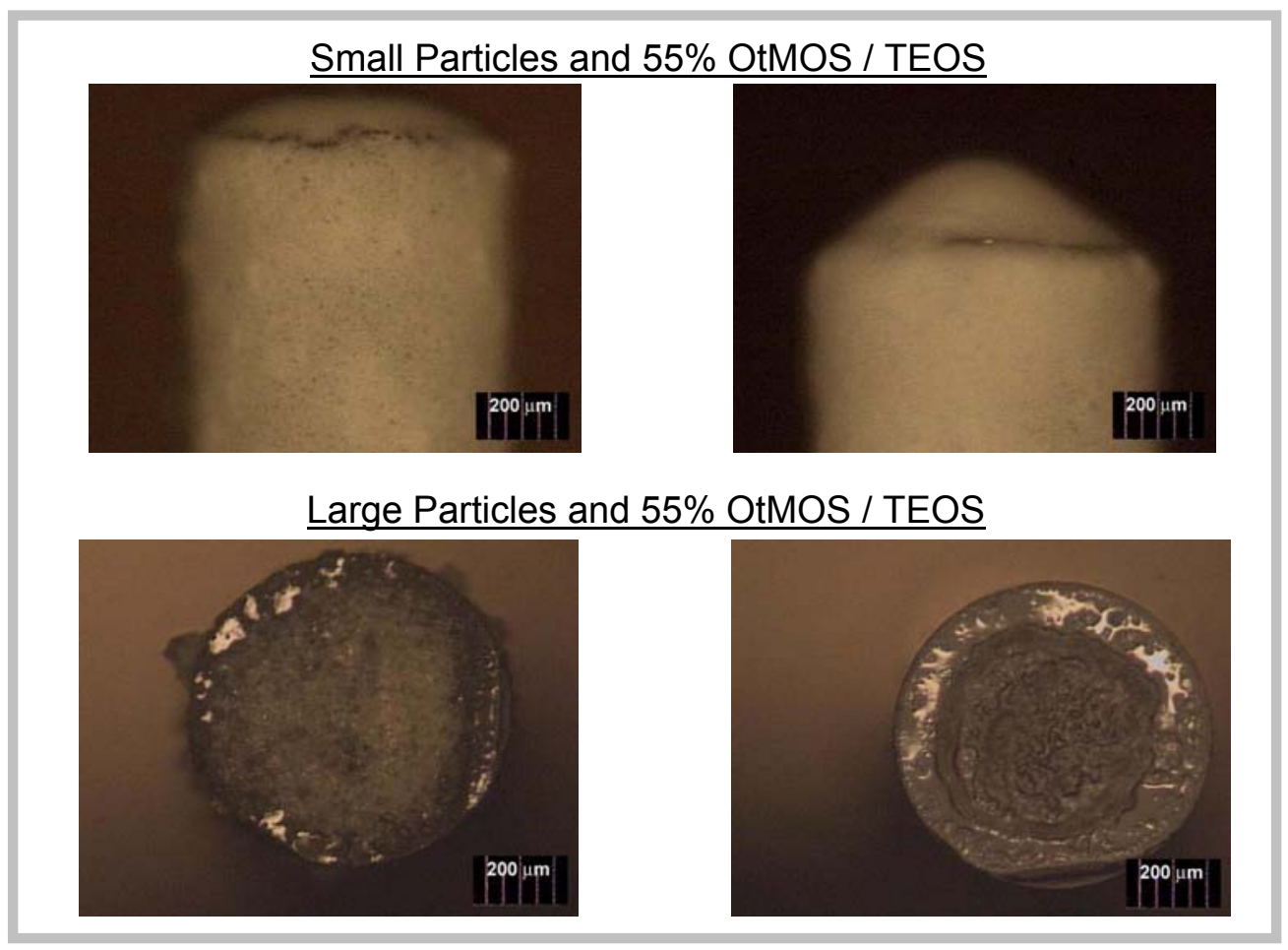

Figure 46. . Images showing the range of results obtained from coating with different binders and particle sizes. Large particles are 25-250 $\mu \mathrm{m}$ and small particles are 1-8 $\mu \mathrm{m}$. 


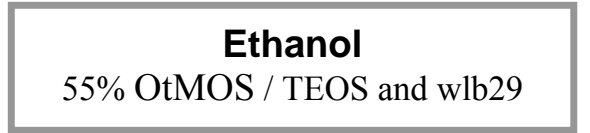

1 hour

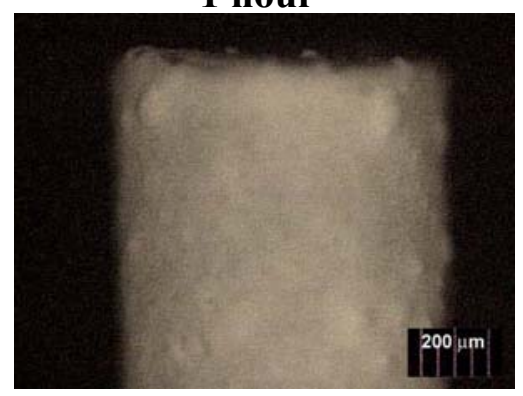

Fiber 45 - 5 days

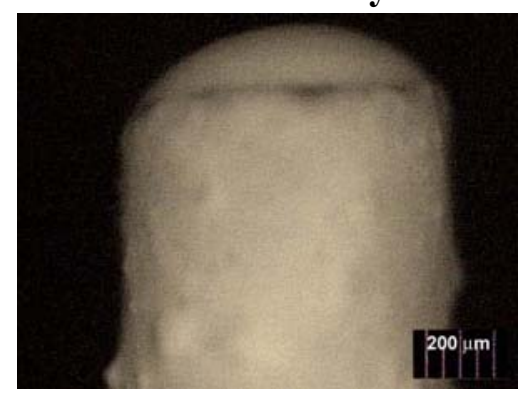

12 davs

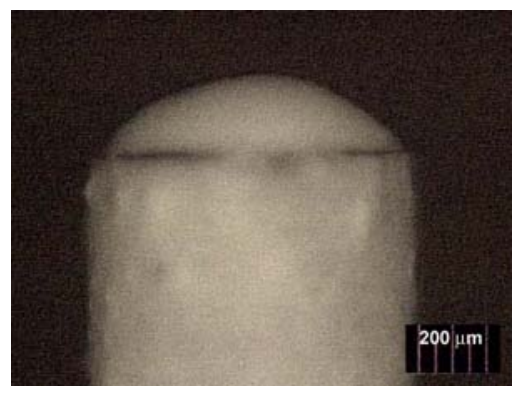

21 days

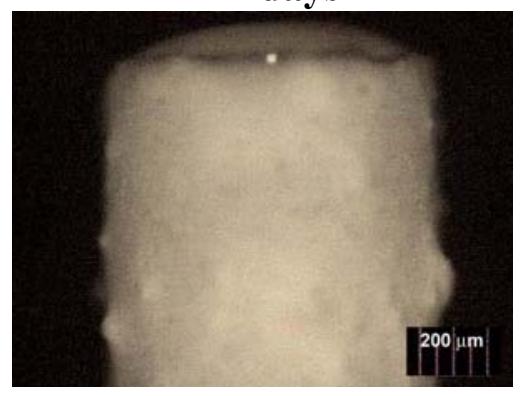

Acetonitrile

55\% OtMOS / TEOS and wlb29

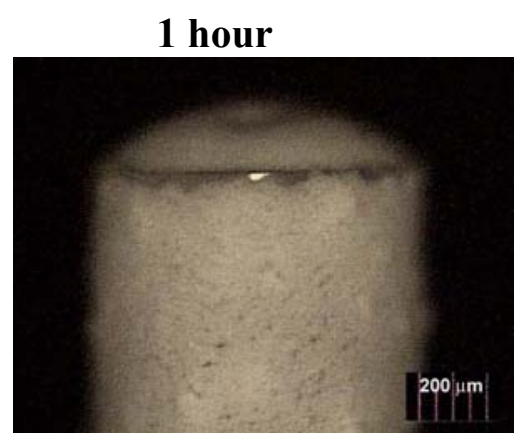

5 days

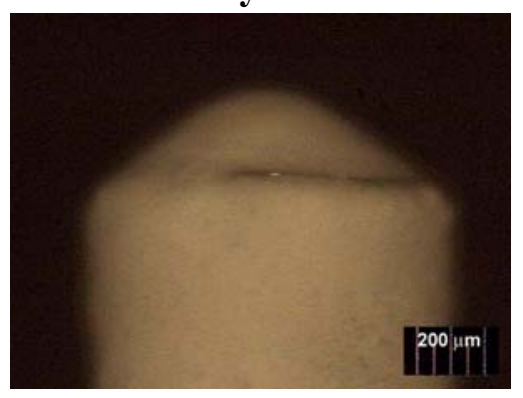

12 davs

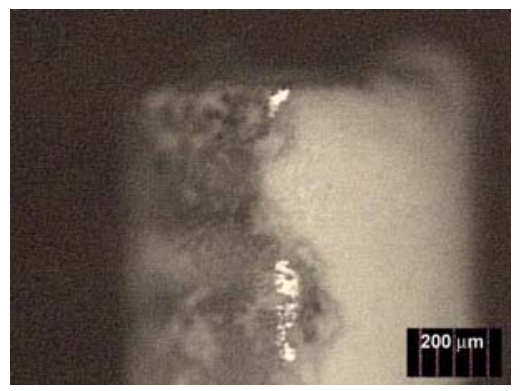

21 days

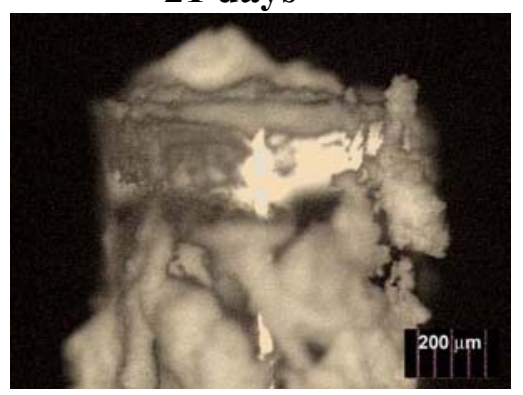

Figure 47. Images showing the range of film properties and adhesion obtained by varying the sol-gel aging time and co-solvent. The binder composition is $55 \%$ OtMOS / TEOS and the diameter of the particles are 1-8 $\mu \mathrm{m}$ for all samples shown. 
Given the success of the $55 \mathrm{~mol} \%$ OtMOS/TEOS binder solution, we briefly investigated two alternative binders. A recent literature report describes quenching ratios of $\sim 14$ and linear Stern-Volmer calibration plots for organic lumophores immobilized in matrices prepared from octyltriethoxysilane (OtEOS) in TEOS. ${ }^{[21]}$ Another recent publication reports quenching ratios of $\sim 35$ and linear Stern-Volmer calibration plots from a 67 mol\% (3,3,3-triflouropropyl)trimethoxysilane (TFP-tMOS) in propyltrimethoxysilane (PtMOS) sol-gel system. ${ }^{[22]}$ The fluorinated sol-gel system may prove interesting in aqueous dissolved oxygen sensing. Figure 48 shows examples of these two sol-gel systems as applied to potassium cluster lumophores. All samples used finely powdered sol-gel particles and all show excellent coating and adhesion to the fiber surface.

$50 \%$ OtEOS/TEOS

(acetonitrile)

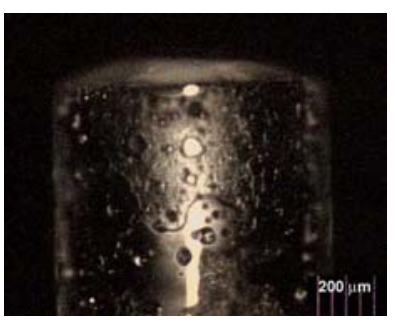

67\% TFP-tMOS / PtMOS (acetonitrile)

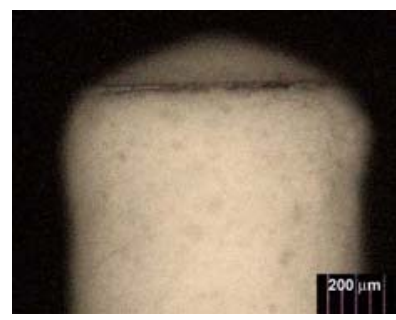

$50 \%$ OtEOS/TEOS

(ethanol)

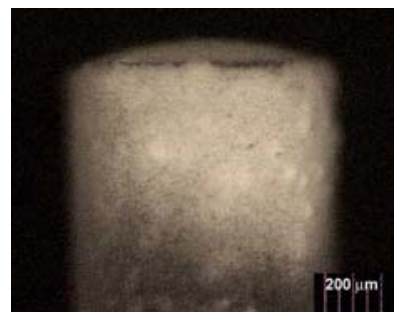

67\% TFP-tMOS / PtMOS (ethanol)

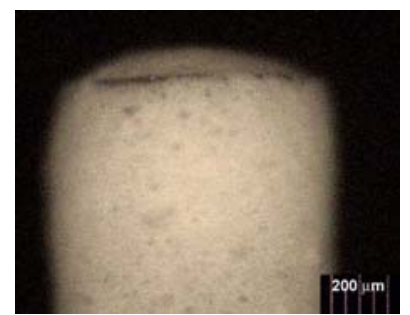

Figure 48. Typical results for fibers coated with $53 \mathrm{w} / \mathrm{w} \%$ particles in a) $55 \mathrm{~mol} \%$ OtMOS/TEOS, b) $50 \mathrm{~mol} \%$ OtEOS/TEOS, and c) $67 \mathrm{~mol} \%$ TFP-tMOS/PtMOS. 


\section{Multifiber Dip-coating of Fiber Sensors}

We moved from single fiber dipping to dip-coating a 5-fiber array to minimize fiber-tofiber variation. In principle, this process can be scaled to allow simultaneous coating of a large number of fibers. Tape was used to assemble a flat bundle of five fibers with the fiber tips separated by $1 \mathrm{~mm}$. The bundle of five fibers was dipped by hand into binder/particle mixtures, being careful to maintain the gap between the fiber tips and dried under ambient conditions for one hour to promote uniform coating of the fiber tips. Typical results from the simultaneous dipping of five fibers are shown in Figure 49. Access to fibers with similar properties enables parallel testing of fibers under a broad range of conditions. Different cluster/sol-gel monoliths were tested to optimize sensor performance and adhesion for each case. The smaller particles obtained using a small ball mill gave better adhesion and sensor performance.

The fibers were weighed, imaged, and then attached to the pendulum via a piece of sewing thread. Fibers images from representative ballistic pendulum tests are shown in Figure 50 and details of the experiments and results are shown in Table 2. The fibers survive these tests surprisingly well. Films that appear to be cracked prior to testing generally survive, when the angle of travel reached $90^{\circ}$. These flaws may be surface features that do not affect adhesion at the fiber-composite interface.
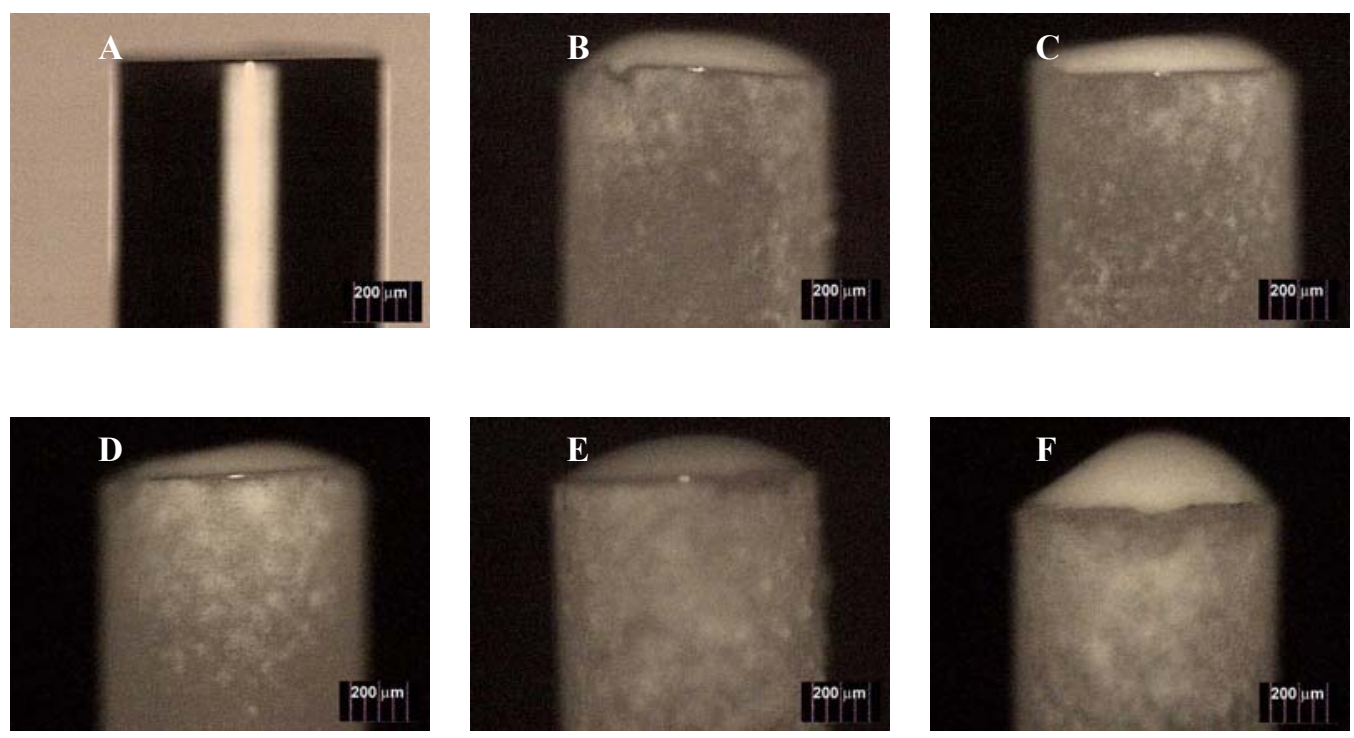

Figure 49. Typical results for simultaneous dip-coating $51000 \mu \mathrm{m}$ diameter fibers with particle / sol-gel binder blends. Image A shows an uncoated fiber for reference. Images B - D are fibers were coated with a mixture of $53 \mathrm{w} / \mathrm{w} \%$ wlb29 powder in 55 mol\% OtMOS/TEOS binder. 
Before Mechanical Testing
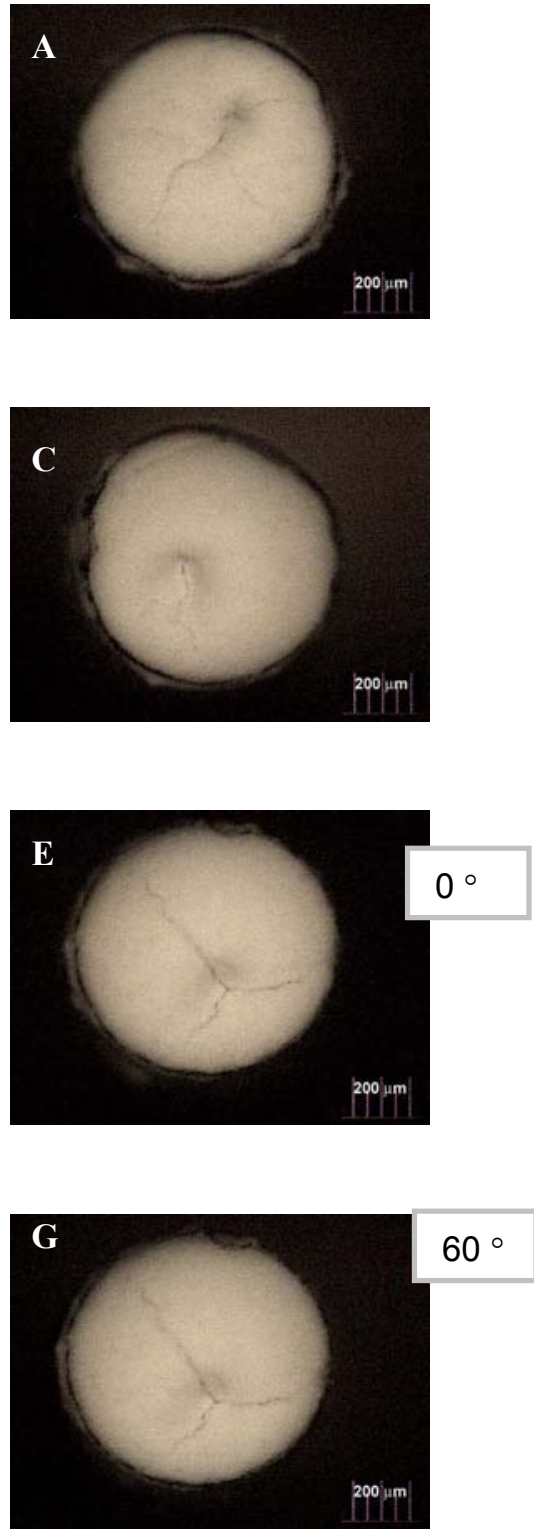

After Mechanical Testing
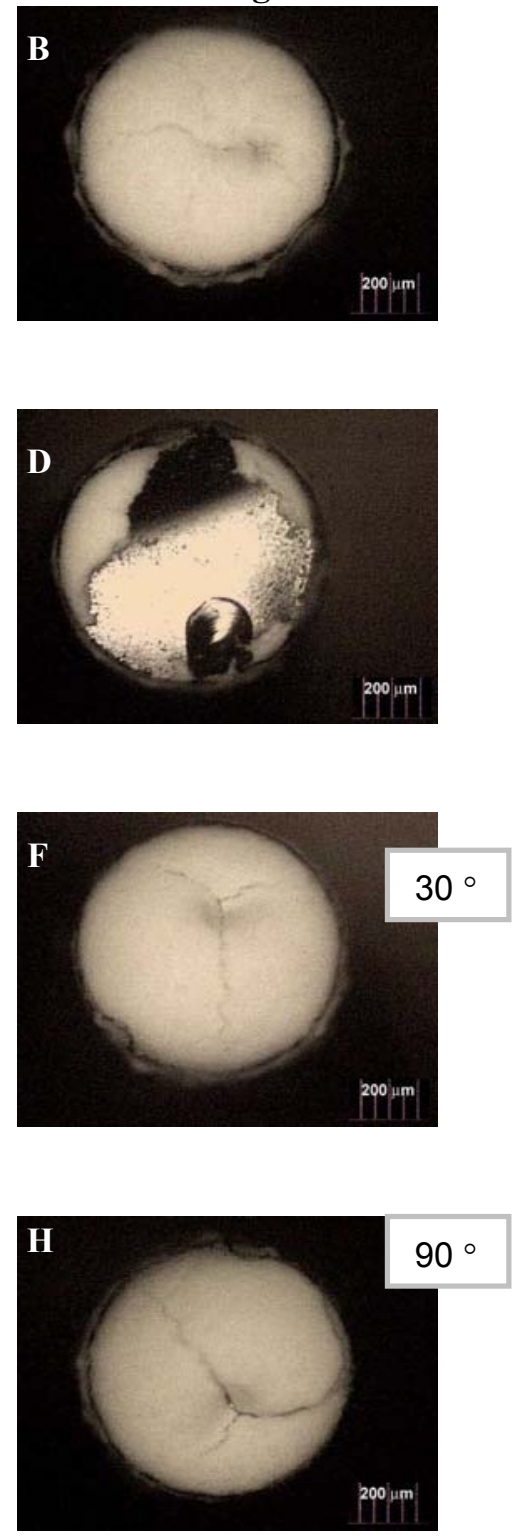

Figure 50. Images of fibers coated with $53 \mathrm{w} / \mathrm{w} \%$ wlb29 powder in $55 \mathrm{~mol} \%$ OtMOS/TEOS binder before and after mechanical testing. A and B are the before and after images of a fiber tested at $30^{\circ}$; $\mathrm{C}$ and $\mathrm{D}$ are the before and after images from a second fiber tested at $90^{\circ}$. Images $\mathrm{E}-\mathrm{H}$ are from a single fiber. Image $\mathrm{E}$ shows the fiber before testing, and $\mathrm{F}, \mathrm{G}$, and $\mathrm{H}$ show results after impacting from $30^{\circ}, 60^{\circ}$ and $90^{\circ}$, respectively. 


\begin{tabular}{|c|c|c|c|c|c|c|c|}
\hline \multicolumn{7}{|c|}{ Table 2. Mechanical Testing Results } \\
\hline Fiber & $\begin{array}{c}\text { Binder Used } \\
\text { (Aged 5 days) }\end{array}$ & $\begin{array}{c}\text { Powder } \\
\text { Used }\end{array}$ & $\begin{array}{c}\text { Cure } \\
\text { Parameters } \\
\left({ }^{\circ} \mathrm{C} \text {, hours) }\right.\end{array}$ & $\begin{array}{c}\text { String, Tape, } \\
\text { and Fiber } \\
\text { Mass } \\
\text { (grams) }\end{array}$ & $\begin{array}{c}\text { Distance to } \\
\text { Impact Point } \\
\text { (meters) }\end{array}$ & $\begin{array}{c}\text { Angle } \\
\text { (degrees) }\end{array}$ & $\begin{array}{c}\text { Impact } \\
\text { Force } \\
(\mathrm{N} \cdot \mathrm{s})\end{array}$ \\
\hline A/B & $\begin{array}{c}\text { OtMOS/TEOS } \\
\text { (ethanol) }\end{array}$ & $\begin{array}{c}53.4 \% \\
\text { wlb34g-o }\end{array}$ & $70,16.5$ & 0.2396 & 0.225 & 90 & 0.62 \\
\hline C/D & $\begin{array}{c}55 \% \\
\text { OtMOS/TEOS } \\
\text { (ethanol) }\end{array}$ & $\begin{array}{c}53.4 \% \\
\text { wlb34g-0 }\end{array}$ & $70,16.5$ & 0.2383 & 0.263 & 30 & 0.24 \\
\hline E-H & $\begin{array}{c}55 \% \\
\text { OtMOS/TEOS } \\
(\text { ethanol) }\end{array}$ & $\begin{array}{c}53.4 \% \\
\text { wlb34g-o }\end{array}$ & $70,16.5$ & 0.2330 & 0.263 & $30-90$ & 0.65 \\
\hline
\end{tabular}




\section{High temperature survivability of $\mathrm{K}_{2} \mathrm{Mo}_{6} \mathrm{Cl}_{14} /$ sol-gel films.}

We measured the optical properties of sol-gel films embedded with $\mathrm{K}_{2} \mathrm{Mo}_{6} \mathrm{Cl}_{14}$ after they were subjected to heating protocols where both temperature and time were varied. We used the measured luminescence intensity of the film in nitrogen and its quenching in air as an indication of the high temperature survivability of each film.

The emission spectra in nitrogen of film 29L and an acetonitrile solution of the potassium salt (FJ-17) used in the preparation of the film are shown in Figure 51. Film 29L was dip coated three times using a 9-day old Mo-cluster/sol-gel solution, dried for 21 days under ambient conditions, and then cured for 24 hours at $70^{\circ} \mathrm{C}$. The film was then aged in air at room temperature for 3 months. Using a variety of time and temperature combinations, film 29L was annealed at $200^{\circ} \mathrm{C}$ for a total of 54 hours, with the emission spectra measured after each heating step. After subtracting the Raman scattering due to the solgel matrix we found that the line-shape had not changed, confirming that sol-gel immobilization and thermal cycling did not adversely affect the emission of the potassium salt (FJ-17).

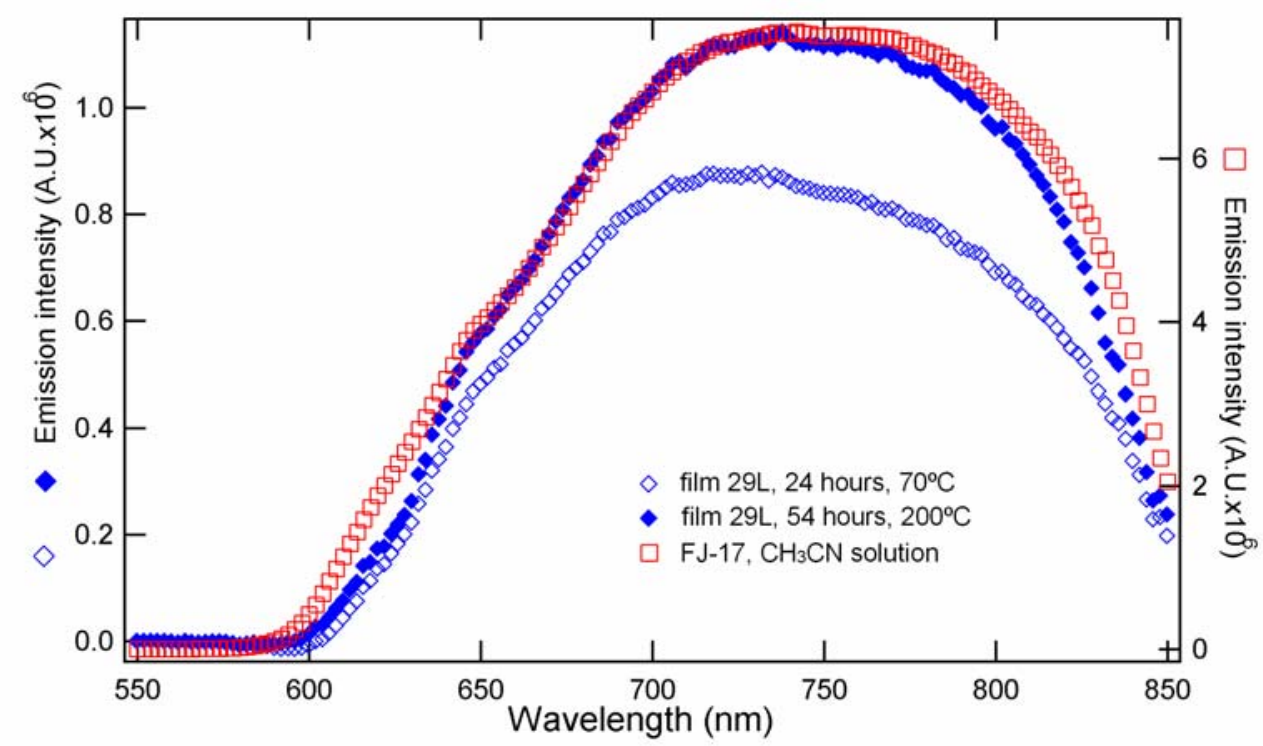

Figure 51. Room temperature emission spectra sol-gel film $29 \mathrm{~L}(\diamond) 1$ day curing at $70^{\circ} \mathrm{C},(\bullet)$ 54 hours of thermal cycling between $200{ }^{\circ} \mathrm{C}$, and the spectrum of its originating potassium salt FJ-17 ( $\square$ ) in $\mathrm{CH}_{3} \mathrm{CN}$. All spectra were measured and in $99.999 \%$ nitrogen. The film concentration is $3.6 \pm 1.6 \times 10^{21}$ cluster $/ \mathrm{cm}^{3}$ based on an estimated film thickness of $700 \pm 300$ $\mathrm{nm}$. The solution concentration is $0.087 \mathrm{mM} \pm 1.4 \%$.

Shown in Figure 52 is the emission intensity of 29L measured in nitrogen after each thermal cycle at $200{ }^{\circ} \mathrm{C}$. The data have been corrected for variations in the lamp intensity. Note that the luminescence intensity is nearly constant over the entire time interval, demonstrating the long-term stability of the cluster photophysics, even after extended aging at $200^{\circ} \mathrm{C}$. However, we observed that the oxygen quenching ratio, 
defined as the ratio of the luminescence intensity in $99.999 \% \mathrm{~N}_{2}$ to that in $21 \% \mathrm{O}_{2}$, decreased to 1.2 at the conclusion of the tests.

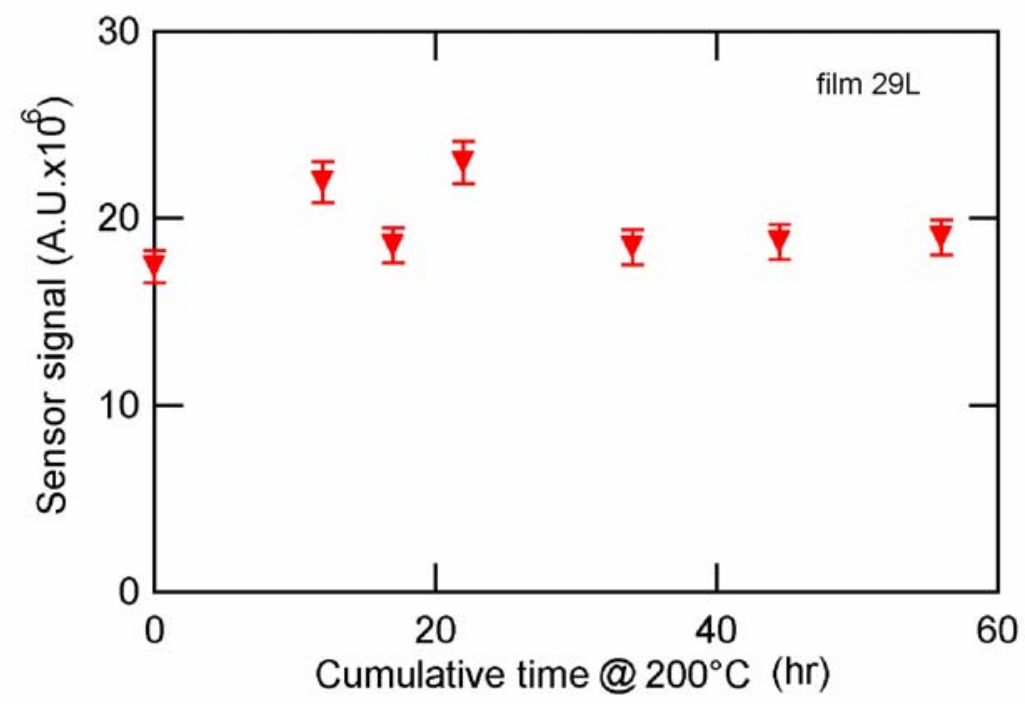

Figure 52. Integrated emission intensity $(550-850 \mathrm{~nm})$ from sol-gel film 29L at room temperature, after heating at $200^{\circ} \mathrm{C}$ for the indicated time interval. See Figure 10 for cluster information. 


\section{In-situ emission spectroscopy up to $200{ }^{\circ} \mathrm{C}$}

In this section we show in-situ measurements of potassium-salt/sol-gel films up to $200{ }^{\circ} \mathrm{C}$ from Slide 38QThe film was fabricated by the composite material approach, using aspray coating procedure and then heated for 30 minutes at $200{ }^{\circ} \mathrm{C}$. Optical measurements of $38 \mathrm{Q}$ were taken 60 days after curing in air at room temperature.

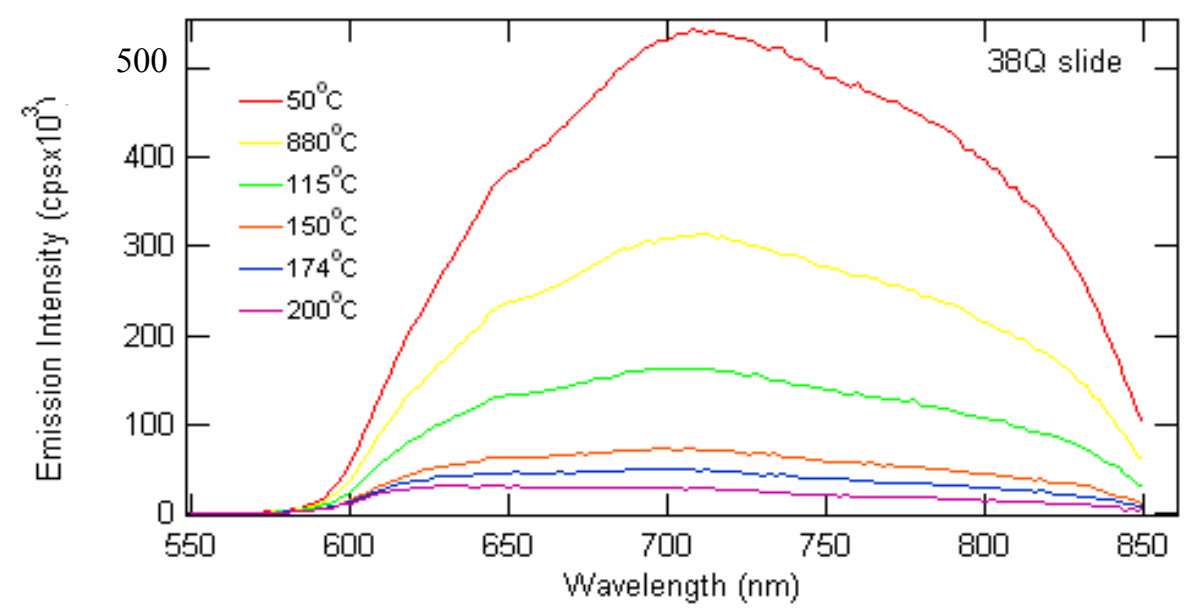

Figure 53. Thermal dependence of the emission spectra for film $38 \mathrm{Q}$ cured at $200^{\circ} \mathrm{C}$ for 30 minutes. The emission intensity is a function of temperature, but the line-shape is temperature independent. All spectra were sampled in $99.999 \%$ nitrogen environments. The cluster source was MM8 and the film concentration is $(5 \pm 1.1) \times 10^{20}$ clusters $/ \mathrm{cm}^{3}$ based on an estimated film thickness of $(700 \pm 300) \mathrm{nm}$.

In-situ measurements of the emission spectra of film 38Q, prepared from potassium salt MM8, from 50 to $200{ }^{\circ} \mathrm{C}$ are shown in Figure 53. These were our first measurements free of fluorescence from the heating structure itself. The backside of the quartz substrate was heated locally in only the area of the pump beam $(2 \times 10 \mathrm{~mm})$ using a Si substrate / Pt heater sandwich. The "sandwich" structure is held in intimate contact with the quartz substrate without the use of any adhesives in the region to be probed to circumvent problems due to fluorescence from the Ag paint and the Pt heater itself. The high thermal conductivity of $\mathrm{Si}$ allows for uniform and rapid heating of the area of interest. We measured the emission spectra at different temperatures. After subtracting the contribution of Raman scattering from the sol-gel matrix, only minor changes in the lineshape were observed confirming that sol-gel immobilization and thermal cycling did not adversely affect the emission from the potassium salt (MM8).

Shown in Figure 54 are time dependent measurements (time base acquisition or TBA, Fluorolog-3) of the emission intensity at $674 \mathrm{~nm}$ while alternating between $99.999 \%$ nitrogen and $20.7 \%$ oxygen. The data indicate fast oxygen quenching as each point represents a 0.5 second time interval. The luminescence intensity decreases with temperature, but the quenching ratio defined as the ratio of the luminescence in $99.999 \%$ $\mathrm{N}_{2}$ versus to that in $20.7 \% \mathrm{O}_{2}$ remains approximately constant but low (1.3) at $200{ }^{\circ} \mathrm{C}$. 


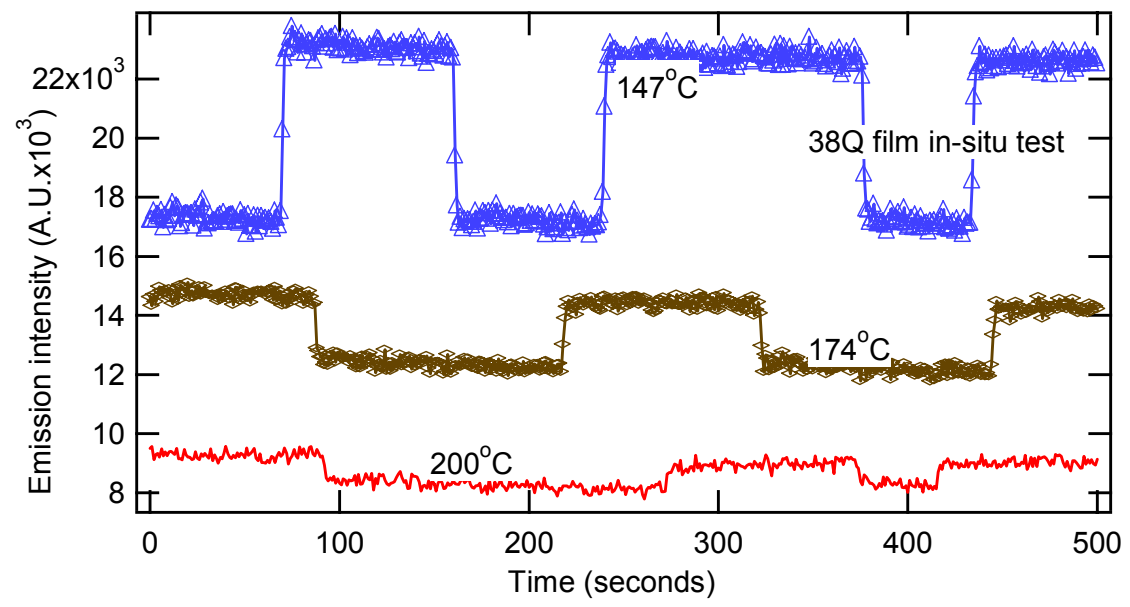

Figure 54. Time dependent quenching measurements at $674 \mathrm{~nm}$ of sol-gel film 38Q alternating between a $99.999 \% \mathrm{~N}_{2}$ and $20.7 \% \mathrm{O}_{2}$ gas environment at $147^{\circ} \mathrm{C}$, $174{ }^{\circ} \mathrm{C}$ and $200{ }^{\circ} \mathrm{C}$. The response time of the film is fast, $\leq 1$ second. The film was pumped at $313 \mathrm{~nm}$.

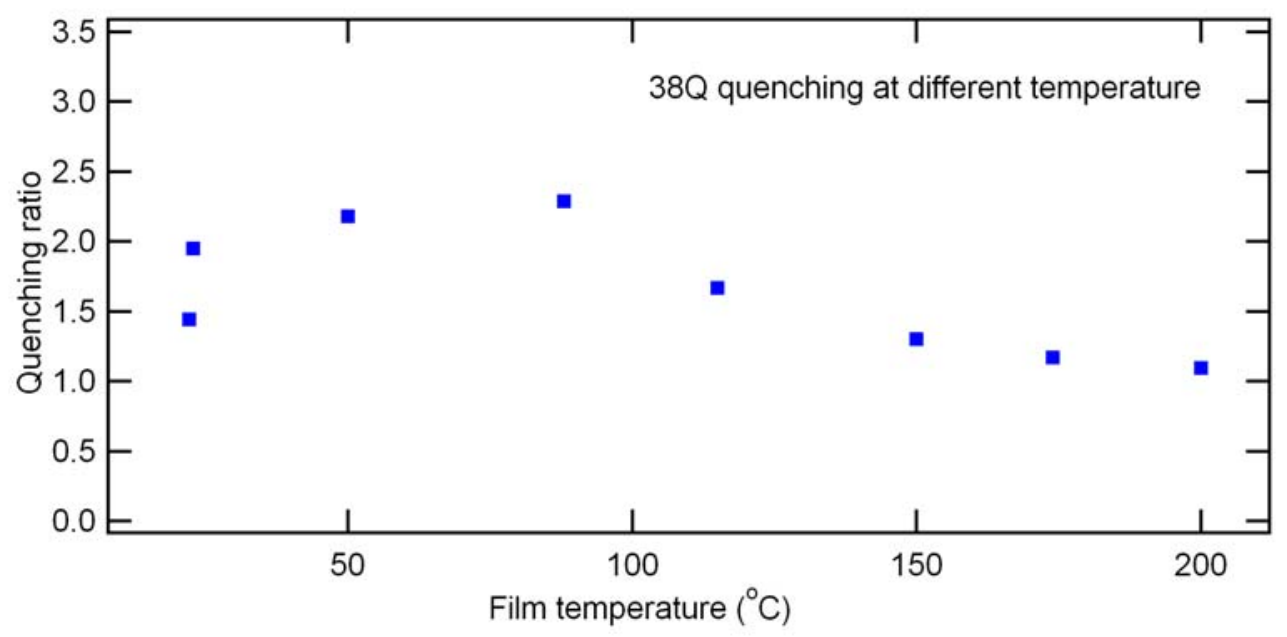

Figure 55. Quenching ratio as a function of film temperature for sol-gel film $38 \mathrm{Q}$ derived from the time dependent measurements of Figure 15. The quenching ratios are relatively independent of temperature, but the magnitude itself is small.

The oxygen quenching ratio over the entire operational temperature range is shown in Figure 55. The initial quenching ratio at room temperature is approximately $1.5 \times$, increasing $\sim 2.3 \times$ at $100{ }^{\circ} \mathrm{C}$. In addition to these measurements, we monitored the oxygen quenching ratio following thermal cycling up to $200{ }^{\circ} \mathrm{C}$, (see Figure 56), to determine the stability of the optical characteristics of the cluster luminescence. The average value of the quenching ratio was $1.6 \times$ with variations of $\sim 30 \%$ around this value. The intensity of luminescence is repeatable to within $5 \%$. 


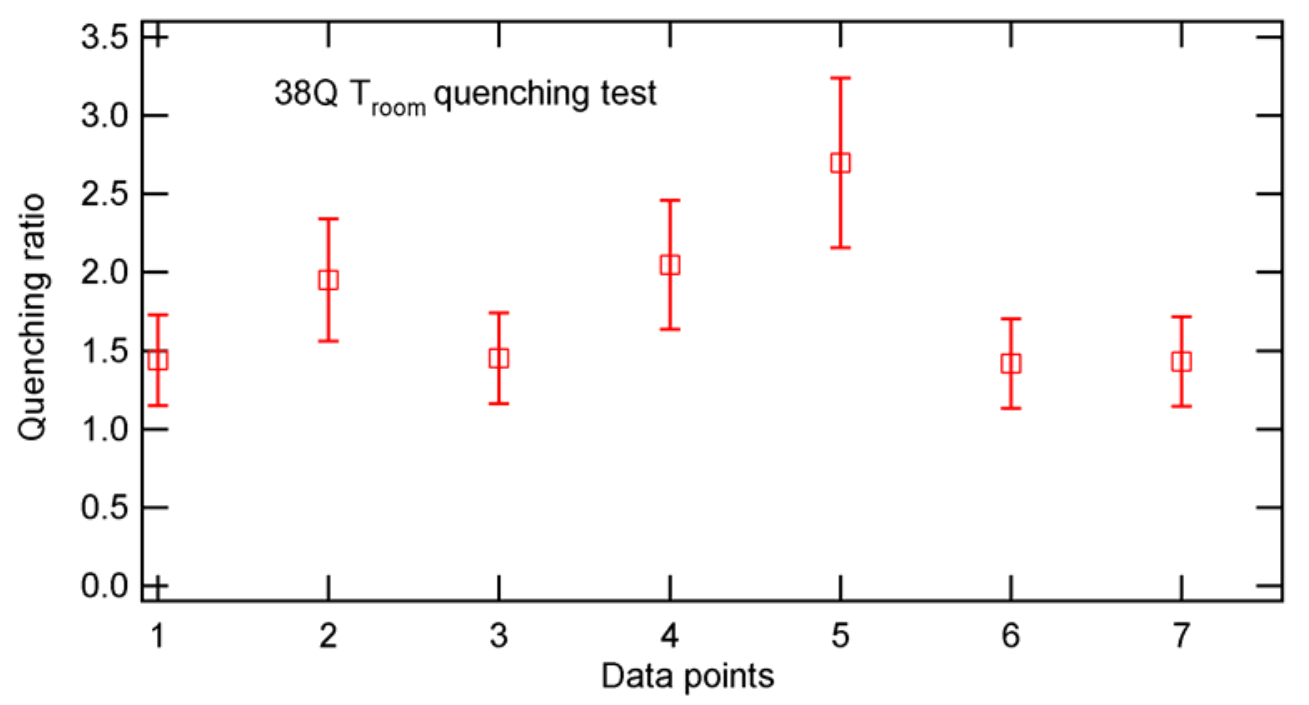

Figure 56. Demonstration that the room temperature quenching ratio of slide $38 \mathrm{Q}$ is relatively unaffected by temperature cycling; measurements from the (1) first day, (2) one day later, following cycling to: (3) $50{ }^{\circ} \mathrm{C}$, (4) $88^{\circ} \mathrm{C}$, (5) $115^{\circ} \mathrm{C}$, (6) $150{ }^{\circ} \mathrm{C}$ and (7) $200{ }^{\circ} \mathrm{C}$. The lowest value obtained is $1.45 \times$.

The results from Film 38Q show that the optical properties of the film are stable even after various long term heating protocol and the oxygen permeability of the composite is not degraded by temperature cycling. These were our first high temperature stable Mocontaining sol-gel films. The permeability of sol-gel matrices is related to the free volume within the matrix and is highly dependent on the details of the synthetic parameters used to prepare the sol-gel matrix cell gel. Briefly, a sol-gel synthesis involves the acid or base catalyzed hydrolysis and condensation of metal alkoxides such as tetraethylorthosilicate. As the reaction proceeds to completion the sol-gel solution is converted to a continuous solid matrix. If spectator compounds are present, in our case $\mathrm{K}_{2} \mathrm{Mo}_{6} \mathrm{Cl}_{14}$, they are entrapped within the matrix. Essentially all sol-gel films densify to some extent as they cure and further densify after drying at high temperatures. In the composite approach, the $\mathrm{K}_{2} \mathrm{Mo}_{6} \mathrm{Cl}_{14}$ is embedded in a sol-gel matrix that has been fully cured. Thus, no further evolution of sol-gel matrix occurs during measurements at high temperature and the permeability and quenching characteristics of the composites are stable. In principle, evolution of the binder could decrease the permeability and reduce the quenching ratio of the composite, but the experimental data to date indicate no deleterious effects from the binder.

In this section we have shown the promising results from planar films prepared from powder sol-gel solutions. The results corroborate one of the potential advantages we had identified for the composite approach - that led to fiber sensors that had stable and predictable optical properties. Preliminary measurements of high quenching ratios for fibers sensors prepared by the composite route suggests a physical model where the cluster-containing particles form a continuous porous network analogous to a scintered glass, highly permeable but mechanically and thermally stable. The data in the next section from Fiber Sensor M, 45, 70 and 121 show our fiber sensor results. 


\section{High temperature fiber sensor measurements.}

The oxygen sensing characteristics of one of our first successful fiber sensors prepared using a sol-gel binder to immobilize sol-gel particles embedded with $\mathrm{K}_{2} \mathrm{Mo}_{6} \mathrm{Cl}_{14}$, Fiber $\mathrm{M}$ (see Figure 57), are shown in Figures 58- 64. Fiber $\mathrm{M}$ is a fiber sensor with large particles using a TEOS binder, and span the temperature range of $100{ }^{\circ} \mathrm{C}$ to room temperature. There are $4 \times 10^{18}$ clusters $/ \mathrm{cm}^{3}$ in the composite, which formed a $\sim 100 \mu \mathrm{m}$ thick hemispherical cap on the end of the fiber. The sensor was characterized in the measurement setup shown in Figure 12 under the following conditions. First using a 900 $\mu \mathrm{W}, 365 \mathrm{~nm}$ LED as the pump source, we were able to obtain a net coupling efficiency of $33 \%$ by coupling $295 \mu \mathrm{W}$ of UV power into the optical fiber. Secondly, the gas flow rate was maintained at $\sim 1000 \mathrm{sccm}$. Thirdly, the temperature of the fiber sensor was monitored continuously with a thermocouple to $\pm 1{ }^{\circ} \mathrm{C}$. During the course of each measurement, the maximum temperature drift was $\sim 3^{\circ} \mathrm{C}$ over 30 minutes.

Our first goal was to determine if elevated temperatures adversely affect the sensitivity of sensor by examining the sensor output in pure nitrogen and synthetic air $(21 \%$ oxygen, balance nitrogen) which are the end points of our concentration range. Figures $58-64$ show the sensor response to alternating pulses of $99.999 \% \mathrm{~N}_{2}$ and $21.1 \% \mathrm{O}_{2}$ at 100,81 , 60,41 and $23{ }^{\circ} \mathrm{C}$ respectively. The signal intensity in nitrogen is stable over the entire temperature range, $2.8 \pm 0.2 \mathrm{nW}$ or a variation of $\pm 7 \%$. Figure 63 shows that the sensor signal is relatively unaffected by a ramp up, followed by a ramp down in temperature.

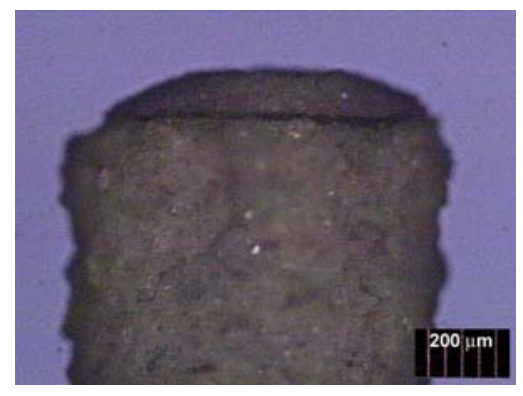

Figure 57. Micrograph of Fiber M

The quenching ratio, or the signal in pure nitrogen divided by that in $21 \%$ oxygen, is a measure of the sensitivity of our sensor. We find that the quenching ratio increases from 4.4 to $6.9 \times$ from room temperature to $72{ }^{\circ} \mathrm{C}$, and then decreases slightly to $6.2 \times$ at $100{ }^{\circ} \mathrm{C}$ (see 58). The temperature dependence of the quenching ratio is due primarily to the temperature sensitivity of the sensor signal in oxygen. We have previously shown that the quenching ratio of the potassium salt in solution, following 4 hours of heating at 200 ${ }^{\circ} \mathrm{C}$ was $13.2 \times$ and are quite satisfied to be able to reach half that value for the clusters immobilized in the matrix. The temperature dependence of the sensor a reversible process may be due to a temperature dependent permeability of oxygen in the sol-gel matrix or that the physical structure of the sol-gel binder matrix is continuing to evolve with heat cycling.

The absolute magnitude of our sensor signal is very encouraging in terms of practical implementations of our device. We obtain a $\sim 3 \mathrm{nW}$ output signal for $\sim 300 \mu \mathrm{W}$ of incident pump power; $10^{-5}$ is a very reasonable power conversion efficiency for a fiber sensor. Autofluorescence or the magnitude of the signal in our measurement bandwidth 
due to fluorescence from a length of fiber without any cluster on the tip sets a lower bound on the smallest signal we can detect from our sensor. For our current $15 \mathrm{~cm}$ long fiber sensor, we have $0.011 \mathrm{nW}$ of autofluorescence, which is a factor of 40 smaller than the $\sim 0.4 \mathrm{nW}$ signal in oxygen.

Fiber $\mathrm{M}$ was thermally cycled above room temperature for a cumulative 7 hours in either nitrogen or oxygen. In addition the cluster containing sol-gel composite at the end of the fiber tip was exposed to a total of at least 15 days of $365 \mathrm{~nm}$ UV radiation in laboratory air. Following the series of experiments shown in Figures 58 -64, we found that the bulk of the cluster containing sol-gel composite had delaminated from the fiber tip; however a thin sol-gel film still remained on the tip. As discussed in the previous section this is due to the shrinkage of the sol-gel binder during curing, so we have chosen to replace a portion of the TEOS binder with OtMOS. Optical and mechanical characterization of the fibers prepared with this technique are quite promising, as shown by the data from Fibers 121,45 and 70 in the next section. At $60{ }^{\circ} \mathrm{C}$ the cluster/sol-gel composite continues to adhere to the end of the silica fiber and the signal level in pure nitrogen is $4 \mathrm{nW}$, slightly higher than that for Fiber M.

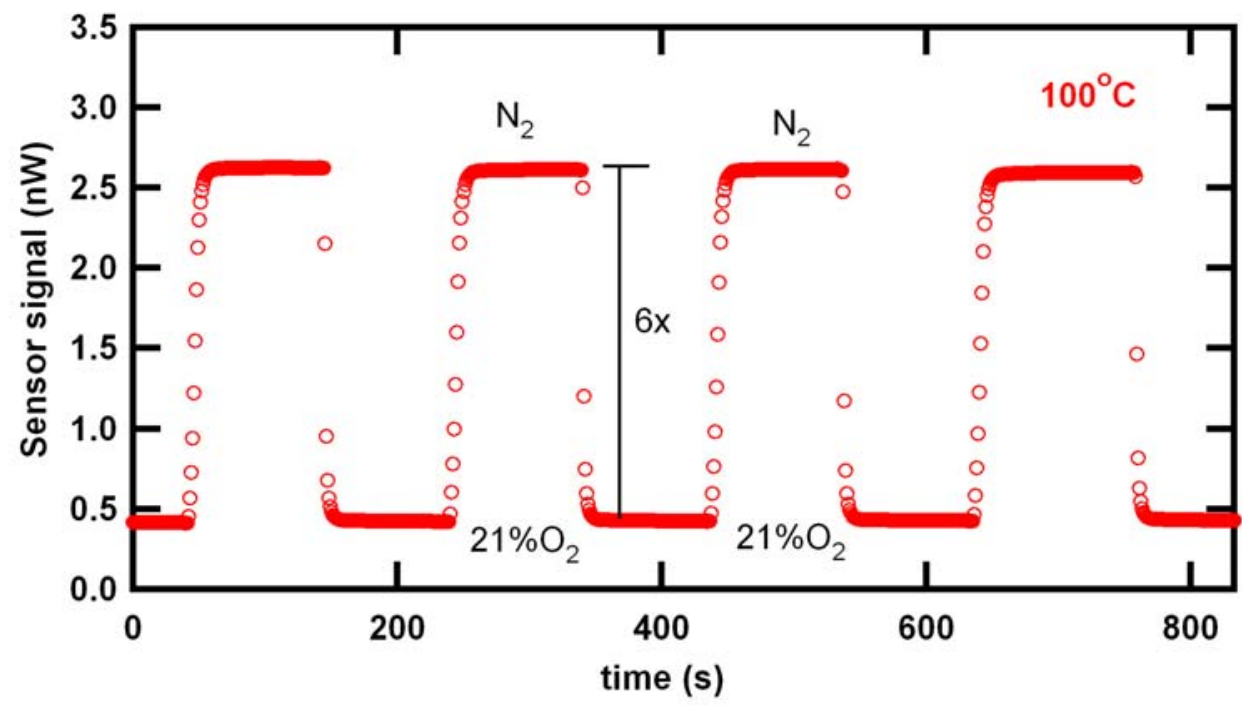

Figure 58. Fiber sensor measurements at $100{ }^{\circ} \mathrm{C}$ demonstrating quenching of $6.1 \times$ between pure nitrogen and $21 \%$ oxygen (balance nitrogen). The sensor signal is large, in the nanowatt regime with the signal magnitude in oxygen $\sim 40$ greater than the measured autofluorescence. The luminescent tip contains $\mathrm{K}_{2} \mathrm{Mo}_{6} \mathrm{Cl}_{14}$ sol-gel particles embedded in a sol-gel binder matrix, with $4 \times 10^{18}$ clusters $/ \mathrm{cm}^{3}$ (Fiber M). The coupled pump power is $295 \mathrm{~W}$ at $365 \mathrm{~nm}$ and the gas flow rate is $1000 \mathrm{sccm}$. 


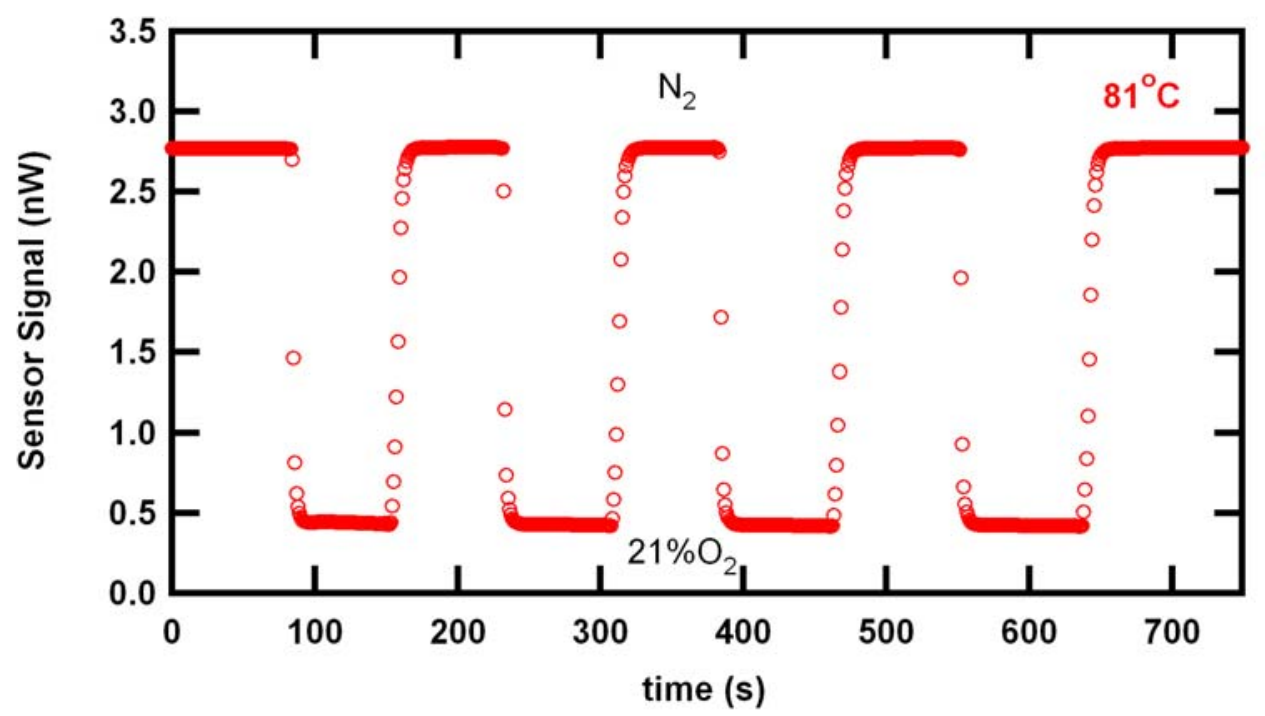

Figure 59. Fiber sensor measurements at $80^{\circ} \mathrm{C}$ demonstrating quenching of $6.4 \times$ between pure nitrogen and $21 \%$ oxygen (balance nitrogen) for Fiber M. The measurement conditions are the same as Figure 58.

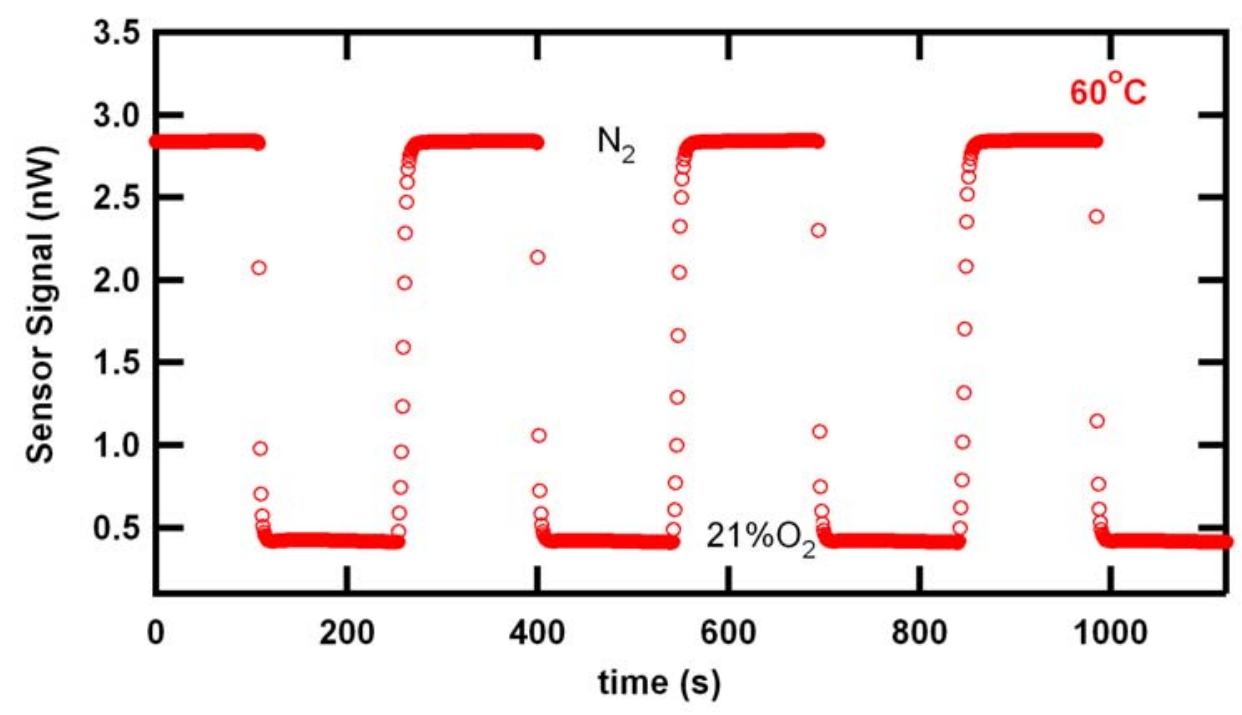

Figure 60. Fiber sensor measurements at $60{ }^{\circ} \mathrm{C}$ demonstrating quenching of $6.8 \times$ between pure nitrogen and $21 \%$ oxygen (balance nitrogen) for Fiber M. The measurement conditions are the same as Figure 58. 


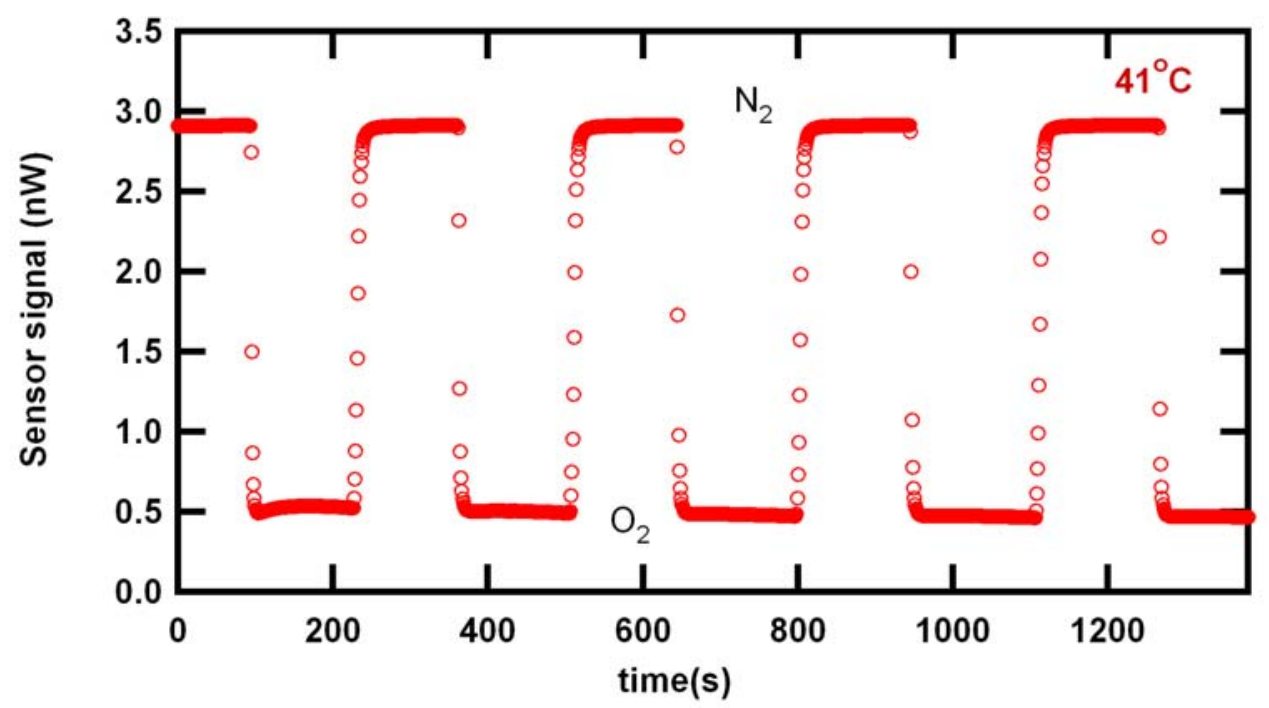

Figure 61: Fiber sensor measurements at $41^{\circ} \mathrm{C}$ demonstrating quenching of $5.9 \times$ between pure nitrogen and $21 \%$ oxygen (balance nitrogen) for Fiber M. The measurement conditions are the same as Figure 58.

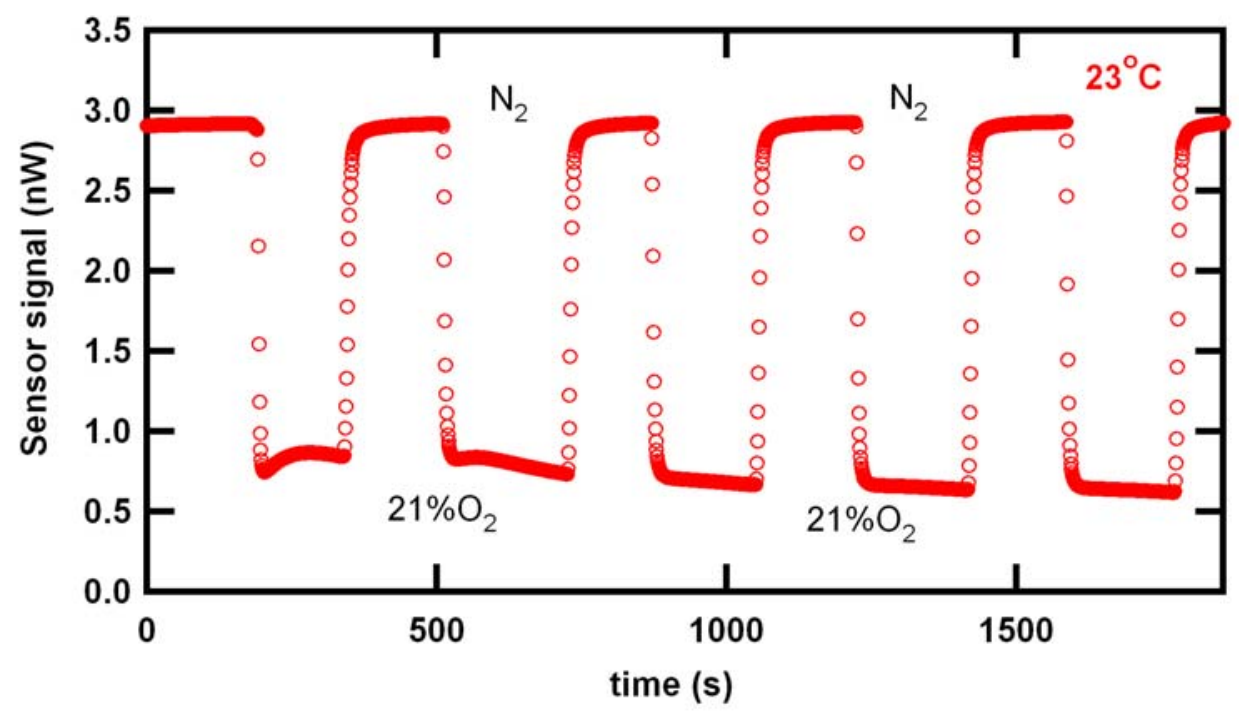

Figure 62. Fiber sensor measurements while scanning the temperature from $23{ }^{\circ} \mathrm{C}$ to $76{ }^{\circ} \mathrm{C}$ and then back down to $23{ }^{\circ} \mathrm{C}$ for fiber $\mathrm{M}$. The date demonstrate that the sensor signal is relatively unaffected by the temperature ramp; the signal magnitude in $\mathrm{N}_{2}$ decreases by $5 \%$ from $23{ }^{\circ} \mathrm{C}$ to $76^{\circ} \mathrm{C}$, whereas the quenching ratio varies by $25 \%$. The measurement conditions are the same as in Figure 58. 


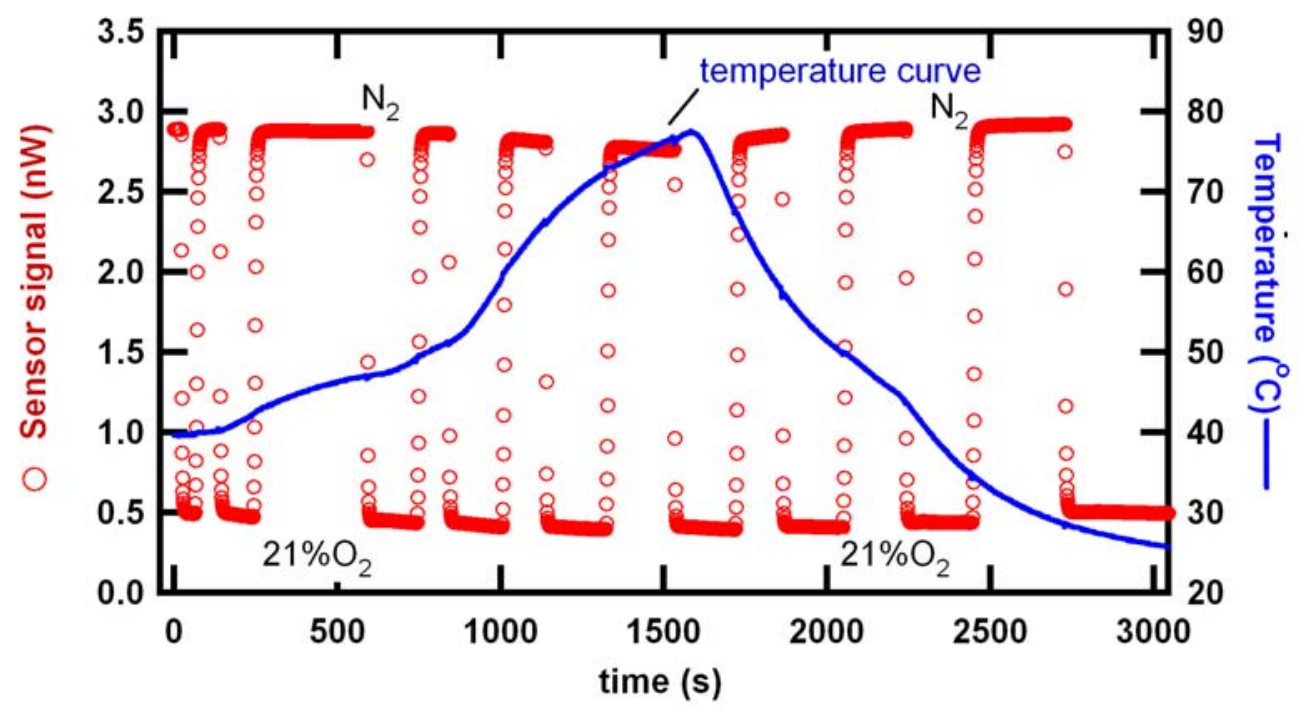

Figure 63. Fiber sensor measurements at room demonstrating quenching of $4.4 \times$ between pure nitrogen and $21 \%$ oxygen (balance nitrogen) for Fiber M. The measurement conditions are the same as Figure 58.

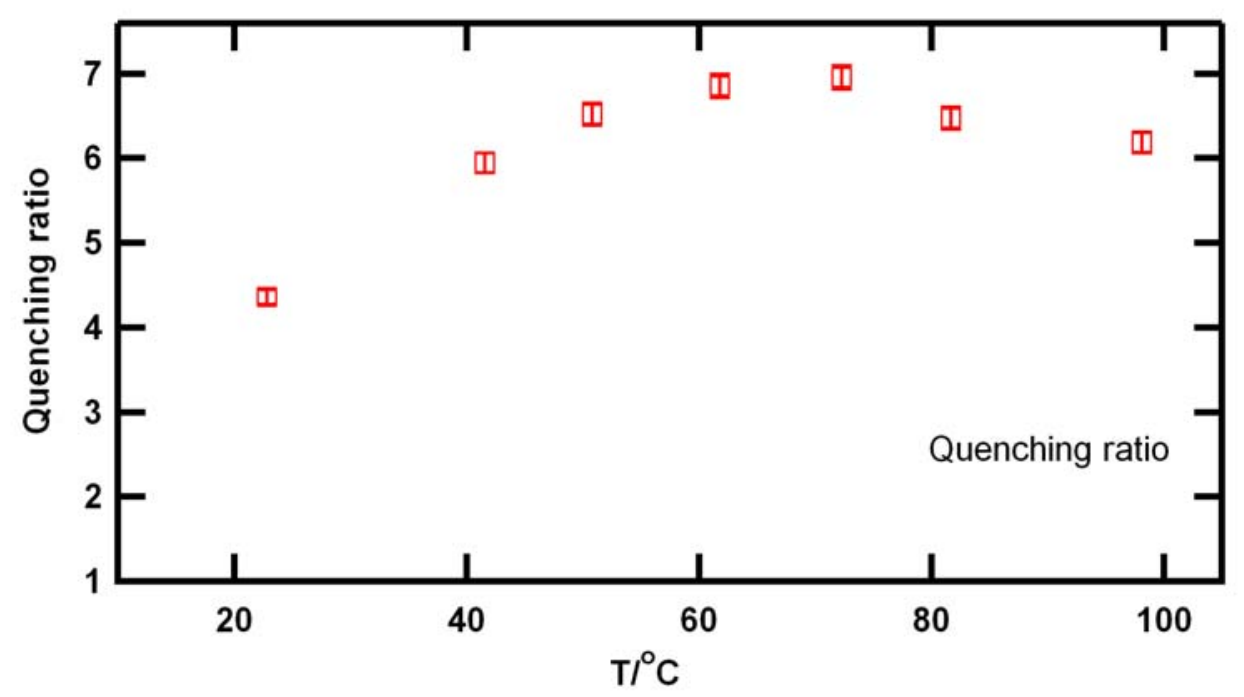

Figure 64. Quenching ratio (signal intensity in $\mathrm{N}_{2}$ vs $21 \% \mathrm{O}_{2}$ ) as a function of temperature for Fiber M, from the data in Figs. 6 - 10. These measurements show that in the temperature range of 50 to $100{ }^{\circ} \mathrm{C}$ the quenching ratio is relatively independent of temperature, varying by $\pm 6 \%$. 


\section{Oxygen Sensitivity of $\mathrm{K}_{2} \mathrm{Mo}_{6} \mathrm{Cl}_{14}$ Fiber Sensors at Elevated Temperatures}

Stern-Volmer relationship up to $100^{\circ} \mathrm{C}$

In this section we demonstrate that the fiber sensor obeys the classic Stern-Volmer relationship up to $100{ }^{\circ} \mathrm{C}$. All the data are from Fiber sensor 121, see Figure 65 for photographs of the as fabricated sensor and after all thermal testing. The sensor tip contains $\mathrm{K}_{2} \mathrm{Mo}_{6} \mathrm{Cl}_{14}$ sol-gel particles embedded in a OtMOS / TEOS binder matrix. The sensing film was cured for 16 hours at $70^{\circ} \mathrm{C}$. The tip contains roughly $8 \times 10^{18}$ clusters $/ \mathrm{cm}^{3}$, after accounting for the volume contraction in forming the monolith and drying of the particle/binder composite.

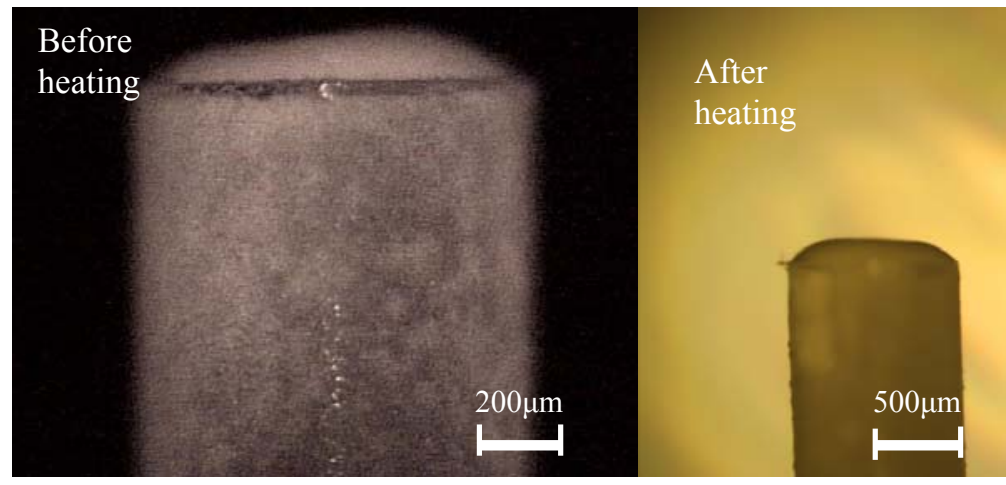

Figure 65. Photograph of Fiber 121 as fabricated and after all thermal testing 
Fiber Sensor 121 at $42^{\circ} \mathrm{C}$

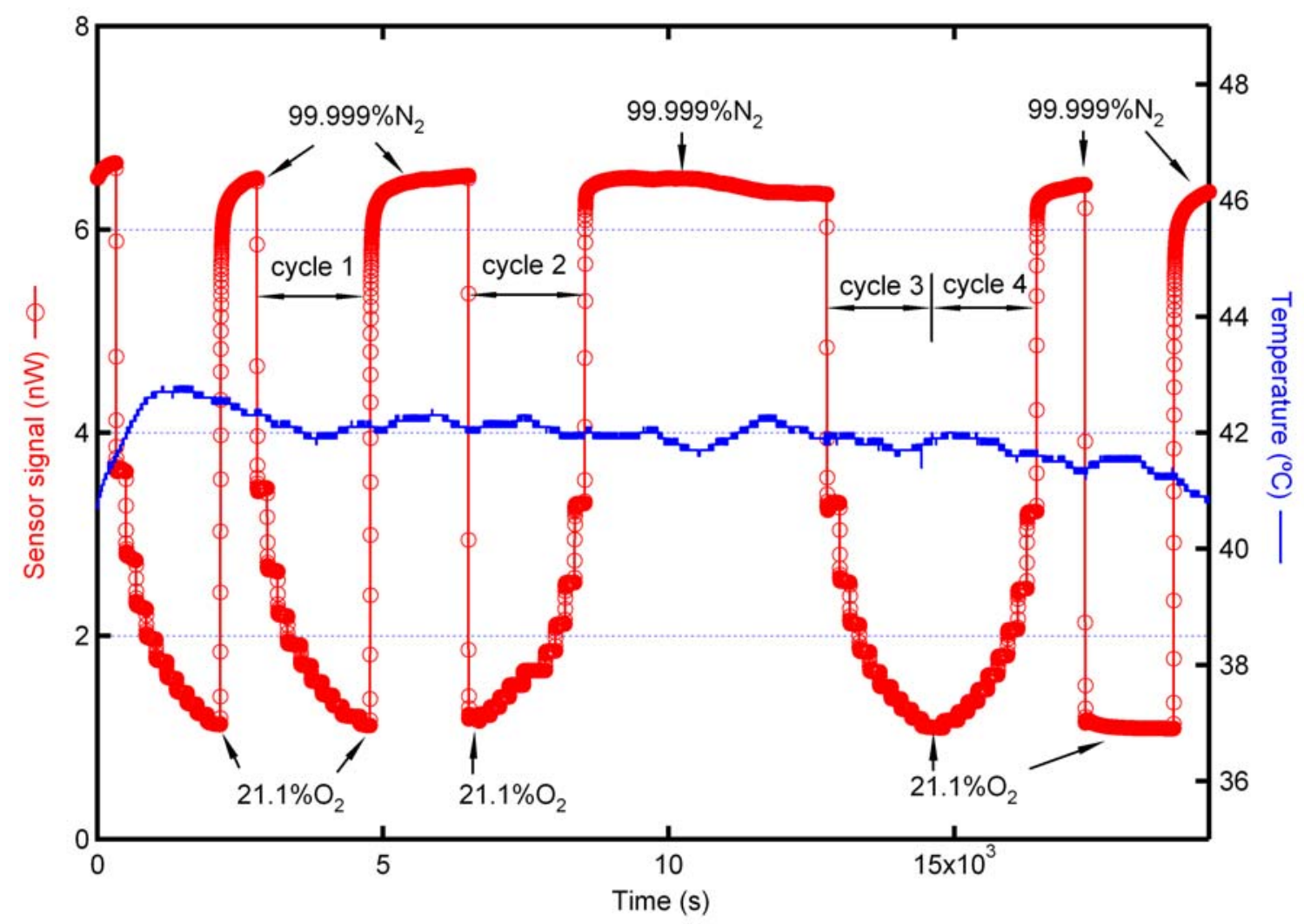

Figure 66. Oxygen sensitivity of Fiber 121 at $42{ }^{\circ} \mathrm{C}$ during several cycles of measurement. The gas composition for each cycle was: (i) $99.999 \% \mathrm{~N}_{2}$, (ii) $2.11 \%$ $\mathrm{O}_{2}$, (iii) $4.22 \% \mathrm{O}_{2}$, (iv) $6.32 \% \mathrm{O}_{2}$, (v) $8.44 \% \mathrm{O}_{2}$, (vi) $10.6 \% \mathrm{O}_{2}$, (vii) $12.7 \% \mathrm{O}_{2}$, (viii) $14.8 \% \mathrm{O}_{2}$, (ix) $16.9 \% \mathrm{O}_{2}$, (x) $19.0 \% \mathrm{O}_{2}$ and (xi) $21.1 \% \mathrm{O}_{2}$, with the balance $\mathrm{N}_{2}$. Note during the two cycles from $6,500-10,000 \mathrm{~s}$ and $14,580-17,062 \mathrm{~s}$ the gas order was reversed going from $21.1 \% \mathrm{O}_{2}$ to $99.999 \% \mathrm{~N}_{2}$. Coupled pump power is $285 \mu \mathrm{W}$, gas flow rate is 400 and $370 \mathrm{sccm}$ at the input and output of the quartz chamber respectively, and the cluster concentration is $\sim 8 \times 10^{18}$ clusters $/ \mathrm{cm}^{3}$.

The oxygen response of Fiber sensor 121 over several cycles from 2 to $21 \% \mathrm{O}_{2}$ at $42{ }^{\circ} \mathrm{C}$ are shown in Figure 66. The device is easily able to detect changes in oxygen concentration at the percent level at this temperature. The data was taken in our flow through system, with the sensor exposed to each gas concentration for about 3 minutes. The wait time in pure nitrogen was significantly longer to allow the device to equilibrate. The temperature stability of our system is quite good, over the 5.5 hours the temperature held at $41.9 \pm 0.4{ }^{\circ} \mathrm{C}$. 
The quenching of cluster luminescence by oxygen is expected to obey the Stern-Volmer relationship ${ }^{[1,23]}$

$$
\mathrm{I}_{0} / \mathrm{I}=1+\mathrm{k}_{\mathrm{q}} \tau_{0}\left[\mathrm{O}_{2}\right]
$$

Where $\mathrm{I}_{0}$ and $\mathrm{I}$ are the luminescence intensities in the absence and presence of oxygen of concentration $\left[\mathrm{O}_{2}\right]$ and $\mathrm{k}_{\mathrm{q}}$ is the quenching rate constant and $\tau_{0}$ the luminescence lifetime in the absence of oxygen. The inverse of the luminescence intensity at a given oxygen concentration normalized with respect to the unquenched intensity, $\mathrm{I}_{0} / \mathrm{I}$ is plotted in Fig. 7. Each measurement point in Fig. 7 is the average value of the normalized sensor signal from cycle $1-4$ of Fig. 6 . The fit is to the Stern-Volmer relationship is quite good. We obtain a linear relationship between $\mathrm{I}_{0} / \mathrm{I}$ and $\left[\mathrm{O}_{2}\right]$, with a slope of $800\left[\mathrm{O}_{2}\right]^{-1}$ and an intercept of 1.5 . The uncertainty in the slope is only $\pm 5 \%$.

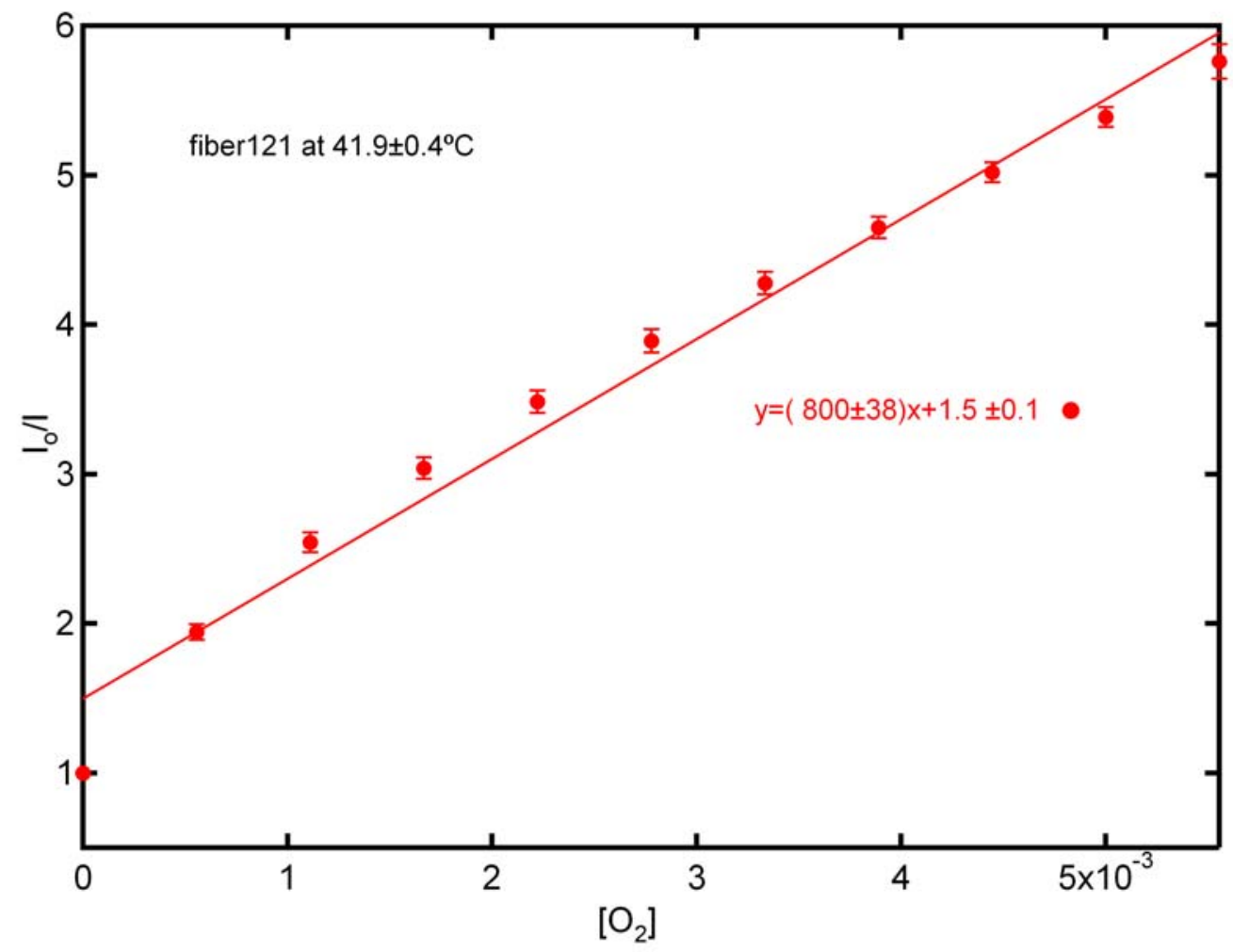

Figure 67. Stern-Volmer relationship, $\mathrm{I}_{0} / \mathrm{I}$ as a function of molar oxygen concentration, at $42{ }^{\circ} \mathrm{C}$ for Fiber sensor 121. The data are from Figure 66 and represent the average over the indicated four cycles. 


\section{Fiber Sensor 121 at $73{ }^{\circ} \mathrm{C}$}

Shown in Fig. 8 is the oxygen response of the sensor at $73{ }^{\circ} \mathrm{C}$. The Stern-Volmer plot was obtained by averaging the measurements from four complete cycles between pure nitrogen and $21 \%$ oxygen. We again obtained a good linear fit between $\mathrm{I}_{0} / \mathrm{I}$ as a function of $\left[\mathrm{O}_{2}\right]$, with a slope of $280\left[\mathrm{O}_{2}\right]^{-1} \pm 5 \%$ and an intercept of 1.16 .

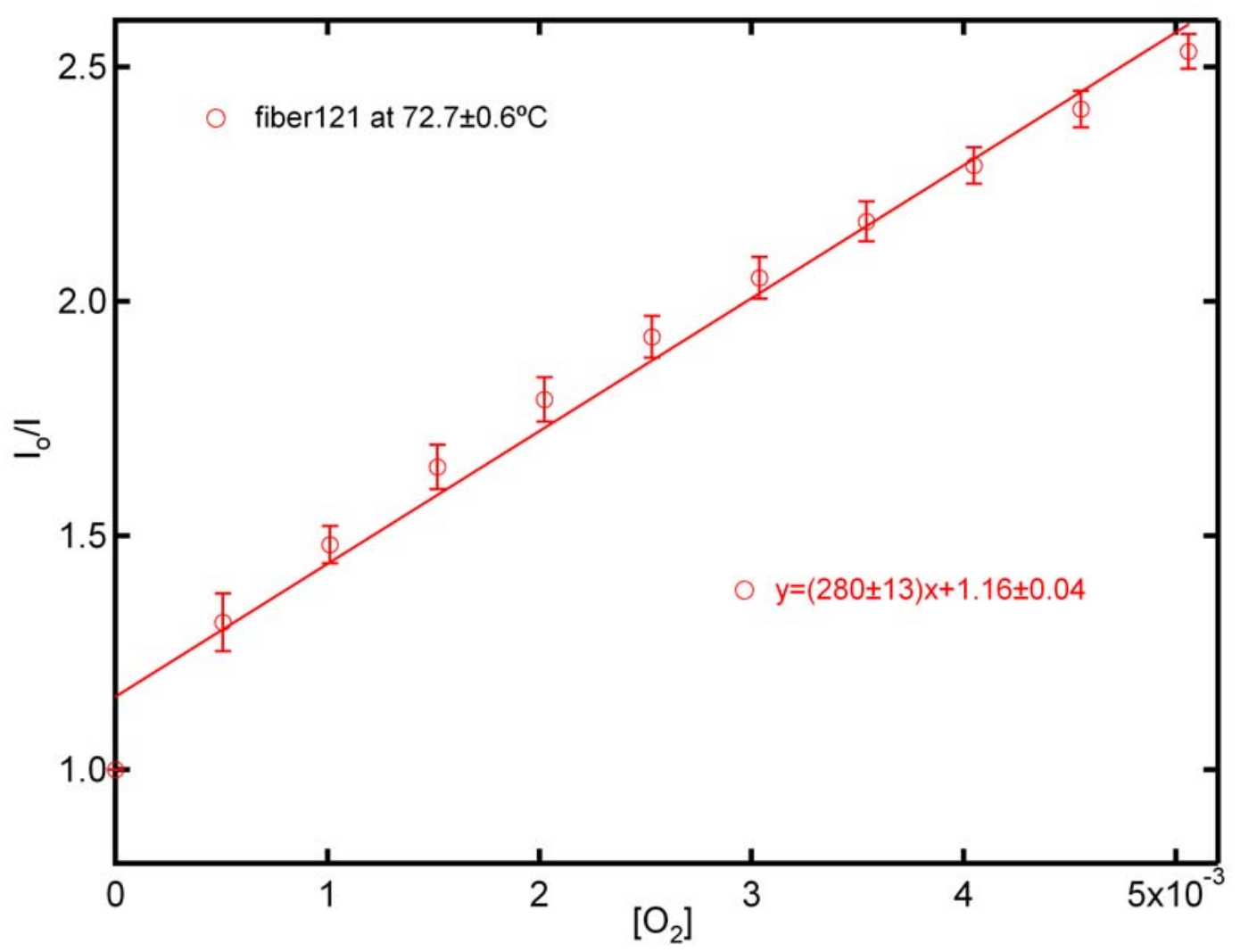

Figure 68. Stern-Volmer relationship, $\mathrm{I}_{0} / \mathrm{I}$ as a function of molar oxygen concentration, at $73{ }^{\circ} \mathrm{C}$ for Fiber sensor 121. Plotted is the average from four cycles of measurement. Coupled pump power is $285 \mu \mathrm{W}$, gas flow rate is 400 and $390 \mathrm{sccm}$ at the input and output of the quartz chamber respectively. 


\section{Fiber Sensor 121 at $102^{\circ} \mathrm{C}$}

Shown in Figure 69 is the oxygen response of the sensor at $102{ }^{\circ} \mathrm{C}$. The Stern-Volmer plot was obtained by averaging the measurements from two complete cycles between pure nitrogen and $21 \%$ oxygen. Even at this elevated temperature, we have a good linear fit between $\mathrm{I}_{0} / \mathrm{I}$ as a function of $\left[\mathrm{O}_{2}\right]$, with a slope of $160\left[\mathrm{O}_{2}\right]^{-1} \pm 4 \%$ and an intercept of 1.07 .

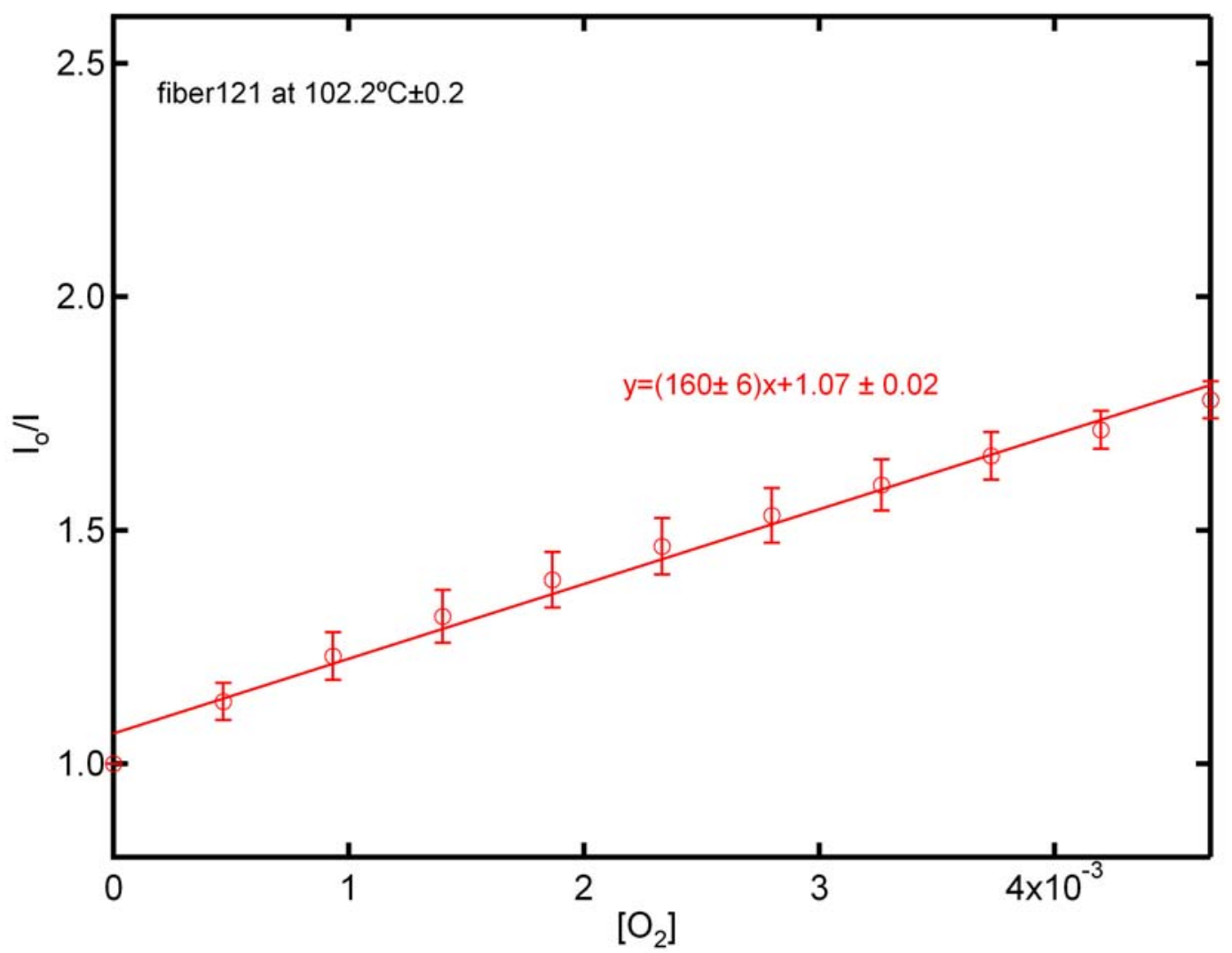

Figure 69. Stern-Volmer relationship, $\mathrm{I}_{0} / \mathrm{I}$ as a function of molar oxygen concentration, at $102{ }^{\circ} \mathrm{C}$ for Fiber sensor 121. Plotted is the average from two cycles of measurements. Coupled pump power is $285 \mu \mathrm{W}$, gas flow rate is 400 and $370 \mathrm{sccm}$ at the input and output of the quartz chamber respectively. 


\begin{tabular}{|c|c|}
\hline $\begin{array}{c}\text { Table 3. Slope of the linear Stern-Volmer plot, "sensor sensitivity" at } \\
\text { elevated temperatures, from the data is Fig. 67, } \mathbf{6 8} \text { and } \mathbf{6 9} .\end{array}$ \\
\hline $\begin{array}{c}\text { Sensor temperature } \\
{ }^{\circ} \mathrm{C}\end{array}$ & $\begin{array}{c}\text { Sensor Sensitivity } \\
{\left[\mathbf{O}_{\mathbf{2}}\right]^{-\mathbf{1}}}\end{array}$ \\
\hline 42 & $800 \pm 5 \%$ \\
\hline 73 & $280 \pm 5 \%$ \\
\hline 102 & $160 \pm 4 \%$ \\
\hline
\end{tabular}

The slope of the linear Stern-Volmer plot provides a measure of the sensitivity of our device towards detection of gaseous oxygen. As shown in Table 1, although the sensitivity is decreasing with temperature our sensor is able to operate up to $100{ }^{\circ} \mathrm{C}$. Considering the linearity of the fit even up to high temperature, we are somewhat puzzled by the fact that the y-intercept does not equal one, within our error bars, as predicted by the Stern-Volmer equation. We need to further analyze of our data to rule out the following experimental problem, i.e. that there is a systematic error in our calculation of the molar oxygen concentration.

Room temperature oxygen sensing experiments by other research groups, ${ }^{[24]}$ using a luminescent indicator in a sol-gel matrix, also report a downwards curvature in the SternVolmer plot near zero concentration as we observe. A phenomenological multiple site model has been invoked to fit such data. However, at present the structural evidence in support of multiple types of quenching sites in the sol-gel matrix is rather weak. In addition the quenching lifetimes obtained from fitting the data in the Stern-Volmer plot to a multi-site model, is in poor agreement with the directly measured luminescence lifetimes. We will need to directly measure the quenching lifetime of our molybdenum cluster/ sol-gel composite sensing film to resolve this question. Unfortunately, we do not currently have access to system that would allow us to determine the lifetime of our material at elevated temperature. 
Long-term performance and sensor repeatability

In this section we present the long-term performance of two fiber sensors at high temperatures, Fiber Sensor 45 at $58^{\circ} \mathrm{C}$ and Fiber Sensor 70 at $71.5^{\circ} \mathrm{C}$. Our goal was to determine the cycle-to-cycle stability of the oxygen measurements as well as the sensor performance over a period of many hours.

Fiber Sensor 45 at $58^{\circ} \mathrm{C}$

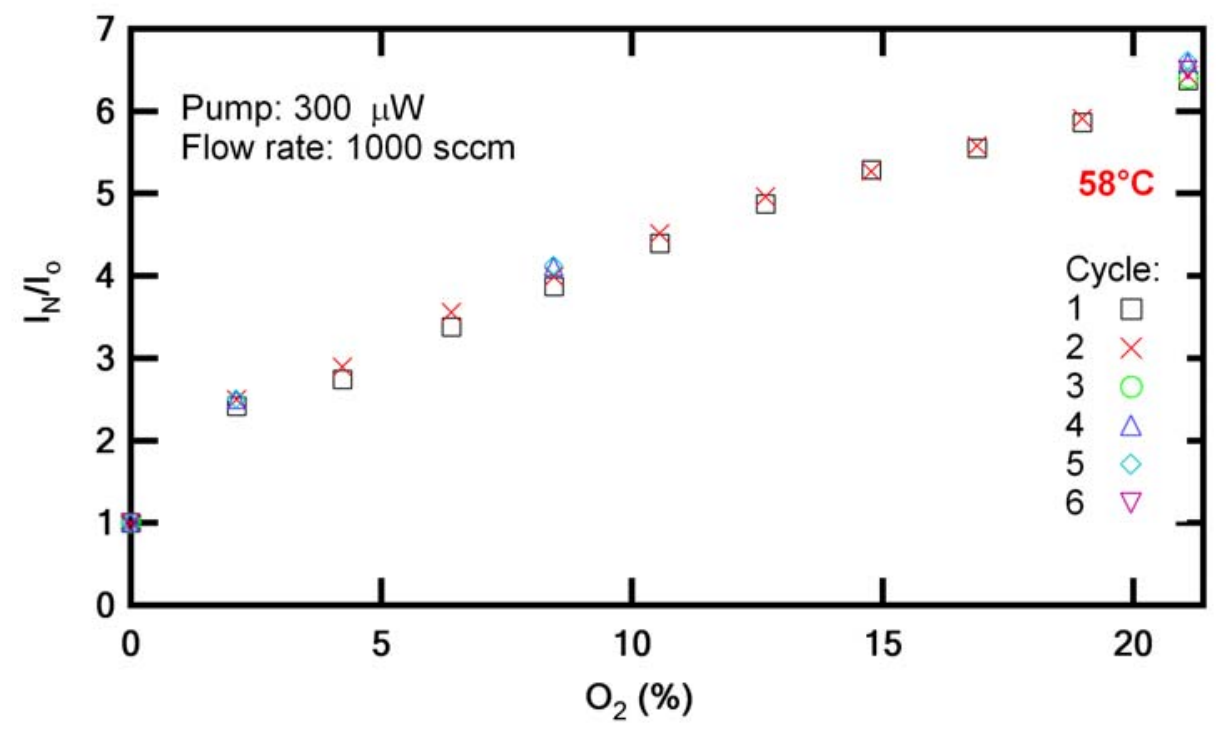

Figure 70. Quenching ratio (intensity in $\mathrm{N}_{2} /$ intensity in $\mathrm{O}_{2}$ ) for $6 \mathrm{~N}_{2} / \mathrm{O}_{2}$ cycles at $58^{\circ} \mathrm{C}$ for Fiber Sensor 45. The cycle-to-cycle variations correspond to a $\pm 1- \pm 15 \%$ uncertainty in oxygen concentration over the entire measurement range from 21.1 $2.1 \%$ oxygen respectively. The luminescent tip contains $\mathrm{K}_{2} \mathrm{Mo}_{6} \mathrm{Cl}_{14}$ sol-gel particles embedded in an OtMOS/TEOS binder matrix, with $1.3 \times 10^{18}$ clusters $/ \mathrm{cm}^{3}$ (Fiber 45). The coupled pump power is $300 \mathrm{nW}$ at $365 \mathrm{~nm}$ and the gas flow rate is $1000 \mathrm{sccm}$. These measurements were made with the "homemade" gas switching system.

Fiber sensor 45 was selected for repeated $\mathrm{N}_{2} / \mathrm{O}_{2}$ cycling measurements and to monitor the sensor signal over a period of 24 days. This particular device was chosen due to the high initial sensor signal and the superior morphology and mechanical stability of the Mocluster/sol-gel compositing sensing film. The sensor was fabricating using a Ceramoptic UV transparent fiber (PUV-1000/1300 N), which has a $1000 \mu \mathrm{m}$ silica core. The sensor tip contains $\mathrm{K}_{2} \mathrm{Mo}_{6} \mathrm{Cl}_{14}$ sol-gel particles (FJ17 particles $1-8 \mu \mathrm{m}$ in size) embedded in an OtMOS/TEOS binder matrix. The solvent is ethanol and the fiber was hand dipped in the binder/particle solution binder, then cured for 16 hours at $70^{\circ} \mathrm{C}$. The tip contains $\sim 1.3 \times$ $10^{18}$ clusters $/ \mathrm{cm}^{3}$. All the sensing measurements on Fiber 45 (Figures 70-74) were made on our first sensor characterization system, with a hand made gas switch prior to purchase of the commercial Horiba gas divider. A simple gas divider was constructed from a twoway switch and two flow meters, which can read from 100 to $1000 \mathrm{sccm}$. The total gas flow was kept at a constant $1000 \mathrm{sccm}$. Pure nitrogen (99.999\%) was mixed with either 
$21.1 \% \mathrm{O}_{2}$ or $1.0 \% \mathrm{O}_{2}$ for gas concentrations between $2.1-21.1 \% \mathrm{O}_{2}$ or $0.1-1.0 \% \mathrm{O}_{2}$ respectively. Note that the residence time for the gas in the sensing chamber was not well defined in the "old" setup as it was not a true flow-thorough geometry.

In Figure 70 we have plotted the quenching ratio (signal in nitrogen divided by the signal in oxygen) as a function of oxygen concentration from each of the six measurement cycles. The cycle-to-cycle variations over the 1 hour measurement period allow us to gauge the repeatability of measurements. We find that at $21.1 \%$ oxygen there is a $\pm 1 \%$ variation in the concentration, whereas at $2.1 \%$ oxygen there is a $\pm 15 \%$ variation in the concentration based on the intensity change. The larger variation in the measurements at low concentration is due primarily to the accuracy with which we can set the flow meter. We are very encouraged by the repeatability of our results at $58^{\circ} \mathrm{C}$.

We are somewhat puzzled by the slow upwards drift in the nitrogen from the first to the sixth cycle. This is a phenomenon we have observed in a number of sensors during the first few days of measurement. An increase in signal under nitrogen suggests that the heated dry gas flowing over the Mo-cluster/sol-gel composite removes an in situ quencher, possibly related to the solvent or byproducts of the sol-gel reaction. One possibility is "drying" or continuing to remove solvent from the sol-gel binder matrix. We are investigating whether curing the sensors in vacuum at $70{ }^{\circ} \mathrm{C}$ immediately after coating will improve performance.

The sensitivity of Fiber 45 at low oxygen concentration is shown in Figure 71, from $0.1 \%$ to $1.0 \% \mathrm{O}_{2}$ in steps of $0.1 \%$ at $60{ }^{\circ} \mathrm{C}$. It shows that the sensor can clearly resolve the $0.1 \%$ changes in absolute oxygen concentration at high temperature. The quenching ratio at $1 \% \mathrm{O}_{2}$ is about 1.65, consistent with the data in Figure 70 .

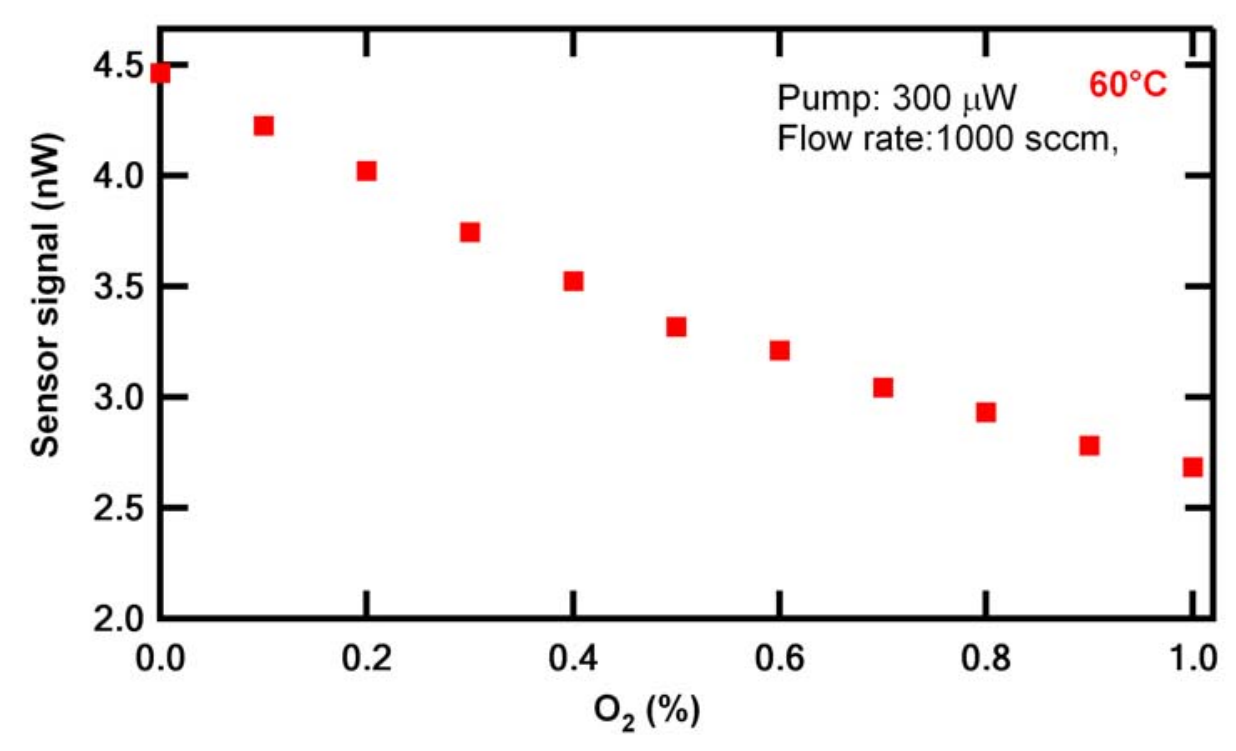

Figure 71. Sensor output signal from Fiber 45 at $60{ }^{\circ} \mathrm{C}$ as a function of oxygen concentration: $0.1 \%, 0.2 \% 0.3 \%, 0.4 \%, 0.5 \%, 0.6 \%, 0.7 \%, 0.8 \%, 0.9 \%$, and $1 \% \mathrm{O}_{2}$ (balance is nitrogen). It shows that the sensor can resolve a $0.1 \%$ change in absolute oxygen concentration in the $0.1 \%-1 \%$ range at $60{ }^{\circ} \mathrm{C}$. 


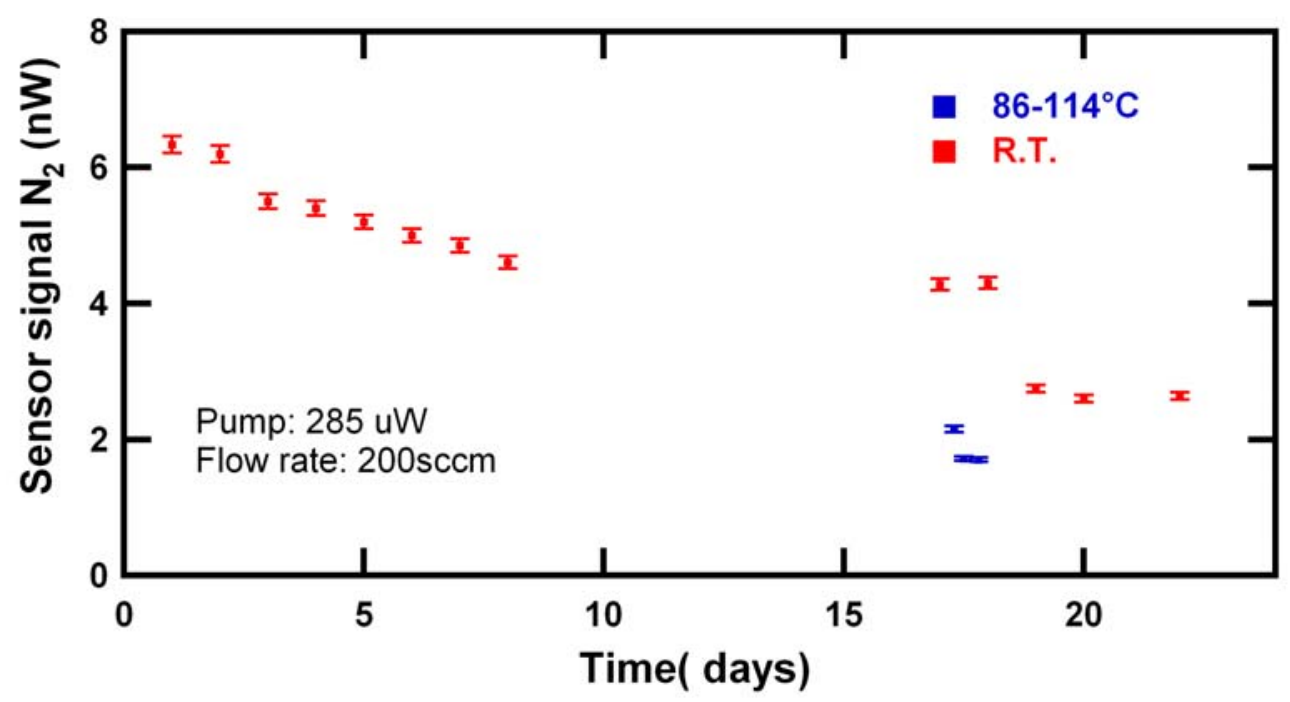

Figure 72. Signal from Fiber 45 measured over a period of 23 days, at room temperature $(\boldsymbol{\square}), 83{ }^{\circ} \mathrm{C}$ and $114{ }^{\circ} \mathrm{C}(\boldsymbol{\square})$, the lower measurement is $144{ }^{\circ} \mathrm{C}$. The measurement sequence (day 0) began 3 days after the sensor was fabricated. On day 17 , the sensor was measured at room temperature, $83{ }^{\circ} \mathrm{C}$ and $114{ }^{\circ} \mathrm{C}$, then left at $90{ }^{\circ} \mathrm{C}$ for 20.5 hours with the LED blocked. As the sensor signal at room temperature on day 18 is the same as day 17, we conclude that high temperature excursions are not intrinsically harmful to the device. See text for explanation of the drop in signal on day 19. Note that the total UV exposure over the entire 23 days is about 22.5 hours.

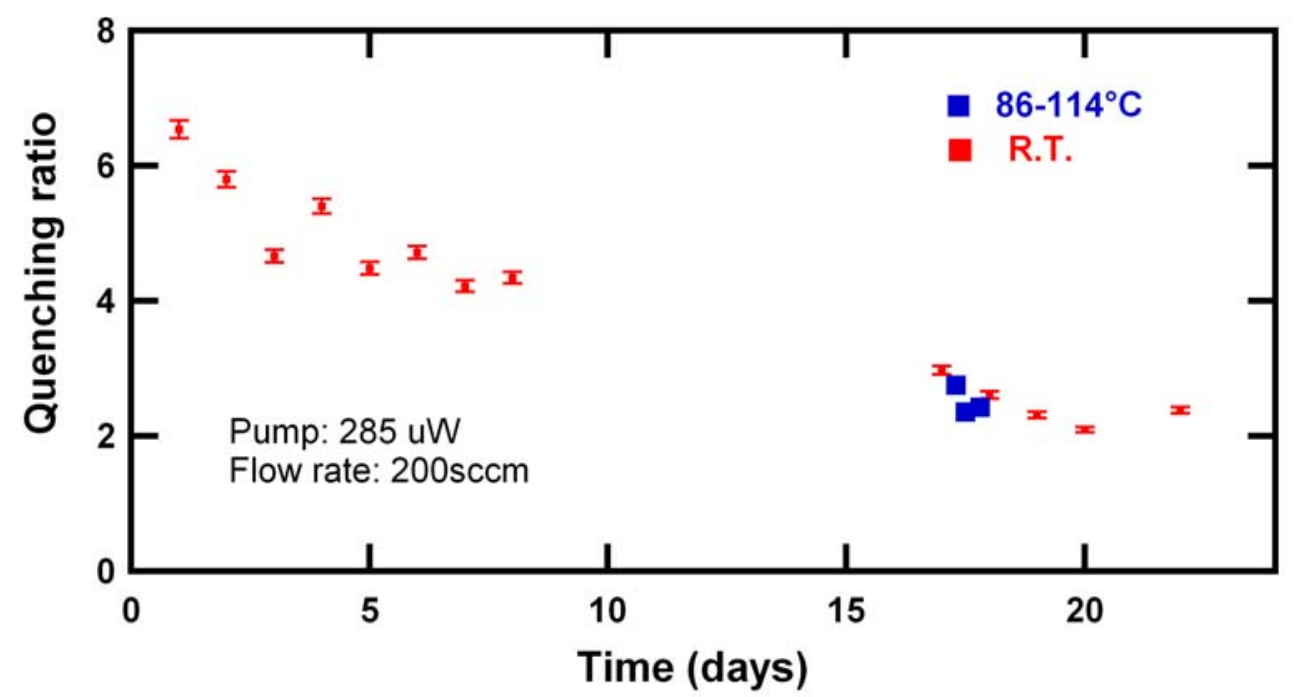

Figure 73. Quenching ratio (signal intensity in $\mathrm{N}_{2}$ divided by $21 \% \mathrm{O}_{2}$ ) for the measurement sequence described in Figure 72. The data demonstrates that after about 17 days and high temperature cycling the sensor response stabilizes. 
In order to assess the stability of Fiber sensor 45 over time we tracked its performance over the 23 days period as shown in Figures 72 and 73. Day 0 of these two measurement sequences is three days after the sensor fabrication. The sensor signal in nitrogen decreased slowly over the first eight days, while the quenching ratio appears to be leveling off after day 5. No measurements were made from day 10 to day 16, during which time the sensor was stored in laboratory air. On day 17 the sensor was measured at room temperature, $86{ }^{\circ} \mathrm{C}$, then $110{ }^{\circ} \mathrm{C}$, and held at $90{ }^{\circ} \mathrm{C}$ for $20.5 \mathrm{hrs}$ without UV exposure in lab air. The purpose of the $90{ }^{\circ} \mathrm{C}$ was to determine if high temperature in and of itself is harmful to the sensor. The answer appears to be no. On day 18, the room temperature measurement was repeated, the signal in nitrogen is the same, $4.3 \mathrm{nW}$, before and after heating while the quenching ratio drops by $10 \%$. Interestingly the quenching ratio, which is the measurement that will be used for sensing, stabilizes after about 17 days and high temperature cycling.

On day 19 the signal in nitrogen drops to $2.5 \mathrm{nW}$ and does not recover. Sudden loss of signal implies a catastrophic loss of clusters which cannot be easily explained by a chemical process. A mechanical failure such as delamination and loss of the sensing layer at the tip of the fiber is more plausible, but micrographs of the sensor tip taken at day 0 and day 25, see Figure 74, show no signs of delamination of the Mo-cluster/sol-gel. We speculate that the composite delaminates from the flat surface at the tip of the fiber, but adhesions of the composite to the lateral surface of the fiber remains intact. This "internal" delamination of the composite likely affects the coupling of UV photons into the composite and the visible signal back to the detector. A better understanding of the drying process as a function of time, temperature and atmospheric pressure may provide insight into delamination, as well as conditions that result in more rapid stabilization of quenching ratios.

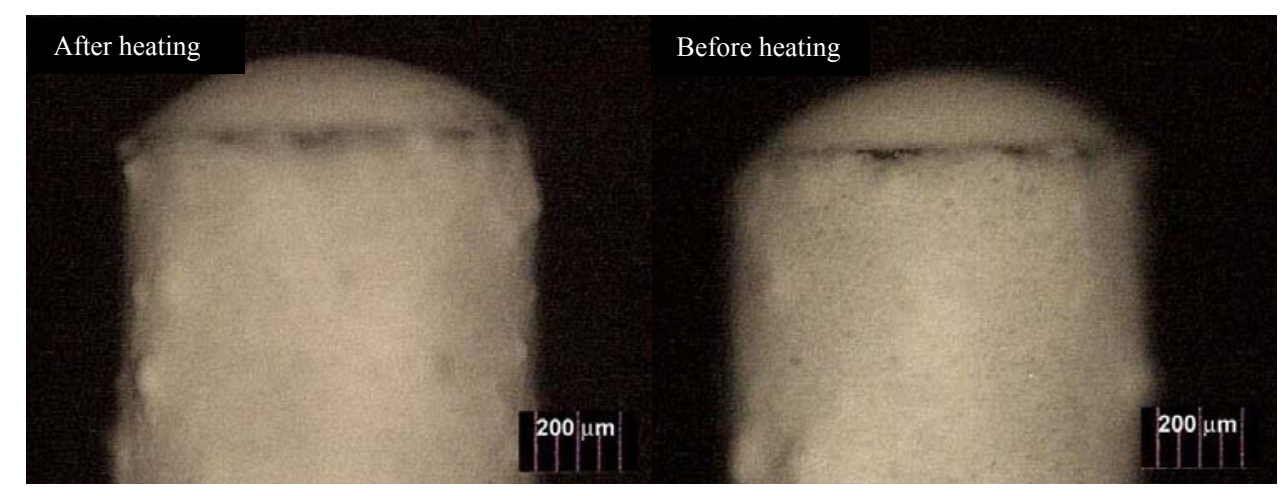

Figure 74. The side view of Fiber 45 before (day 0) and after 23 days of room temperature measurements as well heating at high temperature up to $114^{\circ} \mathrm{C}$. There are no external signs of delamination and the morphology of the Mo-cluster/sol-gel film does not change. 


\section{Fiber Sensor 70 at $71.5^{\circ} \mathrm{C}$}

Following our successful high temperature sensor measurements on Fiber 45, we tested the reproducibility of our sensor fabrication technique by fabricating and testing a "clone" of Fiber sensor 45. Fiber sensor 70 was fabricating using a Ceramoptic UV transparent fiber (PUV-1000/1300 N) which has a $1000 \mu \mathrm{m}$ silica core. The sensor tip contains $\mathrm{K}_{2} \mathrm{Mo}_{6} \mathrm{Cl}_{14}$ sol-gel particles (FJ17 particles, $1-8 \mu \mathrm{m}$ in size) embedded in a OtMOS/TEOS binder matrix. The solvent is ethanol and the fiber was hand dipped in the binder / particle solution, then cured for 16.5 hours at $70^{\circ} \mathrm{C}$. The tip contains $\sim 1.4 \times 10^{18}$ clusters $/ \mathrm{cm}^{3}$. The difference in the fabrication is that this sensor was cured for 0.5 longer than Fiber 45.

Sensor measurements at $70{ }^{\circ} \mathrm{C}$ for 13.8 hours of cycling between $99.999 \% \mathrm{~N}_{2}$ and 21.1 $\% \mathrm{O}_{2}$ are given in Figure 75. These measurements were made using an electronic gas switching system. The sensor was 19 days old at the start of the measurements. Since we know that the input and output gas flows are the same to better than $5 \%$, we can estimate that the gas exchange time is $10 \mathrm{~s}$ for a $200 \mathrm{sccm}$ flow. The temperature stability of the system is $71.5^{\circ} \mathrm{C}+/-1^{\circ} \mathrm{C}$. Note that the $0.4{ }^{\circ} \mathrm{C}$ "jitter" in the temperature data is most likely due to digitization errors in the $\mathrm{D} / \mathrm{A}$ board and could be improved upon by adjusting the voltage input range of the board. Prior to making sensing measurements we determined that the "unwanted" signal from a fiber device without any Mo-clusters, i.e. a fiber with sol-particles in the same binder matrix, was $0.01 \mathrm{nW}$. This is a factor of 70 larger than our lowest signal in oxygen.

The data in Figure $\mathbf{7 5}$ are remarkably stable over time. The variations sensor signal in nitrogen is synchronous with the temperature fluctuations. On top of this behavior is a slow drift over the 13.8 hours of measurement from 3.1 to $2.9 \mathrm{nW}$, which is not due to the drift in the optical coupling. We speculate that as in the case of Fiber Sensor 45 it reflects in situ curing of the sol-gel binder at high temperature. The oxygen intensity decreases linearly with time from $0.8-0.7 \mathrm{nW}$ and seems to be uncorrelated with the temperature variations. The quenching ratio varies from 3.9 to 4.1 over the measurement period.

The performance of Fiber 45 and Fiber 70 are similar, with nitrogen signal intensities in the 3 to $4 \mathrm{nW}$ range and pure nitrogen to $21.1 \%$ oxygen quenching ratios of 2.7 at $86{ }^{\circ} \mathrm{C}$ and 3.9 and $70{ }^{\circ} \mathrm{C}$. Again we believe that the variations between the two sensors are most likely due to evolution of the sol-gel binder with time, gas flow and temperature. These are very exciting results as they demonstrate the feasibility of using Mo-clusters to monitor oxygen at temperature in the $60-70{ }^{\circ} \mathrm{C}$ range for a period of many hours. 


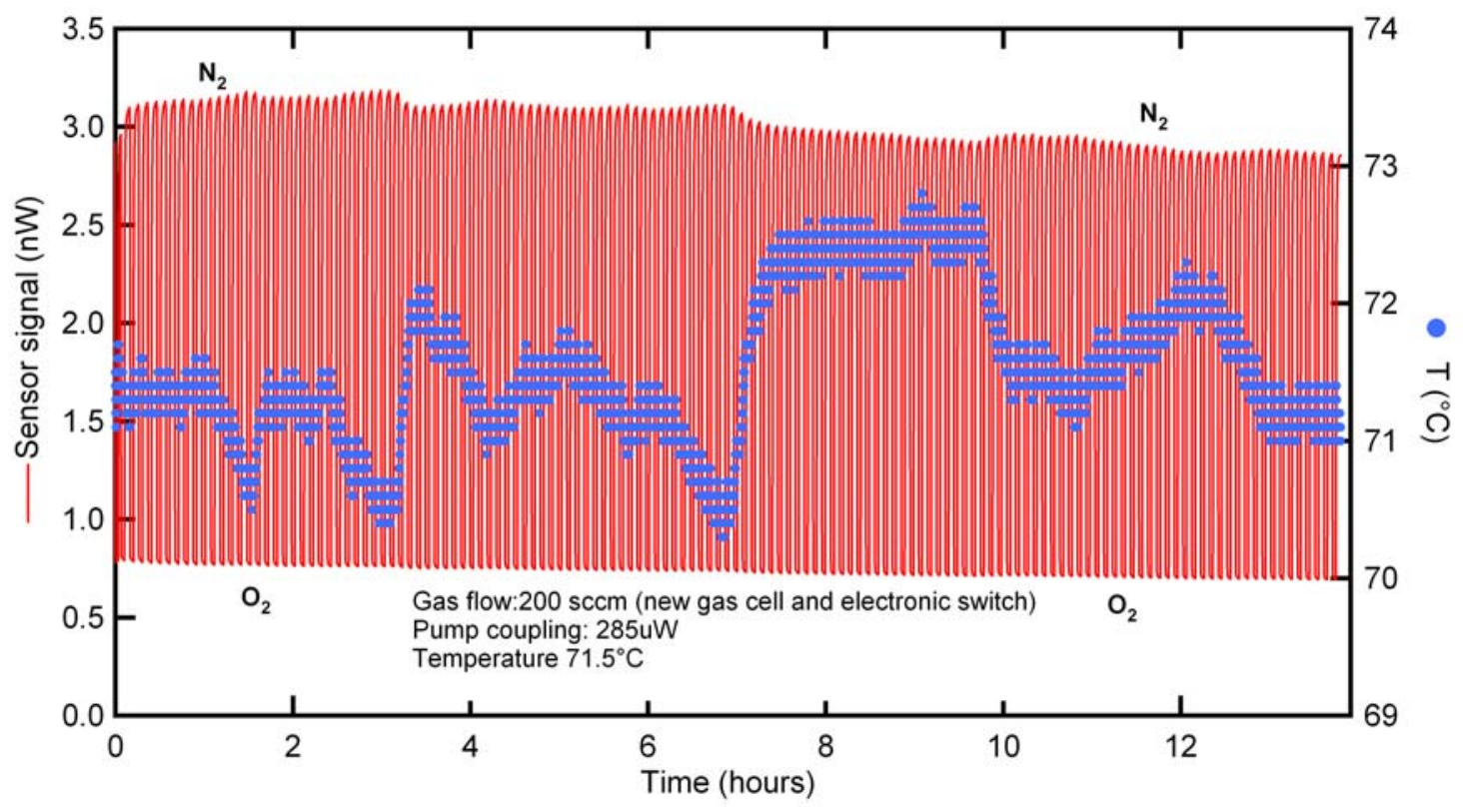

Figure 75: High temperature measurements of Fiber Sensor 70 during 13.8 hours of cycling between $99.999 \% \mathrm{~N}_{2}$ and $21.1 \% \mathrm{O}_{2}$ at $70{ }^{\circ} \mathrm{C}$. These measurements were made in a quartz gas sensor cell, with temperature stability of $\pm 1{ }^{\circ} \mathrm{C}$ for 13.8 hours. In this flow-through cell the gas exchange time is $10 \mathrm{~s}$ for a $200 \mathrm{sccm}$ flow. The gas cycling is controlled by a solenoid switch, with 3.6 min in $\mathrm{N}_{2}$ and 2.3 minutes in $\mathrm{O}_{2}$. The variations in the envelope of the sensor signal are synchronous with the temperature fluctuation. The data demonstrates that we can achieve a quenching ratio of $4 \pm 0.1$ between pure $99.999 \%$ nitrogen and $21 \%$ oxygen over 13.8 hours at 71.5 $\pm 1^{\circ} \mathrm{C}$. 


\section{CONCLUSIONS}

We have developed a reflection mode fiber optic oxygen sensor that can operate at high temperatures for power plant applications. The sensor is based on the ${ }^{3} \mathrm{O}_{2}$ quenching of the red emission from hexanuclear molybdenum chloride clusters. A preliminary study of the high temperature stability of the neutral $\mathrm{Mo}_{6} \mathrm{Cl}_{12}$ cluster in an oxygenated environment revealed a loss of the red luminescence following heating to $>250{ }^{\circ} \mathrm{C}$. We subsequently synthesized $\mathrm{K}_{2} \mathrm{Mo}_{6} \mathrm{Cl}_{14}$ and found that the alkali salts of $\mathrm{Mo}_{6} \mathrm{Cl}_{12}$ are thermally stable and remain luminescent after long-term aging at $280{ }^{\circ} \mathrm{C}$. A composite of sol-gel particles embedded in a thin, oxygen permeable sol-gel binder were used as the optical sensing film. The particles are comprised of thermally stable, luminescent $\mathrm{K}_{2} \mathrm{Mo}_{6} \mathrm{Cl}_{14}$ clusters dispersed in a fully equilibrated sol-gel matrix.

Fiber optic sensors were fabricated by depositing the sensing film on the far end of a high temperature optical fiber. From 40 to $100{ }^{\circ} \mathrm{C}$, the fiber sensor switches $\sim 6 \mathrm{X}$ in intensity in response to alternating pulses of $<0.001 \% \mathrm{O}_{2}$ and $21 \% \mathrm{O}_{2}$ between two well defined levels with a response time of $10 \mathrm{~s}$. The sensor signal is a few $\mathrm{nW}$ for an input pump power of $250 \mu \mathrm{W}$. The normalized sensor signal is linear with molar oxygen concentration and fits the theoretical Stern-Volmer relationship. Although the sensitivity decreases with temperature, at $100{ }^{\circ} \mathrm{C}$ the sensitivity is $160\left[\mathrm{O}_{2}\right]^{-1}$. High temperature measurements of the quenching lifetime of our composite films are needed to elucidate why the y-intercept of the Stern-Volmer relationship is not equal to one. The parameters of our fiber optic sensor are well suited for in-situ, real-time monitoring of oxygen for industrial process control applications. 


\section{REFERENCES}

[1] R. N. Ghosh, G. L. Baker, C. Ruud, D. G. Nocera, Applied Physics Letters 1999, $75,2885$.

[2] N. Prokopuk, D. F. Shriver, in Advances in Inorganic Chemistry, Vol 46, Vol. 46, 1999, pp. 1.

[3] H. Schaefer, H. G. Schnering, J. Tillack, F. Kuhnen, H. Woehrle, H. Baumann, Z. Anorg. Allg. Chem. 1967, 353, 281.

[4] T. C. Zietlow, M. D. Hopkins, H. B. Gray, Journal of Solid State Chemistry 1985, 57,112 .

[5] J. A. Jackson, C. Turro, M. D. Newsham, D. G. Nocera, Journal of Physical Chemistry 1990, 94, 4500.

[6] R. D. Mussell, Ph. D. thesis, Michigan State University (East Lansing), 1988.

[7] M. D. Newsham, Michigan State University (East Lansing), 1988.

[8] M. D. Newsham, M. K. Cerreta, K. A. Berglund, D. G. Nocera, Mater. Res. Soc. Symp. Proc. 1988, 121, 627.

[9] R. N. Ghosh, G. L. Baker, C. Ruud, D. G. Nocera, Appl. Phys. Lett. 1999, 75, 2885.

[10] J. T. Remillard, J. R. Jones, B. D. Poindexter, C. K. Narula, W. H. Weber, Appl. Opt. 1999, 38, 5306.

[11] C. McDonagh, P. Bowe, K. Mongey, B. D. MacCraith, Journal of NonCrystalline Solids 2002, 306, 138.

[12] C. M. McDonagh, A. M. Shields, A. K. McEvoy, B. D. Maccraith, J. F. Gouin, Journal of Sol-Gel Science and Technology 1998, 13, 207.

[13] C. McDonagh, F. Sheridan, T. Butler, B. D. MacCraith, Journal of NonCrystalline Solids 1996, 194, 72.

[14] C. McDonagh, B. D. MacCraith, A. K. McEvoy, Analytical Chemistry 1998, 70, 45.

[15] J. T. Remillard, J. R. Jones, B. D. Poindexter, C. K. Narula, W. H. Weber, Applied Optics 1999, 38, 5306.

[16] Fiberguide Specification sheet for "Superguide G ultraviolet-visible fiber with gold jacket", Fiberguide Industries, Stirling, NJ, http://www.fiberguide.com.

[17] G. M. Ehrlich, C. J. Warren, R. C. Haushalter, F. J. Disalvo, Inorg. Chem. 1995, 34,4284 .

[18] J. C. Sheldon, Nature 1959, 184, 1210.

[19] C. McDonagh, P. Bowe, K. Mongey, B. D. MacCraith, J. Non-Cryst. Solids 2002, 306,138 .

[20] J. C. Sheldon, Journal of the Chemical Society 1962, 410.

[21] Y. Tang, E. C. Tehan, Z. Y. Tao, F. V. Bright, Analytical Chemistry 2003, 75, 2407.

[22] R. M. Bukowski, R. Ciriminna, M. Pagliaro, F. V. Bright, Analytical Chemistry 2005, 77, 2670.

[23] J. A. Jackson, M. D. Newsham, C. Worsham, D. G. Nocera, Chemistry of Materials 1996, 8, 558.

[24] Z. Y. Tao, E. C. Tehan, Y. Tang, F. V. Bright, Analytical Chemistry 2006, 78, 1939. 


\section{BIBLIOGRAPHY}

None.

\section{LIST OF ACRONYMS AND ABBREVIATIONS}

$\mathrm{HCl}$ - Hydrochloric Acid

$\mathrm{MeOH}$ - Methanol

$\mathrm{CH}_{3} \mathrm{CN}$ - Acetonitrile

TEOS - Tetraethyl orthosilicate

\section{APPENDIX A - ACKNOWLEDGEMENTS}

We wish to acknowledge the contribution of Reza Loloee, Michigan State University, towards the gas flow switch box and calculation of high temperature gas flow rate and Per Askeland, Michigan State University, regarding discussion on the thermal properties of various sol-gel binders. The Labview program for sensor data acquisition was developed by Mr. Nate Verhanovitz (Troy Research Systems, LLC) 